Cochrane Database of Systematic Reviews

\title{
Negative pressure wound therapy for open traumatic wounds
} (Review)

Iheozor-Ejiofor Z, Newton K, Dumville JC, Costa ML, Norman G, Bruce J

Iheozor-Ejiofor Z, Newton K, Dumville JC, Costa ML, Norman G, Bruce J.

Negative pressure wound therapy for open traumatic wounds.

Cochrane Database of Systematic Reviews 2018, Issue 7. Art. No.: CD012522.

DOI: 10.1002/14651858.CD012522.pub2.

www.cochranelibrary.com 
TABLE OF CONTENTS

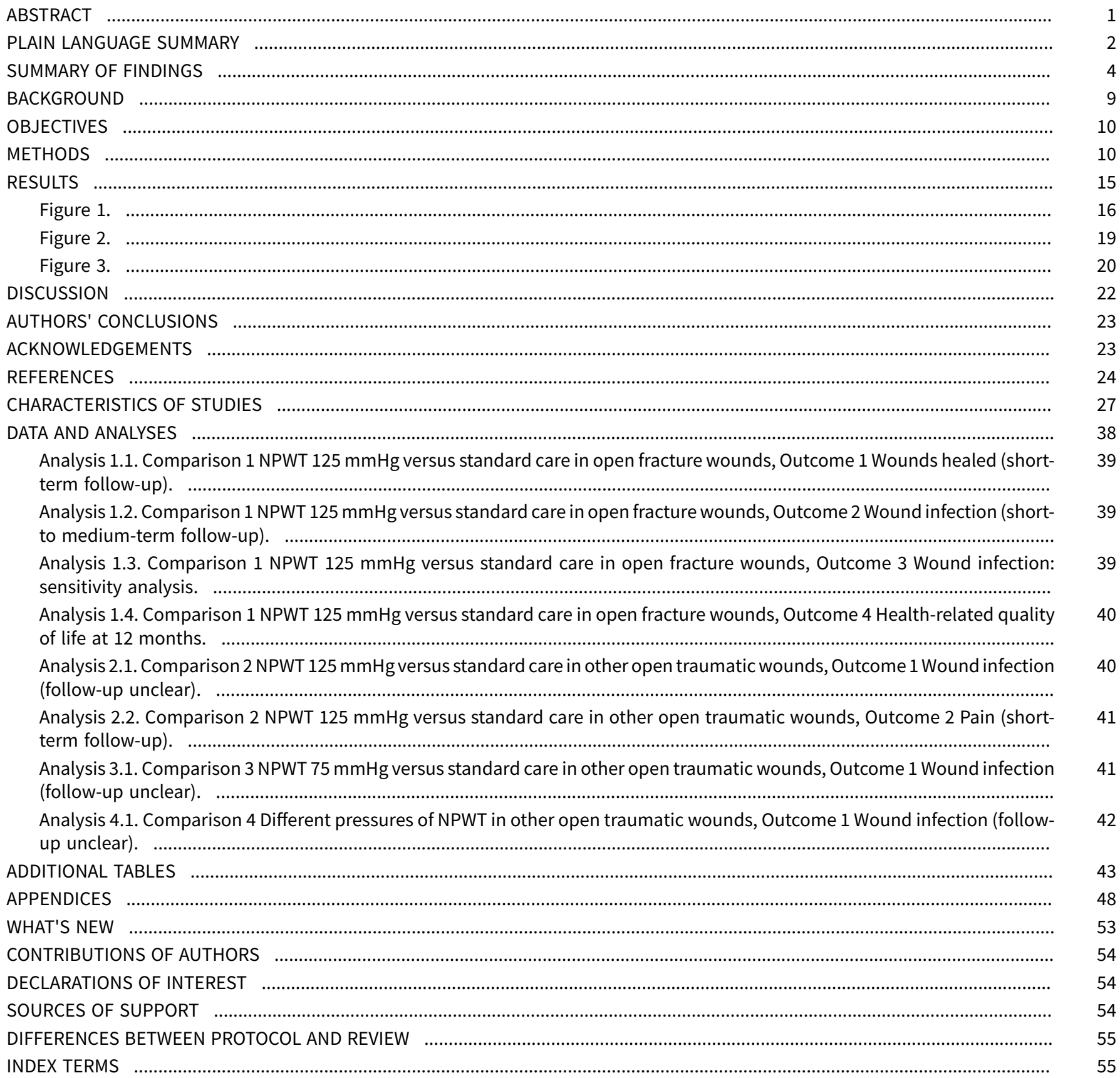


[Intervention Review]

\title{
Negative pressure wound therapy for open traumatic wounds
}

\author{
Zipporah Iheozor-Ejiofor ${ }^{1}$, Katy Newton ${ }^{2}$, Jo C Dumville ${ }^{3}$, Matthew L Costa ${ }^{4}$, Gill Norman ${ }^{3}$, Julie Bruce 5
}

1School of Medicine, University of Central Lancashire, Preston, UK. 2General Surgery, North Western Deanery, Manchester, UK. ${ }^{3}$ Division of Nursing, Midwifery and Social Work, School of Health Sciences, Faculty of Biology, Medicine and Health, University of Manchester, Manchester Academic Health Science Centre, Manchester, UK. ${ }^{4}$ Nuffield Department of Orthopaedics, Rheumatology and Musculoskeletal Sciences (NDORMS), University of Oxford, John Radcliffe Hospital, Oxford, UK. 5 Warwick Clinical Trials Unit, University of Warwick, Coventry, UK

Contact: Zipporah Iheozor-Ejiofor, School of Medicine, University of Central Lancashire, Harrington Building, Preston, Lancashire, UK. Zlheozor-Ejiofor@uclan.ac.uk.

Editorial group: Cochrane Wounds Group.

Publication status and date: New, published in Issue 7, 2018.

Citation: Iheozor-Ejiofor Z, Newton K, Dumville JC, Costa ML, Norman G, Bruce J. Negative pressure wound therapy for open traumatic wounds. Cochrane Database of Systematic Reviews 2018, Issue 7. Art. No.: CD012522. DOI: 10.1002/14651858.CD012522.pub2.

Copyright ( 2018 The Cochrane Collaboration. Published by John Wiley \& Sons, Ltd.

\section{A B S T R A C T}

\section{Background}

Traumatic wounds (wounds caused by injury) range from abrasions and minor skin incisions or tears, to wounds with extensive tissue damage or loss as well as damage to bone and internal organs. Two key types of traumatic wounds considered in this review are those that damage soft tissue only and those that involve a broken bone, that is, open fractures. In some cases these wounds are left open and negative pressure wound therapy (NPWT) is used as a treatment. This medical device involves the application of a wound dressing through which negative pressure is applied and tissue fluid drawn away from the area. The treatment aims to support wound management, to prepare wounds for further surgery, to reduce the risk of infection and potentially to reduce time to healing (with or without surgical intervention). There are no systematic reviews assessing the effectiveness of NPWT for traumatic wounds.

\section{Objectives}

To assess the effects of NPWT for treating open traumatic wounds in people managed in any care setting.

\section{Search methods}

In June 2018 we searched the Cochrane Wounds Specialised Register, the Cochrane Central Register of Controlled Trials (CENTRAL), Ovid MEDLINE (including In-Process \& Other Non-Indexed Citations), Ovid Embase and EBSCO CINAHL Plus. We also searched clinical trials registries for ongoing and unpublished studies, and scanned reference lists of relevant included studies as well as reviews, meta-analyses and health technology reports to identify additional studies. There were no restrictions with respect to language, date of publication or study setting.

\section{Selection criteria}

Published and unpublished randomised controlled trials that used NPWT for open traumatic wounds involving either open fractures or soft tissue wounds. Wound healing, wound infection and adverse events were our primary outcomes.

\section{Data collection and analysis}

Two review authors independently selected eligible studies, extracted data, carried out a 'Risk of bias' assessment and rated the certainty of the evidence. Data were presented and analysed separately for open fracture wounds and other open traumatic wounds (not involving a broken bone). 


\section{Main results}

Seven RCTs (1377 participants recruited) met the inclusion criteria of this review. Study sample sizes ranged from 40 to 586 participants. One study had three arms, which were all included in the review. Six studies compared NPWT at $125 \mathrm{mmHg}$ with standard care: one of these studies did not report any relevant outcome data. One further study compared NPWT at $75 \mathrm{mmHg}$ with standard care and NPWT $125 \mathrm{mmHg}$ with NPWT $75 \mathrm{mmHg}$.

Open fracture wounds (four studies all comparing NPWT $125 \mathrm{mmHg}$ with standard care)

One study (460 participants) comparing NPWT $125 \mathrm{mmHg}$ with standard care reported the proportions of wounds healed in each arm. At six weeks there was no clear difference between groups in the number of participants with a healed, open fracture wound: risk ratio (RR) 1.01 (95\% confidence interval ( $\mathrm{Cl}) 0.81$ to 1.27 ); moderate-certainty evidence, downgraded for imprecision.

We pooled data on wound infection from four studies ( 596 participants). Follow-up varied between studies but was approximately 30 days. On average, it is uncertain whether NPWT at $125 \mathrm{mmHg}$ reduces the risk of wound infection compared with standard care (RR $0.48,95 \% \mathrm{Cl}$ 0.20 to $1.13 ; 1^{2}=56 \%$ ); very low-certainty evidence downgraded for risk of bias, inconsistency and imprecision.

Data from one study shows that there is probably no clear difference in health-related quality of life between participants treated with NPWT $125 \mathrm{mmHg}$ and those treated with standard wound care (EQ-5D utility scores mean difference (MD) $-0.01,95 \% \mathrm{Cl}-0.08$ to 0.06 ; 364 participants, moderate-certainty evidence; physical component summary score of the short-form 12 instrument $\mathrm{MD}-0.50,95 \% \mathrm{Cl}-4.08$ to 3.08; 329 participants; low-certainty evidence downgraded for imprecision).

Moderate-certainty evidence from one trial (460 participants) suggests that NPWT is unlikely to be a cost-effective treatment for open fractures in the UK. On average, NPWT was more costly and conferred few additional quality-adjusted life years (QALYs) when compared with standard care. The incremental cost-effectiveness ratio was GBP 267,910 and NPWT was shown to be unlikely to be cost effective at a range of cost-per-QALYs thresholds. We downgraded the certainty of the evidence for imprecision.

Other open traumatic wounds (two studies, one comparing NPWT $125 \mathrm{mmHg}$ with standard care and a three-arm study comparing NPWT 125 $\mathrm{mmHg}$, NPWT $75 \mathrm{mmHg}$ and standard care)

Pooled data from two studies (509 participants) suggests no clear difference in risk of wound infection between open traumatic wounds treated with NPWT at $125 \mathrm{mmHg}$ or standard care (RR $0.61,95 \% \mathrm{Cl} 0.31$ to 1.18 ); low-certainty evidence downgraded for risk of bias and imprecision.

One trial with 463 participants compared NPWT at $75 \mathrm{mmHg}$ with standard care and with NPWT at $125 \mathrm{mmHg}$. Data on wound infection were reported for each comparison. It is uncertain if there is a difference in risk of wound infection between NPWT $75 \mathrm{mmHg}$ and standard care (RR $0.44,95 \% \mathrm{Cl} 0.17$ to $1.10 ; 463$ participants) and uncertain if there is a difference in risk of wound infection between NPWT $75 \mathrm{mmHg}$ and $125 \mathrm{mmHg}$ (RR 1.04, 95\% Cl 0.31 to 3.51; 251 participants. We downgraded the certainty of the evidence for risk of bias and imprecision.

\section{Authors' conclusions}

There is moderate-certainty evidence for no clear difference between NPWT and standard care on the proportion of wounds healed at six weeks for open fracture wounds. There is moderate-certainty evidence that NPWT is not a cost-effective treatment for open fracture wounds. Moderate-certainty evidence means that the true effect is likely to be close to the estimate of the effect, but there is a possibility that it is substantially different. It is uncertain whether there is a difference in risk of wound infection, adverse events, time to closure or coverage surgery, pain or health-related quality of life between NPWT and standard care for any type of open traumatic wound.

\section{PLAIN LANGUAGE SUMMARY}

\section{Negative pressure wound therapy for open traumatic wounds}

\section{What is the aim of this review?}

The aim of this review was to find out whether negative pressure wound therapy (NPWT) (a sealed wound dressing connected to a vacuum pump that sucks up fluid from the wound) is effective for treating open traumatic wounds (injuries such as animal bites, bullet wounds or fractures that result in bone piercing the skin to form open wounds). Researchers from Cochrane collected and analysed all relevant studies (randomised controlled trials) to answer this question and found seven relevant studies.

\section{Key messages}

We cannot be certain whether NPWT is effective for treating traumatic wounds. We are moderately confident that there is no clear difference in healing rates in open fracture wounds treated with NPWT compared with standard care. We are very uncertain whether people treated with NPWT experience fewer wound infections compared with those treated with standard care. There is moderate-certainty evidence that NPWT is not a cost-effective treatment for open fracture wounds.

\section{What was studied in the review?}

Negative pressure wound therapy for open traumatic wounds (Review) 
Traumatic wounds are open cuts, scrapes or puncture wounds, where both the skin and underlying tissues are damaged. These wounds may have jagged edges and contain items such as gravel or glass. Injuries caused by road traffic accidents, stab and gunshot wounds, and animal bites are common types of traumatic wound.

NPWT is a treatment that is used widely on different types of wounds. In NPWT, a machine that exerts carefully controlled vacuum suction (negative pressure) is attached to a wound dressing that covers the wound. Wound and tissue fluid is sucked away from the treated area into a canister. This is thought to increase blood flow and improve wound healing.

We wanted to find out if NPWT could help open traumatic wounds to heal more quickly and effectively. We wanted to know if people treated with NPWT experienced any side effects or other complications, such as wound infections and pain. We were also interested in the impact of NPWT on people's quality of life.

\section{What are the main results of the review?}

We found seven relevant studies, dating from 2008-2017, which compared the effect of different strengths of NPWT with standard wound care. The studies involved a total of 1381 participants aged 12 years and over. The participants' sex was not recorded. Not all the studies stated how they were funded. One was funded by an NPWT manufacturer.

There is no clear difference in healing rates in participants with open fracture wounds treated with NPWT compared with those receiving standard care. There is moderate-certainty evidence that NPWT is not a cost-effective treatment for open fracture wounds. We are very uncertain as to whether NPWT may reduce the likelihood of wound infection compared with standard care. There is no clear evidence that NPWT impacts on people's experience of pain, adverse events or their experience of receiving therapy.

\section{How up to date is this review?}

We searched for studies that had been published up to June 2018. 
SUMMARY OF FINDINGS

Summary of findings for the main comparison. NPWT $125 \mathrm{mmHg}$ compared with standard care in open fracture wounds

NPWT 125 mmHg compared with standard care in open fracture wounds

Patient or population: open fracture wounds

Setting: orthopaedic ward

Intervention: NPWT $125 \mathrm{mmHg}$

Comparison: standard care (other dressings)

\begin{tabular}{|c|c|c|c|c|c|c|}
\hline \multirow[t]{2}{*}{ Outcomes } & \multicolumn{2}{|c|}{ Anticipated absolute effects ${ }^{\star}(95 \% \mathrm{Cl})$} & \multirow{2}{*}{$\begin{array}{l}\text { Relative effect } \\
(95 \% \mathrm{CI})\end{array}$} & \multirow{2}{*}{$\begin{array}{l}\text { № of partici- } \\
\text { pants } \\
\text { (studies) }\end{array}$} & \multirow{2}{*}{$\begin{array}{l}\text { Certainty of } \\
\text { the evidence } \\
\text { (GRADE) }\end{array}$} & \multirow[t]{2}{*}{ Comments } \\
\hline & $\begin{array}{l}\text { Risk with stan- } \\
\text { dard care }\end{array}$ & $\begin{array}{l}\text { Risk with NPWT } \\
125 \mathrm{mmHg}\end{array}$ & & & & \\
\hline $\begin{array}{l}\text { Complete wound heal- } \\
\text { ing } \\
\text { Follow-up: six weeks }\end{array}$ & 397 per 1000 & $\begin{array}{l}401 \text { per } 1000 \\
\text { (322 to } 504)\end{array}$ & $\begin{array}{l}\text { RR } 1.01(0.81, \\
1.27)\end{array}$ & 460 (1 study) & $\begin{array}{l}\oplus \oplus \oplus \ominus \\
\text { Moderate }^{1}\end{array}$ & $\begin{array}{l}\text { There is no clear difference in num- } \\
\text { ber of wounds healed between NPWT } \\
125 \mathrm{mmHg} \text { and standard care in open frac- } \\
\text { ture wounds over } 6 \text { weeks of follow-up }\end{array}$ \\
\hline $\begin{array}{l}\text { Wound infection } \\
\text { Follow-up: approximate- } \\
\text { ly } 30 \text { days, with variation } \\
\text { between studies }\end{array}$ & 178 per 1000 & $\begin{array}{l}85 \text { per } 1000 \\
\text { ( } 36 \text { to } 201 \text { ) }\end{array}$ & $\begin{array}{l}\text { RR } 0.48 \\
(0.20,1.13)\end{array}$ & 596 (4 studies) & $\begin{array}{l}\oplus \ominus \odot \ominus \\
\text { Very low } 2\end{array}$ & $\begin{array}{l}\text { It is uncertain whether there are differ- } \\
\text { ences in risk of wound infection between } \\
\text { NPWT } 125 \mathrm{mmHg} \text { and standard care }\end{array}$ \\
\hline $\begin{array}{l}\text { Adverse events } \\
\text { Follow-up up to } 12 \\
\text { months }\end{array}$ & Not estimable & Not estimable & Not estimable & 460 (1 study) & $\mathrm{n} / \mathrm{r}$ & $\begin{array}{l}\text { Number of events presented: rather than } \\
\text { data by number of participants }\end{array}$ \\
\hline $\begin{array}{l}\text { Time to closure or cov- } \\
\text { erage surgery (days) } \\
\text { Follow-up: mean } 23 \\
\text { weeks }\end{array}$ & $\begin{array}{l}\text { The mean time } \\
\text { to surgery in the } \\
\text { control group } \\
\text { ranged between } \\
3.2 \text { and } 9.8 \text { days }\end{array}$ & $\begin{array}{l}\text { The mean time to } \\
\text { surgery in the con- } \\
\text { trol group ranged } \\
\text { between } 4 \text { and } 8.3 \\
\text { days }\end{array}$ & - & $\begin{array}{l}151 \\
\text { (2 studies) }\end{array}$ & $\begin{array}{l}\oplus \ominus \odot \odot \\
\text { Very low } 3\end{array}$ & $\begin{array}{l}\text { Measures of variance were not reported. } \\
\text { No further analysis carried out }\end{array}$ \\
\hline Pain & Not estimable & Not estimable & Not estimable & Not estimable & Not estimable & \\
\hline
\end{tabular}

*The risk in the intervention group (and its $95 \%$ confidence interval) is based on the median risk in the comparison group and the relative effect of the intervention (and its $95 \% \mathrm{Cl}$ ).

Cl: confidence interval; $\mathbf{n} / \mathbf{r}$ : not reported; RR: risk ratio 
High certainty: we are very confident that the true effect lies close to that of the estimate of the effect

Moderate certainty: we are moderately confident in the effect estimate: the true effect is likely to be close to the estimate of the effect, but there is a possibility that it is

substantially different

Low certainty: our confidence in the effect estimate is limited: the true effect may be substantially different from the estimate of the effect

Very low certainty: we have very little confidence in the effect estimate: the true effect is likely to be substantially different from the estimate of effect

1Downgraded one level for serious imprecision: the true effect could range from a $19 \%$ reduction in risk of wound healing to a $27 \%$ increase in the NPWT group.

2Downgraded three levels: once for serious risk of bias, once for serious imprecision and once for serious inconsistency.

${ }^{3}$ Downgraded three levels: once for serious risk of bias (no blind outcome assessment); once for very serious imprecision with a small sample size and limited reported information

to quantify imprecision.

Summary of findings 2. NPWT $125 \mathrm{mmHg}$ compared with standard care in other open traumatic wounds

\section{NPWT $125 \mathrm{mmHg}$ compared with standard care in other open traumatic wounds}

Patient or population: other open traumatic wounds

Setting: rabies clinic and orthopaedic ward

Intervention: NPWT $125 \mathrm{mmHg}$

Comparison: standard care (other dressings)

\begin{tabular}{|c|c|c|c|c|c|c|}
\hline \multirow[t]{2}{*}{ Outcomes } & \multicolumn{2}{|c|}{ Anticipated absolute effects ${ }^{\star}(95 \% \mathrm{CI})$} & \multirow{2}{*}{$\begin{array}{l}\text { Relative effect } \\
(95 \% \mathrm{Cl})\end{array}$} & \multirow{2}{*}{$\begin{array}{l}\text { № of partici- } \\
\text { pants } \\
\text { (studies) }\end{array}$} & \multirow{2}{*}{$\begin{array}{l}\text { Certainty of } \\
\text { the evidence } \\
\text { (GRADE) }\end{array}$} & \multirow[t]{2}{*}{ Comments } \\
\hline & $\begin{array}{l}\text { Risk with stan- } \\
\text { dard care }\end{array}$ & $\begin{array}{l}\text { Risk with NPWT } 125 \\
\text { mmHg }\end{array}$ & & & & \\
\hline $\begin{array}{l}\text { Complete wound } \\
\text { healing }\end{array}$ & Not estimable & Not estimable & Not estimable & Not estimable & Not estimable & $\begin{array}{l}\text { One study reported time to complete heal- } \\
\text { ing but this was stratified by infection status } \\
\text { and presented as mean data when it was not } \\
\text { clear that all wounds had healed. Data were not } \\
\text { analysed further }\end{array}$ \\
\hline $\begin{array}{l}\text { Wound infection } \\
\text { Follow-up: not } \\
\text { clear }\end{array}$ & 103 per 1000 & $\begin{array}{l}63 \text { per } 1000 \text { (32 to } \\
121 \text { ) }\end{array}$ & $\begin{array}{l}\text { RR } 0.61 \text { ( } 0.31 \text { to } \\
1.18 \text { ) }\end{array}$ & 509 (2 studies) & $\begin{array}{l}\oplus \oplus \odot \odot \\
\text { Low }^{1}\end{array}$ & $\begin{array}{l}\text { There is no clear difference in NPWT } 125 \mathrm{mmHg} \\
\text { compared with standard care on risk of wound } \\
\text { infection from current evidence. }\end{array}$ \\
\hline Adverse events & Not estimable & Not estimable & Not estimable & Not estimable & Not estimable & - \\
\hline $\begin{array}{l}\text { Time to closure or } \\
\text { coverage surgery }\end{array}$ & Not estimable & Not estimable & Not estimable & Not estimable & Not estimable & - \\
\hline
\end{tabular}




\begin{tabular}{|c|c|c|c|}
\hline $\begin{array}{l}\text { The mean pain } \\
\text { score in the } \\
\text { control group } \\
\text { was } 4.4 \text { units }\end{array}$ & $\begin{array}{l}\text { The mean pain score } \\
\text { in the intervention } \\
\text { group was } 0.3 \text { units } \\
\text { higher } \\
\text { ( } 0.22 \text { lower to } 0.82 \\
\text { higher) }\end{array}$ & - & $\begin{array}{l}51 \\
\text { (1 study) }\end{array}$ \\
\hline
\end{tabular}

Follow-up: 6 to 18

days

${ }^{*}$ The risk in the intervention group (and its 95\% confidence interval) is based on the median risk in the comparison group and the relative effect of the intervention (and its $95 \% \mathrm{Cl}$ ).

Cl: confidence interval; NRS: numeric rating scale; RR: risk ratio

\section{GRADE Working Group grades of evidence}

High certainty: we are very confident that the true effect lies close to that of the estimate of the effect

Moderate certainty: we are moderately confident in the effect estimate: the true effect is likely to be close to the estimate of the effect, but there is a possibility that it is substantially different

Low certainty: our confidence in the effect estimate is limited: the true effect may be substantially different from the estimate of the effect

Very low certainty: we have very little confidence in the effect estimate: the true effect is likely to be substantially different from the estimate of effect

1Downgraded two levels: once for serious risk of bias (no blind outcome assessment and loss to follow-up) and once due to imprecision due to small sample size.

2Downgraded two levels: once for serious risk of bias and once for serious imprecision.

\section{Summary of findings 3 . NPWT $75 \mathrm{mmHg}$ compared with standard care in other open traumatic wounds}

NPWT $75 \mathrm{mmHg}$ compared with standard care in other open traumatic wounds

Patient or population: other open traumatic wounds

Setting: rabies clinic

Intervention: NPWT $75 \mathrm{mmHg}$

Comparison: standard care

\begin{tabular}{|c|c|c|c|c|c|c|}
\hline \multirow[t]{2}{*}{ Outcomes } & \multicolumn{2}{|c|}{ Anticipated absolute effects* $(95 \% \mathrm{Cl})$} & \multirow{2}{*}{$\begin{array}{l}\text { Relative effect } \\
(95 \% \mathrm{CI})\end{array}$} & \multirow{2}{*}{$\begin{array}{l}\text { № of participants } \\
\text { (studies) }\end{array}$} & \multirow{2}{*}{$\begin{array}{l}\text { Certainty of the } \\
\text { evidence } \\
\text { (GRADE) }\end{array}$} & \multirow[t]{2}{*}{ Comments } \\
\hline & $\begin{array}{l}\text { Risk with standard } \\
\text { care }\end{array}$ & $\begin{array}{l}\text { Risk with NPWT } 75 \\
\text { mmHg }\end{array}$ & & & & \\
\hline $\begin{array}{l}\text { Complete wound heal- } \\
\text { ing }\end{array}$ & Not estimable & Not estimable & Not estimable & Not estimable & Not estimable & - \\
\hline $\begin{array}{l}\text { Wound infection } \\
\text { Follow-up: unclear }\end{array}$ & 90 per 1000 & $\begin{array}{l}39 \text { per } 1000 \\
(15 \text { to } 99)\end{array}$ & $\begin{array}{l}\text { RR } 0.44 \\
(0.17 \text { to } 1.10)\end{array}$ & $\begin{array}{l}463 \\
\text { ( } 1 \text { study) }\end{array}$ & $\begin{array}{l}\oplus \odot \odot \ominus \\
\text { Very low } 1\end{array}$ & $\begin{array}{l}\text { It is uncertain whether } \\
\text { there are differences in } \\
\text { incidence of infection }\end{array}$ \\
\hline
\end{tabular}




$\begin{array}{llllll} & & & \\ & & & \\ \text { between the interven- } \\ \text { tion groups. }\end{array}$

${ }^{\star}$ The risk in the intervention group (and its $95 \%$ confidence interval) is based on the median risk in the comparison group and the relative effect of the intervention (and its $95 \% \mathrm{Cl}$ ).

Cl: confidence interval; RR: risk ratio

\section{GRADE Working Group grades of evidence}

High certainty: we are very confident that the true effect lies close to that of the estimate of the effect

Moderate certainty: we are moderately confident in the effect estimate: the true effect is likely to be close to the estimate of the effect, but there is a possibility that it is

substantially different

Low certainty: our confidence in the effect estimate is limited: the true effect may be substantially different from the estimate of the effect

Very low certainty: we have very little confidence in the effect estimate: the true effect is likely to be substantially different from the estimate of effect

1Downgraded three levels: risk of bias (no blind outcome assessment); very serious imprecision due to small sample size and wide confidence interval.

\section{Summary of findings 4. NPWT $125 \mathrm{mmHg}$ compared with NPWT $75 \mathrm{mmHg}$ in other open traumatic wounds}

\section{NPWT $125 \mathrm{mmHg}$ compared with NPWT $75 \mathrm{mmHg}$ in other open traumatic wounds}

Patient or population: other open traumatic wounds

Setting: rabies clinic

Intervention: NPWT $125 \mathrm{mmHg}$

Comparison: NPWT $75 \mathrm{mmHg}$

\begin{tabular}{|c|c|c|c|c|c|c|}
\hline \multirow[t]{2}{*}{ Outcomes } & \multicolumn{2}{|c|}{ Anticipated absolute effects ${ }^{\star}(95 \% \mathrm{Cl})$} & \multirow{2}{*}{$\begin{array}{l}\text { Relative effect } \\
(95 \% \mathrm{CI})\end{array}$} & \multirow{2}{*}{$\begin{array}{l}\text { № of participants } \\
\text { (studies) }\end{array}$} & \multirow{2}{*}{$\begin{array}{l}\text { Certainty of the evi- } \\
\text { dence } \\
\text { (GRADE) }\end{array}$} & \multirow[t]{2}{*}{ Comments } \\
\hline & $\begin{array}{l}\text { Risk with NPWT } 75 \\
\text { mmHg }\end{array}$ & $\begin{array}{l}\text { Risk with NPWT } 125 \\
\mathrm{mmHg}\end{array}$ & & & & \\
\hline $\begin{array}{l}\text { Complete wound } \\
\text { healing }\end{array}$ & Not estimable & Not estimable & Not estimable & Not estimable & Not estimable & - \\
\hline $\begin{array}{l}\text { Wound infection } \\
\text { Follow-up: unclear }\end{array}$ & 39 per 1000 & $\begin{array}{l}41 \text { per } 1000 \\
\text { (12 to } 137)\end{array}$ & $\begin{array}{l}\text { RR } 1.04 \\
\text { (0.31 to } 3.51 \text { ) }\end{array}$ & $\begin{array}{l}251 \\
\text { (1 study) }\end{array}$ & $\begin{array}{l}\oplus \odot \Theta \odot \\
\text { Very low } 1\end{array}$ & $\begin{array}{l}\text { It is uncertain whether } \\
\text { there are differences } \\
\text { in wound infection be- }\end{array}$ \\
\hline
\end{tabular}




\begin{tabular}{|c|c|c|c|c|c|c|}
\hline 竞总 & & & & & & $\begin{array}{l}\text { tween the intervention } \\
\text { groups. }\end{array}$ \\
\hline Adverse events & Not estimable & Not estimable & Not estimable & Not estimable & Not estimable & - \\
\hline $\begin{array}{l}\text { Time to closure or } \\
\text { coverage surgery }\end{array}$ & Not estimable & Not estimable & Not estimable & Not estimable & Not estimable & - \\
\hline Pain & Not estimable & Not estimable & Not estimable & Not estimable & Not estimable & - \\
\hline
\end{tabular}

${ }^{\star}$ The risk in the intervention group (and its $95 \%$ confidence interval) is based on the median risk in the comparison group and the relative effect of the intervention (and its $95 \% \mathrm{Cl}$ ).

Cl: confidence interval; RR: risk ratio

\section{GRADE Working Group grades of evidence}

High certainty: we are very confident that the true effect lies close to that of the estimate of the effect

Moderate certainty: we are moderately confident in the effect estimate: the true effect is likely to be close to the estimate of the effect, but there is a possibility that it is substantially different

Low certainty: our confidence in the effect estimate is limited: the true effect may be substantially different from the estimate of the effect

Very low certainty: we have very little confidence in the effect estimate: the true effect is likely to be substantially different from the estimate of effect

1Downgraded three levels: risk of bias (no blind outcome assessment); very serious imprecision due to small sample size and wide $95 \%$ confidence intervals. 


\section{B A C K G R O U N D}

\section{Description of the condition}

The World Health Organization estimates that 5.8 million people worldwide die annually from injuries (WHO 2014). These deaths account for a small proportion of the overall number of injured (Alexandrescu 2009). Traumatic wounds (wounds caused by injury) range from abrasions and minor skin incisions or lacerations (tears), to wounds with extensive tissue damage or loss, and may be associated with injury to underlying structures such as bone, or viscera (internal organs) (DeBoard 2007; Edlich 2010). The extent of tissue damage is influenced by the mechanism of injury: traumatic wounds can be caused by blunt trauma, penetrating trauma (such as stabbing and gunshots), crush injury, blast injury, burns, de-gloving injuries (in which an extensive layer of skin is torn from the underlying tissue) and animal bites. Early management of traumatic wounds is frequently dictated by the need for urgent assessment and management of concomitant severe, lifethreatening injuries (Hollander 1995). Ongoing management of traumatic injuries is governed by the degree of damage to underlying or associated structures and aims to preserve, or restore, both function and form, thus minimising disability and disfigurement. Some traumatic wounds will be closed or covered with a skin graft or other reconstruction very quickly. These closed traumatic wounds are not the focus of this review. Rather we focus on those traumatic wounds that are left open for a period of time rather than being closed immediately with surgery on admission to hospital.

There is no current classification system for open traumatic wounds beyond the general causes and structural involvement listed above. For this review we will separately consider two broad categories: open fracture wounds and other open traumatic wounds.

\section{Open fracture wounds}

An open (or compound) fracture is a fracture accompanied by an open wound at or near to the fracture site. The simultaneous exposure of tissue and bone presents specific management challenges. As with most wounds, damage to the soft tissue increases the risk of infection: however, prophylaxis against osteomyelitis (bone infection) is also key factor in treatment. The severity of open fractures is generally assessed using the GustiloAnderson open fracture classification system, which considers wound size; contamination and tissue damage (Gustilo 1976; Gustilo 1984).

\begin{tabular}{ll}
\hline Grade & Definition \\
\hline I & Open fracture with a clean wound that is less than $1 \mathrm{~cm}$ in length \\
\hline II & $\begin{array}{l}\text { Open fracture, without extensive soft-tissue damage, flaps, avulsions with a wound greater than } 1 \\
\text { cm but less than } 10 \mathrm{~cm} \text { in length }\end{array}$ \\
\hline III & $\begin{array}{l}\text { An open fracture with extensive soft tissue damage; a traumatic amputation or an open segmen- } \\
\text { tal fracture. Can also include specific categories of open fracture such as those caused by farm } \\
\text { injuries, fractures requiring vascular repair, or fractures that have been open for } 8 \text { hours prior to } \\
\text { treatment. }\end{array}$ \\
\hline IIIA & $\begin{array}{l}\text { Type III fracture with adequate coverage of the fracture bone despite extensive soft-tissue damage } \\
\text { IIIB }\end{array}$ \\
\hline IIIC & $\begin{array}{l}\text { Type III fracture with extensive soft-tissue loss and periosteal stripping and bone damage (usually } \\
\text { associated with massive contamination) }\end{array}$ \\
\hline
\end{tabular}

Standard treatment for open fracture is, where possible, the prophylactic use of antibiotics, to prevent infection and surgical intervention to clean the wound and debride (remove) devitalised tissue. During surgery vascular and tissue repair may also be undertaken and the fracture either internally or externally fixated with metal pins. At the end of the surgery the wound might be closed over the fracture, covered with reconstruction (e.g. a skin graft) or left open. The decision to leave a wound open is normally based on the extent of damage, the risk of infection and the potential need for further surgery. Those wounds that are left open will often undergo further surgical debridement with the aim of achieving wound closure or coverage as quickly as possible.

\section{Other open traumatic wounds}

Most trauma wounds are limited to soft tissue damage with no or limited direct orthopaedic involvement in the wound. The severity of such wounds varies based on the extent of damage and the anatomical location and corresponding internal organ involvement. Treatment of these wounds varies but will generally involve wound cleaning that ranges from local irrigation with saline solution for minor cuts, abrasions and lacerations to surgical debridement. Wounds may then be closed (e.g. with stitches), covered as part of reconstructive surgery (e.g. with a skin graft) or left open in order for further surgery to be performed or for the wound to heal by secondary intention (from the bottom up). Acute traumatic wounds can be described as contaminated or dirty/infected (dependent on the mechanism and area of the body injured) (Mangram 1999). Older traumatic wounds that may have 
retained devitalised (dead) tissue, those presenting with signs of infection or involving infected material, and those involving perforated viscera (internal organs) can be described as dirty/ infected (Mangram 1999).

\section{Description of the intervention}

Negative pressure wound therapy (NPWT) is a technology that is currently used widely in wound care and is promoted for use on complex wounds (open wounds) (Guy 2012). NPWT involves the application of a wound dressing through which a negative pressure is applied, often with any wound and tissue fluid drawn away from the area being collected into a canister. The amount of pressure applied using the therapy can vary and there is no single protocol for use, however, pressure being delivered ranges from $75 \mathrm{mmHg}$ to $150 \mathrm{mmHg}$, with $125 \mathrm{mmHg}$ being commonly used (Peinemann 2011). The intervention was developed in the 1990s, and the uptake of NPWT in the healthcare systems of developed countries has been dramatic. A US Department of Health report estimated that between 2001 and 2007, Medicare payments for NPWT pumps and associated equipment increased from USD 24 million to USD 164 million (an increase of almost 600\%) (HHS 2009). No national cost data is available for the UK. Initially only one NPWT manufacturer supplied NPWT machines (the V.A.C. system: $\mathrm{KCl}$, San Antonio Texas), however, as the NPWT market has grown, a number of different commercial NPWT systems have been developed, with machines becoming smaller and more portable. Indeed, the most recent introduction to the market is a single use, or 'disposable', negative pressure product (e.g. PICO: Smith \& Nephew, UK). Ad hoc, non-commercial , negative pressure devices are also used, especially in resource-poor settings. These devices tend to use simple wound dressings, such as gauze, or transparent, occlusive (non-permeable) dressings, with negative pressure generated in hospital by vacuum suction pumps.

A number of different healthcare professionals prescribe and apply NPWT, and it is now used both in secondary and primary (community) care, particularly following the introduction of ambulatory systems. Whilst the NPWT systems outlined above differ in a number of respects - such as type of pressure (constant or cyclical) applied to the wound, the material in contact with the surface of the wound and also the type of dressing used the principle of applying a negative pressure to the wound in a closed environment is the same for all products. The place of NPWT in the treatment pathway and the rationale for its use vary based on different types of traumatic wound and local treatment protocols. For open fracture wounds that have been debrided but are still waiting for soft tissue cover, National Institute for Health and Care Excellence (NICE) guidelines recommend that NPWT is considered as an intermediate wound dressing prior to further surgical intervention. Thus, NPWT would be used for a short period of time on an open, post-trauma/post-surgical wound, with a key aim of reducing infection risk.

For more general soft tissue trauma wounds, the use of NPWT can vary: the treatment may be used on open wounds with the aim of promoting healing by secondary intention and also, potentially, to ready a wound for further surgery as with open fractures.

\section{How the intervention might work}

NPWT is thought to facilitate wound healing via several different mechanisms. The negative pressure exerted by the dressing causes deformation of the wound, drawing the skin edges closer together therefore reducing the volume of tissue and skin needed to heal the wound ( $\mathrm{KCl}$ Medical 2012). The pressure effects also cause strain or tension across the tissue, which is thought to increase capillary flow, ultimately stimulating granulation tissue formation and growth of new blood vessels (Saxena 2004). Removal of high volumes of wound exudate, containing enzymes and other proteins involved in inflammation, may prevent further tissue damage. Removal of this fluid also reduces the frequency of dressing changes by keeping the surrounding skin dry, particularly around anatomically-challenging wounds (for example around joints or skin creases). Manufacturers have also suggested that NPWT removes infected material, which may reduce the bacterial burden that can delay healing and reconstructive surgery $(\mathrm{KCl}$ Medical 2012). The molecular effects of negative pressure on the wound bed are still being investigated (Glass 2014).

There are some potentially negative aspects associated with NPWT; these include wound maceration (softening due to prolonged exposure to liquid), retention of dressings, and wound infection as well as other injuries (FDA 2011). NPWT devices are usually worn continually by patients during treatment so they can interfere with mobility, and, anecdotally, are often noisy, which prevents some patients from sleeping. However there have been some recent technological advances of smaller, more portable machines, which may reduce these issues and may also be more cost-effective.

\section{Why it is important to do this review}

It is important to assess current evidence regarding the clinicaland cost-effectiveness of NPWT given its widespread use. Currently consideration of the use of NPWT is recommended by NICE guidelines as a treatment for open fracture wounds (NICE 2017). There is limited guidance for the use of NPWT on trauma wounds more widely. There is no recently published, high-quality review on the use of NPWT for traumatic wounds. The aim of this review is to inform decision makers and guide future research.

\section{O B J E C T IVES}

To assess the effects of NPWT for treating open traumatic wounds in people managed in any care setting.

\section{METHODS}

\section{Criteria for considering studies for this review}

\section{Types of studies}

We considered published and unpublished randomised controlled trials (RCTs), including cluster RCTs, irrespective of language of report. We planned to exclude cross-over trials, as they are not an appropriate design in this context. We also intended to exclude studies using quasi-randomisation.

\section{Types of participants}

We considered RCTs recruiting people (adults and children) described in the primary report as having open traumatic wounds involving either soft tissue wounds (including for example blunt degloving injuries (where skin is completely torn off underlying tissue) and gunshot wounds), or open fractures, managed in any care setting, to be eligible for inclusion. We excluded RCTs recruiting people with traumatic wounds due to burns (including exclusion of blast-related injuries that are likely to be burns). As 
the method of defining soft tissue traumatic wounds may vary, we intended to accept definitions as used by the study authors. We excluded studies that recruited participants with traumatic wounds alongside people with other types of wounds, where randomisation did not take wound type into account and data for traumatic wounds were not presented separately. Studies on skin grafts and open abdomen were not eligible for inclusion. We also excluded studies that recruited people with trauma wounds that were not treated as open wounds prior to closure. These were considered solely to be surgical wounds healing by primary intention and would be included in the review focused on these wounds (Webster 2014).

Following publication of the protocol we decided, in collaboration with further experts in the field, to present the results of the review for populations with open fracture and with other types of open traumatic wounds as separate sub-populations within this review. This decision was based on differences in the wound types, wound management protocols and differences in the use of NPWT in the treatment pathway. (See How the intervention might work, Types of interventions and Differences between protocol and review).

\section{Types of interventions}

The primary intervention of interest is NPWT (both commercial and non-commercial treatments). We included RCTs in which the use of a specific NPWT intervention during the treatment period was the only systematic difference between treatment groups. We anticipated that likely comparisons would include the use of NPWT during the care pathway compared with no use of NPWT or comparison of different types/brands of NPWT used during the care pathway.

\section{Types of outcome measures}

We list primary and secondary outcomes below. If a study was otherwise eligible (i.e. correct study design, population and intervention/comparator) but did not report a listed outcome, then we contacted the study authors where possible to establish whether an outcome of interest here was measured but not reported.

We reported outcome measures at the latest time point available (assumed to be length of follow-up if not specified) and the time point specified in the methods as being of primary interest (if this was different from latest time point available). For wound infection we planned to class assessment of outcomes from:

- up to 30 days as short term;

- 31 days to 12 months as medium term;

- over 12 months as long term.

for all other outcomes we planned to class assessment of outcome measures from:

- one week or less to eight weeks as short term;

- eight weeks to 16 weeks as medium term; and

- more than 16 weeks as long term.

\section{Primary outcomes}

The primary outcomes for this review are wound healing, wound infection and adverse events.

\section{Complete wound healing}

For this review we intended to regard the following as providing the most relevant and rigorous measures of complete wound healing:

- time to complete wound healing (we would have recorded if this had been correctly analysed using censored data and with adjustment for prognostic covariates such as baseline size);

- the proportion of wounds healed (frequency of complete wound healing).

Had both outcomes above been reported, we would have presented all data in a summary outcome table for reference, but focused on reporting time to wound healing. We planned to accept study authors' definitions of what constituted a healed wound.

\section{Wound infection}

Proportion of wounds infected (with infection as defined by study authors). The inclusion of this outcome represents a change from the protocol; see Differences between protocol and review for more details. We considered both superficial and deep infection within this outcome. Traumatic wounds are at risk of contamination and thus infection as soon as a wound is formed. Since trauma wounds are often operated on shortly after their formation they are also at risk from surgical site infection. Decisions about whether wound infections were surgical or not surgical in origin were seldom reported and any difference was not deemed important here; thus we did not delineate between wound infection and surgical site infection within this outcome.

\section{Adverse events}

We extracted reported data on adverse events that were classed as 'serious adverse events' and 'non-serious adverse events' where the study provided a clear methodology for the collection of adverse event data. We anticipated that the methodology should make it clear whether events were reported at the participant level or, where multiple events per person were reported, that an appropriate adjustment was made for data clustering. We did not extract individual types of adverse events such as pain or infection, which require specific assessment under this outcome, rather we used the assessment of any event classed as adverse by the participant or health professional, or both, during the trial.

\section{Secondary outcomes}

- Proportion of wounds closed or covered with surgery: complete wound closure as the result of delayed surgical closure but without subsequent wound healing (that is, the wounds were surgically closed but not yet healed).

- Time to closure or coverage surgery: NPWT is often not used until complete wound healing but until a point where the wound is ready for further treatment such as closure surgery.

- Participant health-related quality of life/health status (measured using a standardised generic questionnaire such as EQ-5D, Short Form (SF)-36, SF-12 or SF-6 or wound-specific questionnaires such as the Cardiff wound impact schedule). We did not include ad hoc measures of quality of life that are unlikely to be validated and would not be common to multiple trials.

- Wound recurrence: we accepted study author definitions of wound recurrence unless it was clear that the term had not 
been used to describe the return of a wound that was previously healed.

- Mean pain scores: (including pain at dressing change) were included only where reported as either a presence or absence of pain or as a continuous outcome using a validated scale such as a visual analogue scale (VAS).

- Within-trial cost-effectiveness analysis comparing mean differences in effects with mean cost differences between the two arms: data extracted were incremental mean cost per incremental gain in benefit (incremental cost-effectiveness ratio (ICER)). The inclusion of this outcome represents a change from the protocol; see Differences between protocol and review for more details.

\section{Search methods for identification of studies}

\section{Electronic searches}

We searched the following electronic databases for RCTs:

- the Cochrane Wounds Specialised Register (searched 25 June 2018);

- the Cochrane Central Register of Controlled Trials (CENTRAL; 2018, Issue 5) in the Cochrane Library (searched 25 June 2018);

- Ovid MEDLINE including In-Process \& Other Non-Indexed Citations (1946 to 25 June 2018);

- Ovid Embase (1974 to 25 June 2018);

- EBSCO CINAHL Plus (1937 to 25 June 2018).

The search strategies for the Cochrane Wounds Specialised Register, CENTRAL, Ovid MEDLINE, Ovid Embase and EBSCO CINAHL Plus can be found in Appendix 1 . We combined the Ovid MEDLINE search with the Cochrane Highly Sensitive Search Strategy for identifying randomised trials in MEDLINE: sensitivityand precision-maximising version (2008 revision) (Lefebvre 2011). We combined the Embase search with the Ovid Embase filter developed by the UK Cochrane Centre (Lefebvre 2011). We combined the EBSCO CINAHL Plus searches with the trial filters developed by the Scottish Intercollegiate Guidelines Network (SIGN 2017). There were no restrictions with respect to language, date of publication or study setting.

We also searched the following clinical trials registries for unpublished and ongoing studies in the area - we searched for trials evaluating NPWT and explored these records for those pertaining to traumatic wounds as defined above:

- ClinicalTrials.gov (www.clinicaltrials.gov) (searched 30 May 2018);

- WHO International Clinical Trials Registry Platform (ICTRP) (www.who.int/ictrp/search/en/) (searched 30 May 2018);

- EU Clinical Trials Register (www.clinicaltrialsregister.eu/ctrsearch/search) (30 May 2018).

Search strategies for clinical trials registries can be found in Appendix 1.

\section{Searching other resources}

We contacted corresponding study authors and the manufacturers and distributors of NPWT. We aimed to identify other potentially eligible trials or ancillary publications by searching the reference lists of retrieved included trials as well as relevant systematic reviews, meta-analyses, and health-technology assessment reports.

\section{Data collection and analysis}

We carried out data collection and analysis according to methods stated in the published protocol (Newton 2017), which were based on the Cochrane Handbook for Systematic Reviews of Interventions (Higgins 2011a).

\section{Selection of studies}

Two review authors independently assessed the titles and abstracts of the citations retrieved by the searches for relevance. After this initial assessment, we obtained full-text copies of all studies considered to be potentially relevant. Two review authors independently checked the full papers for eligibility; we resolved any disagreements by discussion and, where required, the input of a third review author. Where required and possible, we contacted study authors where the eligibility of a study was unclear. We recorded all reasons for exclusion of studies for which we had obtained full copies. We completed a PRISMA flowchart to summarise this process (Liberati 2009).

Where studies had been reported in multiple publications/reports we obtained all publications. Whilst the study would be included only once in the review, we intended to extract data from all reports to ensure maximal relevant data were obtained.

\section{Data extraction and management}

We extracted and summarised details of the eligible studies using a data extraction sheet. Two review authors extracted data independently and resolved disagreements by discussion, drawing on a third review author where required. Review authors who had authored included studies did not participate in data extraction or checking. Where data were missing from reports, we attempted to contact the study authors to obtain this information. Where a study with more than two intervention arms was included, we extracted only data from intervention and control groups that met the eligibility criteria. In the case of a three-arm trial with two NPWT groups and a control group, we extracted all data and reported comparisons narratively. Review authors made a decision as to how to analyse data further but ensured that multiple analyses, which posed a risk of spurious findings, were avoided. Options included grouping NPWT groups together or the inclusion of comparisons in different meta-analyses depending on treatments being evaluated.

We extracted the following data, where possible, by treatment group for the pre-specified interventions and outcomes in this review. We collected outcome data for relevant time points as described in Types of outcome measures. Where details were unclear, we contacted study authors for clarification where possible:

- country of origin;

- type of wound (including whether it was an open fracture wound);

- unit of randomisation (per participant) - single wound or multiple wounds on the same participant;

- unit of analysis;

- trial design, for example, parallel, cluster;

- care setting; 
- number of participants randomised to each trial arm;

- eligibility criteria and key baseline participant data;

- details of treatment regimen received by each group;

- duration of treatment;

- details of any co-interventions;

- primary and secondary outcome(s) (with definitions);

- outcome data for primary and secondary outcomes (by group);

- duration of follow-up;

- number of withdrawals (by group);

- publication status of study; and

- source of funding for trial.

\section{Assessment of risk of bias in included studies}

Two review authors independently assessed included studies using the Cochrane tool for assessing risk of bias (Higgins 2011b). This tool addresses six specific domains: sequence generation, allocation concealment, blinding, incomplete data, selective outcome reporting and other issues. In this review we recorded issues with unit of analysis, for example where a cluster trial had been undertaken but analysed at the individual level in the study report (Appendix 2). We assessed blinding and completeness of outcome data for each of the review outcomes separately. We note that, since wound healing is a subjective outcome, it can be at high risk of measurement bias when outcome assessment is not blinded. We presented our assessment of risk of bias using two 'Risk of bias' summary figures; one is a summary of bias for each item across all studies, and the second shows a cross-tabulation of each trial by all of the risk of bias items. We classed studies with an assessment of high risk of bias for the randomisation sequence domain and/or the allocation concealment domain and/or the blinded outcome assessment domain (for specified outcome) as being at overall high risk of bias (for specified outcome).

If trials using cluster randomisation become available in future updates, we will also consider the risk of bias from recruitment bias, baseline imbalance, loss of clusters, incorrect analysis and comparability with individually randomised trials (Higgins 2011c) (Appendix 3).

\section{Measures of treatment effect}

For dichotomous outcomes we calculated the risk ratio (RR) with $95 \%$ confidence intervals $(\mathrm{Cl})$. For continuously distributed outcome data we used the mean difference (MD) with $95 \% \mathrm{Cls}$. If trials reporting continuous data used different assessment scales, we would have used the standardised mean difference (SMD) with $95 \%$ Cls. We would have only considered mean or median time to healing without survival analysis as a valid outcome if reports specified that all wounds had healed (i.e. if the trial authors regarded time-to-healing as a continuous measure as there was no censoring). We intended to report time-to-event data (e.g. time-to-complete wound healing) as hazard ratios (HR), where possible in accordance with the methods described in the Cochrane Handbook for Systematic Reviews of Interventions (Deeks 2011). In future updates, if studies reporting time-to-event data (e.g. time to healing) do not report a hazard ratio, then, where feasible, we plan to estimate this using other reported outcomes, such as the numbers of events, through the application of available statistical methods (Parmar 1998).

\section{Unit of analysis issues}

Where studies randomised at the participant level and measured outcomes at the wound level, for example, wound healing, we treated the participant as the unit of analysis when the number of wounds assessed appeared equal to the number of participants (e.g. one wound per person).

Particular unit of analysis issues in wound care trials can occur when (1) studies randomise at the participant level, use the allocated treatment on multiple wounds per participant, and then analyse outcomes per wound, or (2) studies undertake multiple assessments of an outcome over time per participant. These approaches were to be treated as cluster trials, alongside more standard cluster designs, such as delivery of interventions at an organisational level. There was only one study where a participant had more than one wound and the unit of randomisation differed from the unit of analysis. As we were unable to quantify the difference this would have made to the study findings we decided to use the participants as the unit of analysis.

Where a cluster trial had been conducted and correctly analysed, we planned to use the generic inverse-variance method in Review Manager 5 (RevMan 5) (RevMan 2014) to meta-analyse effect estimates and their standard errors.

We planned to record where a cluster-randomised trial had been conducted but incorrectly analysed. This was to be recorded as part of the 'Risk of bias' assessment. If possible we would have approximated the correct analyses based on guidance in the Cochrane Handbook for Systematic Reviews of Interventions (Higgins 2011d) using information on:

- the number of clusters (or groups) randomised to each intervention group; or the average (mean) size of each cluster;

- the outcome data ignoring the cluster design for the total number of individuals (for example, number or proportion of individuals with events, or means and standard deviations);

- and an estimate of the intra-cluster (or intra-class) correlation coefficient (ICC).

If the study data could not be analysed correctly, we would have extracted and presented outcome data but not analysed them further.

We would have also noted when randomisation had been undertaken at the wound level; that is a split-site or split-body design. We planned to assess whether the correct paired analysis had been undertaken in the study. Again, we planned to record issues in the 'Risk of bias' section. If an incorrect analysis had been undertaken we would have approximated a correct analysis if the required data were available from the study report or the study authors. If this was not possible we would have extracted and presented the relevant outcome data but not analysed them further.

\section{Dealing with missing data}

It is common to have data missing from trial reports. Excluding participants post-randomisation from the analysis, or ignoring those participants who are lost to follow-up compromises the randomisation, and potentially introduces bias into the trial. Where there were missing data that the review authors thought should 
have been included in the analyses, we contacted the relevant study authors to request whether these data were available.

Where an included study reported on wound healing or wound infection and data were missing, for analysis we assumed that if randomised participants were not included in an analysis, their wound did not heal (i.e. they were considered in the denominator but not the numerator).

For all secondary outcomes we presented available data from the study reports/study authors and did not impute missing data. Where measures of variance were missing and calculation was not possible we contacted study authors. Where these measures of variation were not available, we excluded the study from any relevant meta-analyses that were conducted.

\section{Assessment of heterogeneity}

Assessment of heterogeneity can be a complex, multi-faceted process. Firstly, we considered clinical and methodological heterogeneity: that is, the degree to which the included studies varied in terms of participant, intervention, outcome and characteristics such as length of follow-up. This assessment of clinical and methodological heterogeneity was supplemented by information regarding statistical heterogeneity, assessed using the $\mathrm{Chi}^{2}$ test (we considered a significance level of $\mathrm{P}<0.10$ to indicate statistically significant heterogeneity) in conjunction with the $I^{2}$ statistic (Higgins 2003). $I^{2}$ examines the percentage of total variation across RCTs that is due to heterogeneity rather than chance (Higgins 2003). In general $I^{2}$ values of $40 \%$, or less, may not be important (Higgins 2003), and values of more than $75 \%$, or more, indicate considerable heterogeneity (Deeks 2011). However, these figures are only a guide and it has been recognised that statistical tests and metrics may miss important heterogeneity. Thus, whilst these were assessed, the overall assessment of heterogeneity assessed these measures in combination with the methodological and clinical assessment of heterogeneity. Where there was evidence of high heterogeneity we attempted to explore this further: see Data synthesis for further information about how we handled potential heterogeneity in the data analyses.

\section{Assessment of reporting biases}

Reporting biases arise when the dissemination of research findings is influenced by the nature and direction of results. Publication bias is one of a number of possible causes of 'small study effects', that is, a tendency for estimates of the intervention effect to be more beneficial in smaller RCTs. Funnel plots allow a visual assessment of whether small study effects may be present in a meta-analysis. A funnel plot is a simple scatter plot of the intervention effect estimates from individual RCTs against some measure of each trial's size or precision (Sterne 2011). We planned to present funnel plots for meta-analyses comprising 10 RCTs or more using RevMan 5 (RevMan 2014).

\section{Data synthesis}

We combined details of included studies in a narrative review. Data are presented separately for open fractures and other open traumatic wounds. Within these sub-populations comparisons were further structured according to type of comparator and then by outcomes ordered by follow-up period. We considered clinical and methodological heterogeneity and undertook pooling when studies appeared appropriately similar in terms of wound type, intervention type, duration of follow-up and outcome type.

We were unable to pre-specify the amount of clinical, methodological and statistical heterogeneity in the included studies. Thus, we used a random effects approach for metaanalysis. Conducting meta-analysis with a fixed effect model in the presence of even minor heterogeneity may provide overly narrow confidence intervals. We would only have used a fixedeffect approach when clinical and methodological heterogeneity was assessed to be minimal, and the assumption that a single underlying treatment effect was being estimated held. Chi-squared and I-squared were used to quantify heterogeneity but were not used to guide choice of model for meta-analysis. We would have exercised caution when meta-analysed data were at risk of small study effects because use of a random effects model may be unsuitable here. In this case, or where there were other reasons to question the selection of a fixed effect or random effects model, we planned to assess the impact of the approach using sensitivity analyses to compare results from alternate models, but this was not implemented (Thompson 1999).

We presented data using forest plots where possible. For dichotomous outcomes we presented the summary estimate as a risk ratio (RR) with $95 \% \mathrm{Cl}$. Where continuous outcomes were measured, we presented a mean difference (MD) with $95 \%$ $\mathrm{Cl}$; we planned to pool standardised mean difference (SMD) estimates where studies measured the same outcome using different methods. For time-to-event data, we planned to plot (and, if appropriate, pool) estimates of hazard ratios and $95 \% \mathrm{Cls}$ as presented in the study reports using the generic inverse-variance method in RevMan 5 (RevMan 2014). In future updates, where timeto-healing is analysed as a continuous measure but it is not clear if all wounds healed, we will document use of the outcome in the study but will not summarise data or use them in any meta-analysis.

We obtained pooled estimates of treatment effect from the available data using RevMan 5 software (RevMan 2014).

\section{'Summary of findings' tables}

We presented the main results of the review in 'Summary of findings' tables where data were available. These tables present key information concerning the certainty of the evidence, the magnitude of the effects of the interventions examined, and the sum of the available data for the main outcomes (Schünemann 2011a). The 'Summary of findings' tables also include an overall grading of the evidence related to each of the main outcomes using the GRADE approach, which defines the certainty of a body of evidence as the extent to which one can be confident that an estimate of effect or association is close to the true quantity of specific interest. The certainty of a body of evidence involves consideration of within-trial risk of bias (methodological quality), directness of evidence, heterogeneity, precision of effect estimates and risk of publication bias (Schünemann 2011b). We planned to present the following outcomes in the 'Summary of findings' tables:

- time to complete wound healing, where analysed using appropriate survival analysis methods

- proportion of wounds completely healed during the trial period (with or without surgery)

- wound infection

- adverse events 
- time to closure or coverage surgery

- mean pain scores.

\section{Subgroup analysis and investigation of heterogeneity}

We had previously suggested that we would conduct subgroup analysis on primary outcomes based on type of traumatic wound. However, following the protocol stage of the review we revised our plan to present the results of the review by two distinct subpopulations and did not conduct further subgroup analysis within these.

We did not conduct any further pre-specified subgroup analysis based on the categories below due homogeneity in the data or lack of data, or both:

- grade of wound injury

- contamination level of wounds.

\section{Sensitivity analysis}

We planned to perform sensitivity analyses to explore the effect of the following, but this was not possible due to lack of available data:
- removal of studies classed at high risk of bias for any domain.

We also conducted a post-hoc sensitivity analysis exploring the impact of using alternate wound infection data from Costa 2017.

\section{RES U L T S}

\section{Description of studies}

\section{Results of the search}

We present the results of the search in the PRISMA diagram (Figure 1). The literature search found 175 records after duplicates were removed. From the initial screening we removed 142 records and sought 33 full-text articles for further scrutiny. Of the 33 articles that we scrutinised, we included seven studies (reported in eight articles) and excluded 20 studies (reported in 25 articles). We did not identify any ongoing studies and there are none awaiting classification. 
Figure 1. Study flow diagram

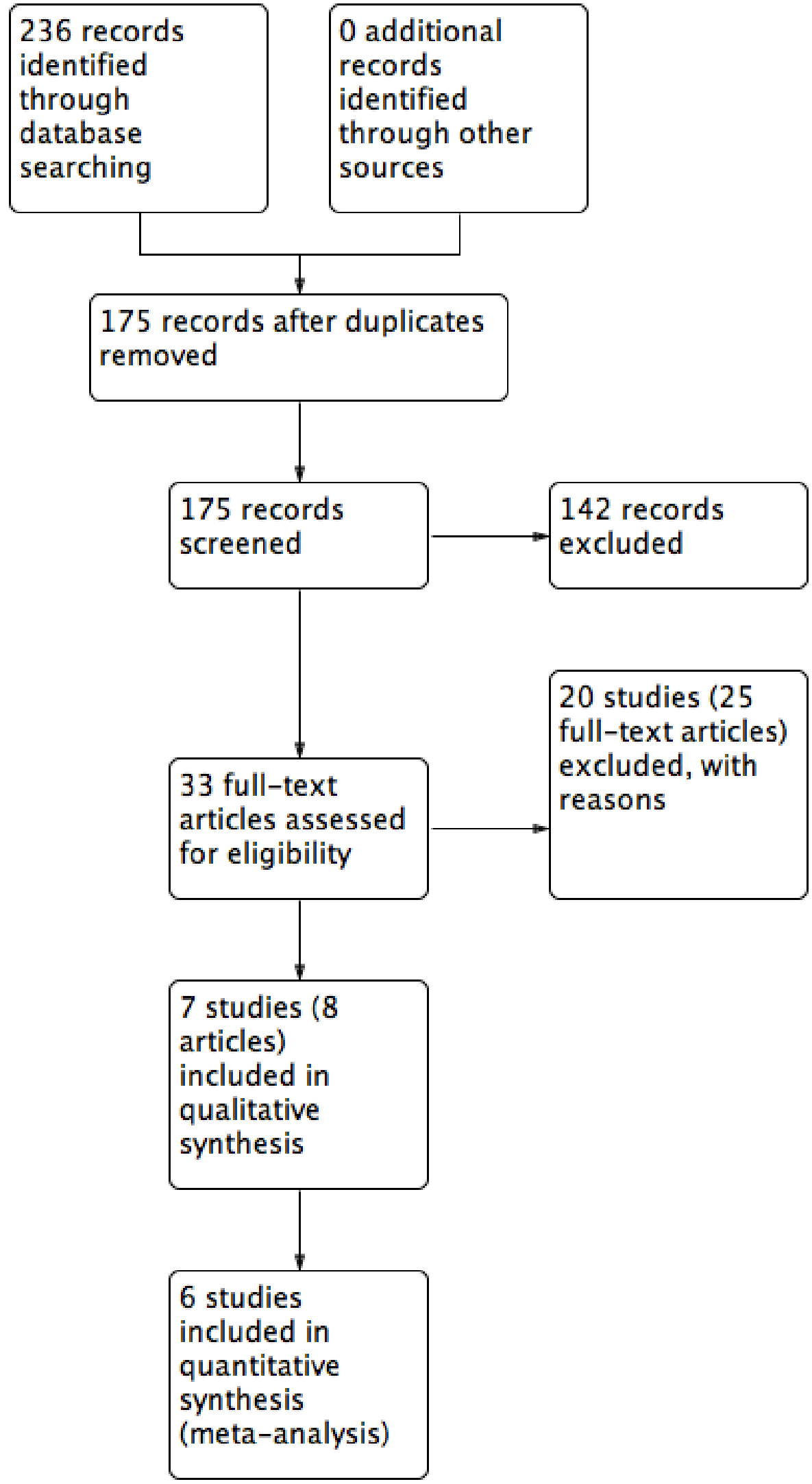


Study characteristics are detailed (Characteristics of included studies; Characteristics of excluded studies) and summarised below. We contacted all trial authors for additional information and missing data; any responses are noted in relevant tables.

\section{Included studies}

\section{Study design and setting}

All studies were two-arm, parallel-group RCTs except Chen 2016, which was a three-arm trial. One study provided care in a rabies clinic (Chen 2016) and two in hospital orthopaedic wards (Ondieki 2012; Stannard 2009). Studies were conducted in different countries as follows: China (Chen 2016), India (Virani 2016), Iran (Arti 2016), Kenya (Ondieki 2012), Turkey (Keskin 2008), the UK (Costa 2017) and the USA (Stannard 2009). Two studies reported their funding source: Stannard 2009 received a grant from a manufacturer of wound healing technology and Costa 2017 was funded by the UK National Institute for Health Research.

\section{Participants}

Sample size ranged between 40 and 586 participants.

- Four trials included only participants with open fractures where NPWT was used on open wounds (Arti 2016; Costa 2017; Stannard 2009; Virani 2016). In Arti 2016 participants had to be aged between 15 and 55 years, in Costa 201716 years or older and in Stannard 2009 and Virani 2016 over 18 years. The severity of open fractures (based on the Gustilo-Anderson classification) varied but largely included the more severe injuries, which are those that cannot be closed after initial surgical debridement. Arti 2016 included participants with a grade IIIB open fracture; Costa 2017 those with a grade II or III open fracture; Stannard 2009 and Virani 2016 included heavily contaminated grade II and IIIA open fractures, grade IIIA injuries with very severe soft tissue damage and all IIIB or IIIC open fractures.

- Three trials included participants with other types of open traumatic wounds (Chen 2016; Keskin 2008; Ondieki 2012). Ondieki 2012 included trauma wounds with a contamination level of dirty, involving soft tissue loss on the lower limb, Keskin 2008 included people with general traumatic wounds with no further information and Chen 2016 included people with severe dog bites to the limbs. Chen 2016 notes that $13 \%$ of participants suffered open fractures, with some participants also having finger amputation. Participants needed to be over 12 years in Ondieki 2012 and over 18 years in Chen 2016 and Keskin 2008.

\section{Interventions}

\section{Open fracture trials}

Arti 2016; Stannard 2009 and Virani 2016 assessed NPWT use at $125 \mathrm{mmHg}$. In Costa 2017, the amount of pressure applied was at the discretion of the clinician, but $125 \mathrm{mmHg}$ was the predominant setting.

The NPWT dressing used was noted as: solid foam or gauze (Virani 2016) 'open-cell' solid foam or gauze (Costa 2017), sponge foam (Arti 2016), and 'VAC dressing', which the review authors believe to be GranuFOAM (Stannard 2009). The control arm in the studies received conventional wound care consisting of cleaning and dressing (in the absence of NPWT), which we refer to in this review as 'standard care'. Dressings in the control groups varied between studies being described as conventional in Arti 2016; saline dressings in Stannard 2009 and not described in Virani 2016. Costa 2017 described use of a standard dressing comprising a nonadhesive layer applied directly to the wound, covered by a sealed dressing or bandage: the study notes that the exact details of the materials used were left to the discretion of the treating surgeon as per UK routine care.

All studies used NPWT following surgical debridement until wounds were ready for coverage or closure surgery, after which they followed up to assess subsequent outcomes, such as wound infection and healing. All studies periodically carried out further debridement and all had regimes using antibiotic prophylaxis.

- Arti 2016: used NPWT on debrided open wounds for 10 to 14 days with the aim of reducing wound size and promoting granulation to allow either change to a conventional dressing or further surgery for skin grafting or flap closure.

- Costa 2017: following UK guidelines the aim was to use NPWT on debrided, open wounds until a second operation between 48 and 72 hours after the first. The second surgery involved further debridement and wound closure or soft tissue reconstruction where possible. Where further use of dressings for open wounds were required this followed the allocated treatment until definitive closure/cover of the wound.

- Stannard 2009: after initial debridement participants were allocated to trial treatment with subsequent surgeries within 36 to 72 hours until the wound was granulated and ready for coverage or closure surgery.

- Virani 2016: used the trial treatments until the wound was granulated and the participant was able to undergo coverage or closure surgery. Participants had serial irrigation and debridements during treatment.

\section{Other open traumatic wounds trials}

All studies (Chen 2016; Keskin 2008; Ondieki 2012) used NPWT at $125 \mathrm{mmHg}$ and $75 \mathrm{mmHg}$ (Chen 2016). The NPWT dressing used was noted as: a combined with polyvinyl alcohol shrink formaldehyde bubble dressing (Chen 2016); a polyurethane foam (Keskin 2008) and a sterile foam manufactured by Bobamil and gauze (Ondieki 2012). The control arm in the studies received conventional wound care consisting of cleaning and dressing (in the absence of NPWT), which we refer to in this review as 'standard care'. Dressings in the control groups varied between studies being described as "sterilised' (Chen 2016) or gauze (Keskin 2008; Ondieki 2012).

- Chen 2016: used NPWT on clean and debrided wounds and following surgery to repair damaged bone, organs and muscle. They removed NPWT after four to five days following initial surgery and followed the wound to healing.

- Ondieki 2012: used NPWT until the wound achieved 100\% granulation and was ready for closure or coverage surgery.

- Keskin 2008: did not present any information on the timing and treatment aims of NPWT use.

\section{Outcomes}

None of the included studies reported the number of wounds closed with surgery or wound recurrence. Duration of follow-up ranged between 10 days (Keskin 2008) and 67 months (Stannard 2009).

The studies reported the following outcomes: 


\section{Open fracture wound trials}

- Number of wounds healed: Costa 2017

- Wound infection: Arti 2016; Costa 2017; Stannard 2009; Virani 2016. Costa 2017 reported unblinded data for superficial and deep wounds at 30 days and for persistent and deep wound infection diagnosed after 30 days and before 12 months. They also reported the blinded assessment of wound infection (per participant at six weeks) (see Table 1). We used the blinded, six-week wound infection data and explored use of unblinded, 30-day wound infection outcome data (superficial and deep infection data at 30 days combined) in a post hoc sensitivity analysis. Additional data are presented in Table 1. Costa 2017 was the only study to present clearly blinded data for this outcome.

- Adverse events: Costa 2017

- Time to surgery: Stannard 2009; Virani 2016

- Health-related quality of life: Stannard 2009; Costa 2017

- Cost effectiveness: Costa 2017

\section{Other open traumatic wounds trials}

- Time to wound healing: Chen 2016

- Wound infection: Chen 2016; Ondieki 2012
- Time to closure or coverage surgery (time to full granulation): Ondieki 2012

- Pain: Ondieki 2012

- Keskin 2008 did not report any outcomes relevant to the review.

\section{Excluded studies}

We excluded 20 studies for including an ineligible patient population (Braakenburg 2006; Dorafshar 2012; Moisidis 2004; Mouës 2004; Mouës 2005; Mouës 2007; Mouës 2008; RahmanianSchwarz 2012; Stannard 2006; Stannard 2012), having an ineligible study design (Rovee 2004; Brown 2012; Fleischmann 1993; Fleischmann 1995; Lesiak 2013; MAS 2006; Ubbink 2008; Vikatmaa 2008) and using an ineligible intervention (Colom 2006; Jeschke 2004).

\section{Risk of bias in included studies}

Details of the risk of bias in the included studies are presented in the 'Risk of bias' tables (Included studies) and summarised for each study in Figure 2 and overall in Figure 3. Overall none of the studies were at low risk of bias for all domains. All studies were at high risk of performance bias, which is common in device trials where it is difficult to blind health professionals and participants to treatments applied to wounds. 
Figure 2. Risk of bias summary: review authors' judgements about each risk of bias item for each included study

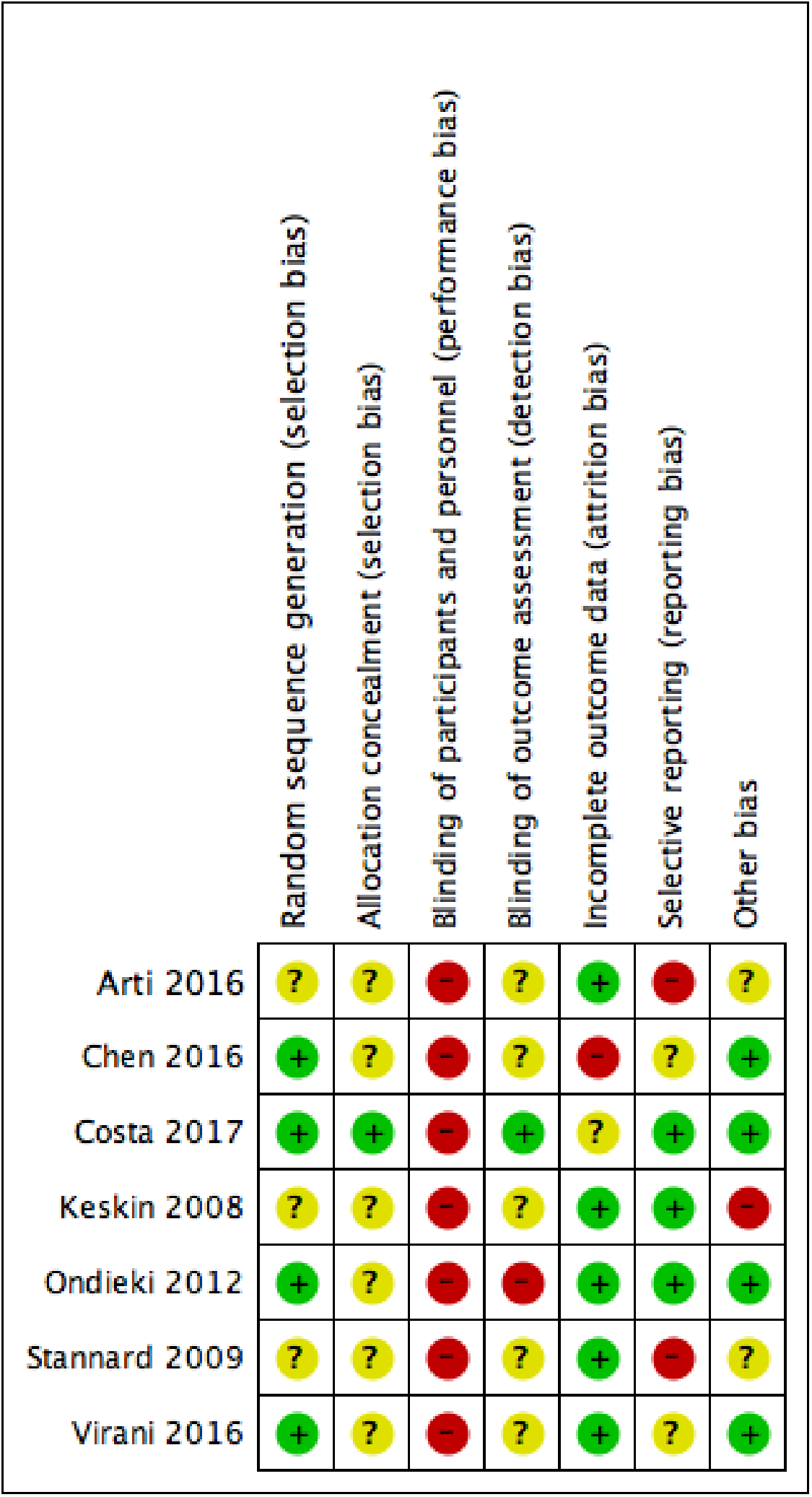


Figure 3. Risk of bias graph: review authors' judgements about each risk of bias item presented as percentages across all included studies

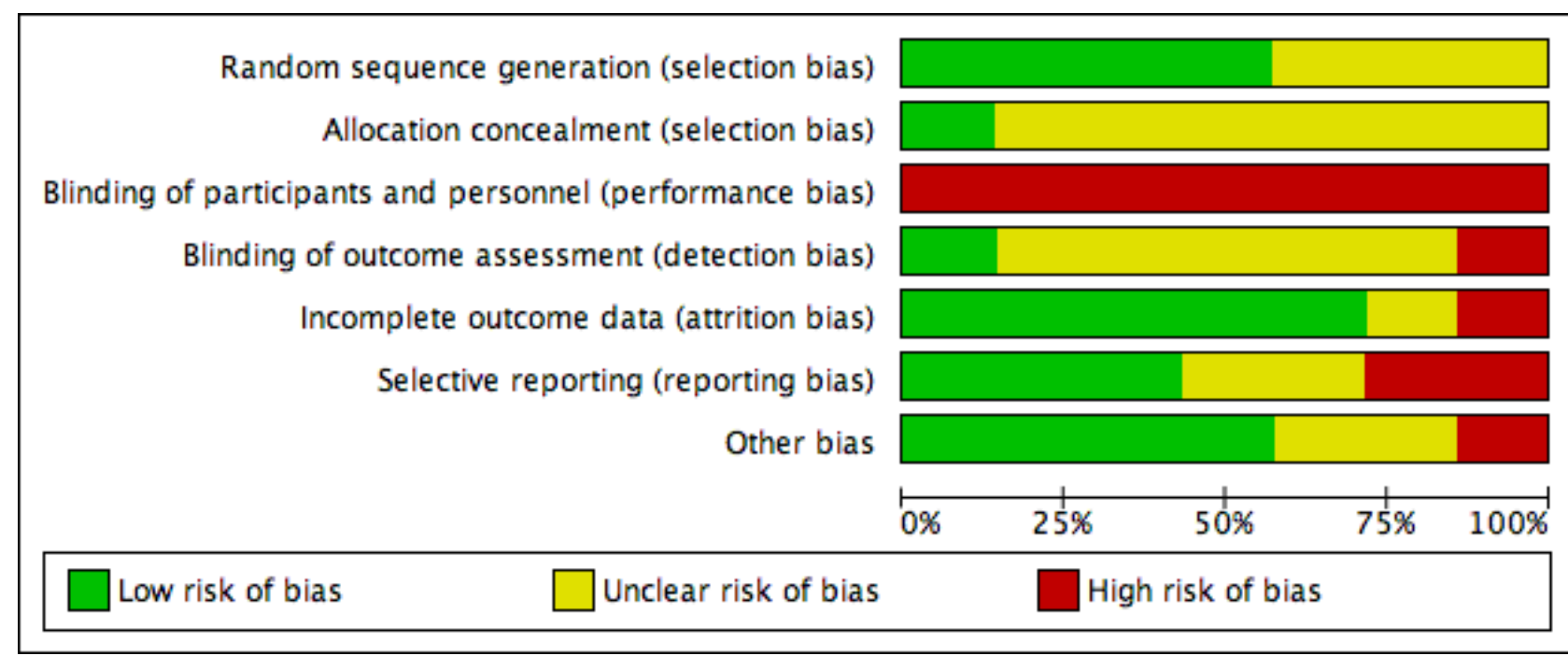

Two studies had no additional domains with a high risk of bias (Costa 2017; Virani 2016). The remaining five studies were at high risk of bias for two domains; the additional domains with high risk of bias varied.

\section{Allocation}

Randomisation was adequately undertaken using random number tables, computer, a random number generator and algorithm in five studies (Chen 2016; Costa 2017 Ondieki 2012; Stannard 2009; Virani 2016), but was not clearly described in two studies (Arti 2016; Keskin 2008). We classed allocation concealment as unclear in all studies except Costa 2017, where further details from the study authors confirmed that adequate allocation concealment had been conducted.

\section{Blinding}

Blinding to delivering or receiving interventions that are clearly different is challenging and often not achievable, therefore we assessed all studies as high risk of performance bias. Blind outcome assessment was not mentioned, therefore all studies were at unclear risk of detection bias except Ondieki 2012, which we assessed as being at high risk of detection bias for stating that the evaluation of outcomes such as pain may have been biased; and Costa 2017, which we assessed as being at low risk of detection bias for using blind outcome assessors for wound healing and wound infection outcomes.

\section{Incomplete outcome data}

We assessed four studies as being at low risk of bias given that there was minimal (Ondieki 2012; Stannard 2009; Virani 2016) or no (Arti 2016) loss to follow-up/exclusion. One study recruited additional participants to make up for attrition (Keskin 2008) (see other potential sources of bias). Chen 2016 was at high risk of attrition bias due to an imbalance in attrition across groups. Costa 2017 randomised 625 participants in an emergency setting where potentially eligible patients often went immediately into theatre and/or were unconscious or had reduced levels of consciousness - a number of randomised participants could only be assessed and consented post randomisation, leading to inclusion of 460 participants in the final trial follow-up and results. We classed this study as being at unclear risk of bias.

\section{Selective reporting}

We assessed Arti 2016 as being at high risk of reporting bias for not reporting a proposed outcome and reporting a surrogate outcome instead. We also classed Stannard 2009 as being at high risk of bias, having measured but failed to report the 12-month and final follow-up data for the health-related quality of life outcome. Trial registration was not available for any included study except Costa 2017, however, from data included in the methods of papers, we judged that all measured outcomes appeared to have been reported in Keskin 2008 and Ondieki 2012; we judged the three studies to be at low risk of bias. It was unclear whether all measured outcomes were reported in Virani 2016. Chen 2016 reported an average of 4.6 wounds even though the unit of analysis and randomisation appear to be the participants. We assessed all three studies as being at unclear risk of bias.

\section{Other potential sources of bias}

We assessed Keskin 2008 as being at high risk of other bias because of a difference in frequency of change of wound dressings, which may have resulted in bias. The assignment of additional participants to study groups to replace those lost to follow-up may also not have been done at random.

\section{Effects of interventions}

See: Summary of findings for the main comparison NPWT 125 $\mathrm{mmHg}$ compared with standard care in open fracture wounds; Summary of findings 2 NPWT $125 \mathrm{mmHg}$ compared with standard care in other open traumatic wounds; Summary of findings 3 NPWT $75 \mathrm{mmHg}$ compared with standard care in other open traumatic wounds; Summary of findings 4 NPWT $125 \mathrm{mmHg}$ compared with NPWT $75 \mathrm{mmHg}$ in other open traumatic wounds

All extracted data are reported here: Table 1. 
Negative pressure wound therapy versus standard care in open fracture wounds

\section{Comparison 1. Negative pressure wound therapy $125 \mathrm{mmHg}$ versus standard care (4 studies; 701 participants)}

Four studies with 701 participants assessed this comparison (Arti 2016; Costa 2017; Stannard 2009; Virani 2016). Whilst the magnitude of applied pressure was pragmatic in the Costa 2017 study, the majority of participants received NPWT at $125 \mathrm{mmHg}$, thus we have included it in this comparison.

Summary of findings for the main comparison

\section{Primary outcomes}

\section{Complete wound healing}

Only Costa 2017 reported the number of healed wounds, this was at six weeks following randomisation. There was no clear difference in the number of participants with a healed wound between the NPWT and the standard care groups (RR $1.01,95 \% \mathrm{Cl} 0.81$ to 1.27 ; 460 participants); moderate-certainty evidence downgraded once for imprecision (Analysis 1.1).

\section{Wound infection}

Duration of follow-up for wound infection was not clear in all studies but was largely around 30 days. It is uncertain whether NPWT $125 \mathrm{mmHg}$ reduces the risk of wound infection in open fracture wounds compared with standard care over this follow-up period (RR 0.48, 95\% Cl 0.20 to 1.13; 4 studies (Arti 2016; Costa 2017; Stannard 2009; Virani 2016); 596 participants; $I^{2}=56 \%$ ); very lowcertainty evidence, downgraded due to serious risk of bias, serious inconsistency and serious imprecision (Analysis 1.2).

In a post-hoc sensitivity analysis we re-analysed these data using the unblinded, combined deep and superficial surgical site infection data at 30 days' follow-up from Costa 2017. There was little change to findings (RR $0.49,95 \% \mathrm{Cl} 0.19$ to $1.27 ; 4$ studies (Arti 2016; Costa 2017; Stannard 2009; Virani 2016); 701 participants (more data from Costa 2017 included in this analysis); $1^{2}=66 \%$ ) (Analysis 1.3).

\section{Adverse events}

Costa 2017 presented data on post-operative complications related to the relevant open fracture 12 months following randomisation. These are presented here as further surgery and other woundrelated complications in the trial. There were 111 further woundrelated surgical events in the standard care arm and 95 in the NPWT arm. There were 43 other post-operative complications in the standard care arm and 39 in the NPWT arm. No difference was reported as statistically significant in the trial report. We have not re-analysed the data here due to their clustered nature (event clustered by person).

\section{Secondary outcomes}

\section{Time to closure or coverage surgery}

Time to closure or coverage surgery was reported in two studies (Stannard 2009; Virani 2016) analysing 151 participants. Mean time to further surgery ranged between 4 to 8.3 days with NPWT and 3.2 to 9.8 days with standard care, however, we were unable to analyse the results as the studies did not report measures of variance or we were unable to obtain them. It is uncertain whether NPWT 125
$\mathrm{mmHg}$ reduces the time to closure or coverage surgery for open fracture wounds because the certainty of the evidence is very low. The evidence was downgraded for serious risk of bias and very serious imprecision.

\section{Health-related quality of life}

This evidence is from two studies (518 participants) (Costa 2017; Stannard 2009) that measured health-related quality of life at 3 months, 6 months, 9 months and 12 months. Stannard 2009 used the short form-36 (SF-36), reporting the physical component score (PCS score) in participants who were infected (a subgroup of the overall population; we have presented data in Table 1). Costa 2017 used the SF-12 and EQ-5D utility and also assessed data at 12 months. As noted in the methods we reported the latest time point here. There is probably no clear difference in the EQ-5D utility score at 12 months between NPWT and standard care (MD -0.01, $95 \% \mathrm{Cl}-0.08$ to $0.06 ; 364$ participants); moderate-certainty evidence downgraded once for imprecision. There is no clear difference in SF-12 PCS score (MD -0.50, 95\% Cl -4.08 to 3.08; 329 participants); low-certainty evidence downgraded twice for imprecision (Analysis 1.4).

\section{Cost effectiveness}

Costa 2017 reported that it was unlikely that NPWT was a costeffective treatment. The mean total cost of resource use was GBP 678 (95\% Cl GBP -1082 to 2438 ) more in the NPWT group than the control group. Incremental mean quality-adjusted life years (QALYs) were very slightly higher in the NPWT group: 0.002 (-0.0054 to 0.059): the incremental cost-effectiveness ratio (ICER) was GBP 267,910 . To further explore uncertainty in findings, the authors assessed the probability of NPWT being cost effective for open fracture wounds at cost-per-QALY thresholds of GBP 15,000 to GBP 30,000. The probability of NPWT being cost effective at these threshold was never higher than $27 \%$; moderate-certainty evidence downgraded once for serious imprecision.

\section{Other outcomes}

None of the included studies reported proportion of wounds closed with coverage or closure surgery and wound recurrence.

\section{Negative pressure wound therapy versus standard care in other open traumatic wounds}

\section{Comparison 2. Negative pressure wound therapy $125 \mathrm{mmHg}$ versus standard care (2 studies; 509 participants)}

\section{Primary outcomes}

\section{Complete wound healing}

Chen 2016 reported time to wound healing but this was stratified by infection status and presented as mean data when it was not clear that all wounds had healed, in which case the mean is not an appropriate summary measure. We have presented outcome data in Table 1 but have not analysed them further.

\section{Wound infection}

Two studies with 509 participants contributed data to this comparison (Chen 2016; Ondieki 2012). The duration of followup for outcome assessment was not clear. Both studies had a total follow-up duration of six months. There is no clear difference between NPWT and standard care-treated wounds in the risk of wound infection (RR $0.61,95 \% \mathrm{Cl} 0.31$ to 1.18 ; 509 participants; 2 
studies; $\left.\right|^{2}=0 \%$ ); low-certainty evidence downgraded due to serious risk of bias and serious imprecision (Analysis 2.1).

\section{Adverse events}

Not reported for this comparison.

\section{Secondary outcomes}

\section{Pain}

One study with 51 participants with soft tissue trauma wounds measured pain using the numeric rating scale ranging from 0 (no pain) to 10 (worst possible pain) (Ondieki 2012). There is no clear, clinically meaningful difference in pain score between the intervention groups from current evidence (MD $0.30,95 \% \mathrm{Cl}-0.22$ to 0.82; 51 participants; 1 study); low-certainty evidence downgraded for serious risk of bias and serious imprecision (Analysis 2.2).

\section{Comparison 3. Negative pressure wound therapy $75 \mathrm{mmHg}$ versus standard care (1 trial; 463 participants)}

One trial assessed this comparison (Chen 2016). This was a threearm study involving people with soft tissue trauma, and 463 of the 586 participants were included in this comparison.

\section{Primary outcomes}

\section{Complete wound healing}

Chen 2016 reported time to wound healing but this was stratified by infection status and presented as mean data when it was not clear that all wounds had healed. We have presented outcome data Table 1 but not analysed them further.

\section{Wound infection}

The duration of follow-up was unclear. It is uncertain if there is a difference in risk of wound infection between NPWT $75 \mathrm{mmHg}$ and standard care (RR $0.44,95 \% \mathrm{Cl} 0.17$ to $1.10 ; 463$ participants; 1 study). The evidence is very low certainty and we downgraded it for serious risk of bias and very serious imprecision (Analysis 3.1).

\section{Adverse events}

Not reported for this comparison.

\section{Secondary outcomes}

Not reported for this comparison.

\section{Different pressures of negative pressure wound therapy in other open traumatic wounds}

Comparison 4. Negative pressure wound therapy $125 \mathrm{mmHg}$ versus negative pressure wound therapy 75 mmHg (1 trial; 251 participants contributing data to this comparison)

One trial assessed this comparison (Chen 2016). This was a threearm study involving people with soft tissue trauma, and 251 of the 586 participants were included in this comparison.

\section{Primary outcomes}

\section{Complete wound healing}

Not reported for this comparison.

\section{Wound infection}

The duration of follow-up was unclear. It is uncertain if there is a difference in risk of wound infection between NPWT $75 \mathrm{mmHg}$ and
$125 \mathrm{mmHg}$ (RR 1.04, 95\% Cl 0.31 to 3.51; 251 participants; 1 study) because the certainty of the evidence is very low. We downgraded the evidence for serious risk of bias and very serious imprecision (Analysis 4.1).

\section{Adverse events}

Not reported for this comparison.

\section{Secondary outcomes}

Not reported for this comparison.

\section{DISCUSSION}

Summary of findings for the main comparison; Summary of findings 2; Summary of findings 3; Summary of findings 4

\section{Summary of main results}

We included seven studies with 1381 participants in the review. The included studies either compared NPWT at $125 \mathrm{mmHg}$ or $75 \mathrm{mmHg}$ with standard care or NPWT at $125 \mathrm{mmHg}$ with NPWT at $75 \mathrm{mmHg}$. Four studies enrolled participants with open fracture wounds.

- There is no clear difference in wound healing between NPWT $125 \mathrm{mmHg}$ and standard care in open fracture wounds at six weeks' follow-up. This is based on moderate-certainty evidence (1 study, 460 participants, undertaken in the UK).

- It is uncertain whether NPWT $125 \mathrm{mmHg}$ reduces the risk of wound infection compared with standard care in open fracture wounds. Very low-certainty evidence (4 studies, 596 participants, varying locations).

- From the EQ-5D utility and SF-12 scores assessed, there is no clear difference in scores for health-related quality of life between study groups in open fracture wounds; moderateand low-certainty evidence (1 study, 364 and 329 participants respectively).

- There is moderate-certainty evidence that NPWT $125 \mathrm{mmHg}$ is not a cost-effective treatment for open fractures in the UK.

- Data on the effectiveness of NPWT for the treatment of other open traumatic wounds are uncertain and we cannot draw any conclusions.

\section{Overall completeness and applicability of evidence}

The included studies recruited adults and children with traumatic wounds involving open fractures and other open traumatic wounds. The included studies compared NPWT with standard care and also compared different NPWT applied at different pressures. Only one study reported complete wound healing and adverse events. Wound infection, which is a key issue in these wounds was the most commonly reported outcome. Wound recurrence was also not addressed. Apart from wound infection, the other outcomes were mostly reported in single studies.

The included studies took place in a range of settings and countries, including low- to middle-income countries. A recent and rigorous, publicly-funded study from the UK presented important costeffectiveness information but it is not clear how transferable these data might be to other countries. The use of NPWT for the treatment of open fracture wounds was similar in that the treatment was used on the most serious wounds that could not be easily covered or closed during initial surgery. The treatment aim in most open 
fracture studies was to close the wounds in the near future, which seems to reflect common practice in this area. Beyond this, treatment protocol varied across studies in terms of frequency of dressing change and dressing type, however, these variations are common in clinical practice. We grouped the remaining treatments under other open traumatic wounds, which we acknowledge is a broad grouping. In this iteration of the review, this group contained only three studies, of which only two reported data relevant to the review. The types of wounds were quite different, and one study in particular (Chen 2016) included people with severe dog bites, which led to a range of injuries including partial loss of digits and also some open fractures. The generalisability from such a grouping is unclear and the evidence will need to be considered alongside the results of further studies when these become available.

\section{Quality of the evidence}

All the studies were at high risk of bias due to the risk of performance bias but this is common in device trials and it is blinded outcome assessment that is key. We therefore did not downgrade solely for high risk of performance bias because this was considered inherent in the nature of the comparisons. Only one study, Costa 2017, clearly stated that it conducted blinded outcome assessment of wound healing and also wound infection. The blinded assessment process used wound photographs, which the study authors noted might have been an imperfect method for the assessment of wound infection in particular. For these reasons we also assessed the alternative 30-day infection data from this study, and no differences in outcome data were reported.

The certainty of evidence was often low or very low. This was due to the risk of bias, small sample size and wide confidence intervals that included both an effect and no effect or even a harm of the intervention.

We were only able to pool data for the wound infection outcome. Results were uncertain, with studies being imprecise, and there was heterogeneity between studies in terms of whether confidence intervals suggested the potential for the true population effect to be one of harm rather than benefit. The reasons for this are not clear but the issues of risk of bias and imprecision have led to an overall assessment of very low-certainty evidence. There was no indirectness as the studies addressed the population, intervention and outcome that we set out to address in our protocol. Due to the paucity of data we were unable to assess the studies for publication bias.

\section{Potential biases in the review process}

In one of the included studies (Ondieki 2012) the unit of randomisation ( 25 versus 25 participants) differed from the unit of analysis ( 25 versus 26 wounds). In that study, one participant appeared to have multiple wounds, however, we analysed the results on participant level on the assumption that this would make little difference to the findings. We made a post hoc decision to include wound infection as a primary outcome. Changing the outcomes of a review is often a potential source of bias. However, wound infection is a clinically important outcome and the fact that it was not included in the protocol represented an oversight on our part. The inclusion of this outcome in the review was not driven by the data available in the included studies. We also made a post hoc decision to include cost effectiveness as a secondary outcome, in view of the importance of this in determining the implementation of relatively high-cost interventions such as NPWT.

\section{Agreements and disagreements with other studies or reviews}

There are no reviews on NPWT for traumatic wounds. Existing Cochrane Reviews address NPWT for partial thickness burns, surgical wounds, ulcers, and foot wounds in people with diabetes mellitus. Only two of these reviews reported outcomes relevant to this review. Both reviews found insufficient evidence to determine whether NPWT reduces pain (Dumville 2015a) and wound infection (Dumville 2015b). We are uncertain about whether NPWT reduces pain and, on the other hand, found low-certainty evidence that NPWT may slightly reduce wound infection in traumatic wounds. However, we note that the participants in the two reviews are different from the population of interest in our review.

\section{AUTHORS' CONCLUSIONS}

\section{Implications for practice}

There is moderate-certainty evidence that negative pressure wound therapy (NPWT) probably leads to no clear difference in the number of wounds healed in open fracture wounds when compared with standard wound care (in the UK context) and is probably not a cost-effective treatment in the UK. There is insufficient evidence to determine the effect of NPWT at $125 \mathrm{mmHg}$ on wound infection, time to coverage or closure surgery, healthrelated quality of life and pain in open fracture wounds. There are limited data on other open traumatic wounds.

\section{Implications for research}

There is moderate evidence from one robust study that NPWT in people with open fractures is probably not cost effective. Evidence for other outcomes considered in this review are less clear and further research is likely warranted, however the clinical and research community need to consider the research priorities in this heterogeneous population. The presence of a robust trial of NPWT in open fractures may lessen the prioritisation of a repeat trial for this type of traumatic wound where other uncertainties with less evidence become key. This might not be the case for other types of traumatic wounds - depending on how generalisable the clinical community deems these data. Any new trials should aim to report on wound healing, infection, adverse events, pain, wound recurrence and health- related quality of life. Wound healing should primarily be investigated as a time-to-event outcome and participants should be followed up for a sufficient period of time. Trials should be designed in such a way as to minimise the potential risks of bias that impacted the studies identified in this review, and should follow internationally recognised reporting principles.

\section{ACKNOWLEDGEMENTS}

The authors are grateful to the following peer reviewers for their time and comments: Andrew Jull (Editor), Sarah Rhodes, Joel Beam, Adam Reid and Janet Wale. They are also grateful to Paulo Alves, Farrah-Hani Imran and Abram D Janis for their comments on the protocol. The authors would like to acknowledge the contribution of Denise Mitchell (copy-editor) and of Matthew Wordsworth and Anna Allen who were involved in advising on the protocol. 


\section{R E F E R E N C E S}

\section{References to studies included in this review}

Arti 2016 \{published data only\}

Arti H, Khorami M, Ebrahimi-Nejad V. Comparison of negative pressure wound therapy (NPWT) and conventional wound dressings in the open fracture wound. Pakistan Journal of Medical Sciences Quarterly 2016;32(1):65-9.

\section{Chen 2016 \{published data only\}}

Chen R, Huang L, Zheng J, Jia Y, Liu Y, Shan Y. Negative pressure wound therapy for serious dog bites of extremities: a prospective randomized trial. American Journal of Emergency Medicine 2016;34(6):1006-10.

\section{Costa 2017 \{published data only}

Achten J, Parsons NR, Bruce J, Petrou S, Tutton E, Willett K, et al. Protocol for a randomised controlled trial of standard wound management versus negative pressure wound therapy in the treatment of adult patients with an open fracture of the lower limb: UK Wound management of Open Lower Limb Fractures (UK WOLFF). BMJ Open 2015;5(9):e009087. [DOI: 10.1136/ bmjopen-2015-009087]

* Costa ML, Achten J, Bruce J, Davis S, Hennings S, Willett K, et al. UK Wound management of Open Lower Limb Fractures (UK WOLLF) - a randomised controlled trial and health economic evaluation of standard wound management versus negative pressure wound therapy in the treatment of adults with an open fracture of the lower limb. Health Technology Assessment (in press).

Costa ML, Achten J, Bruce J, Tutton E, Petrou S, Lamb SE, Parsons NR, UK WOLLF Collaboration. Effect of Negative Pressure Wound Therapy vs Standard Wound Management on 12-Month Disability Among Adults With Severe Open Fracture of the Lower Limb: The WOLLF Randomized Clinical Trial. JAMA 2018;319:2280-8.

\section{Keskin 2008 \{published data only\}}

Keskin M, Karabekmez FE, Yilmaz E, Tosun Z, Savaci N. Vacuumassisted closure of wounds and anxiety. Scandinavian Journal of Plastic and Reconstructive Surgery and Hand Surgery 2008;42(4):202-5.

\section{Ondieki 2012 \{published data only\}}

Ondieki JG, Khainga SO, Owilla F, Nangole FW. Outcome of foam versus gauze dressings in negative pressure wound therapy for the management of acute traumatic wounds with soft tissue loss at Kenyatta National Hospital. East African Medical Journal 2012;89(7):230-40

\section{Stannard 2009 \{published data only\}}

Stannard JP, Volgas DA, Stewart R, McGwin G Jr, Alonso JE. Negative pressure wound therapy after severe open fractures: a prospective randomized study. Journal of Orthopaedic Trauma 2009;23(8):552-7.

\section{Virani 2016 \{published data only\}}

Virani SR, Dahapute AA, Bava SS, Muni SR. Impact of negative pressure wound therapy on open diaphyseal tibial fractures: a prospective randomized trial. Journal of Clinical Orthopaedics and Trauma 2016;7(4):256-9.

\section{References to studies excluded from this review}

Braakenburg 2006 \{published data only\}

Braakenburg A, Obdeijn MC, Feitz R, Van Rooij IA, Van Griethuysen AJ, Klinkenbijl JH. The clinical efficacy and cost effectiveness of the vacuum-assisted closure technique in the management of acute and chronic wounds: a randomized controlled trial. Plastic and Reconstructive Surgery 2006;118(2):390-7. [DOI: 10.1097/01.prs.0000227675.63744.af]

Brown 2012 \{published data only\}

Brown KV, Guthrie HC, Ramasamy A, Kendrew JM, Clasper J. Modern military surgery: lessons from Iraq and Afghanistan. Journal of Bone and Joint Surgery 2012;94 B(4):536-43.

Colom 2006 \{published data only\}

Colom MJ. Evaluation of a self-adherent soft silicone dressing for the treatment of hypertrophic postoperative scars: negative pressure wound therapy to treat hematomas and surgical incisions following high-energy trauma. Journal of Wound Care 2006;15(5):193-6.

Dorafshar 2012 \{published data only\}

Dorafshar AH, Franczyk M, Gottlieb LJ, Wroblewski KE, Lohman RF. A prospective randomized trial comparing subatmospheric wound therapy with a sealed gauze dressing and the standard vacuum-assisted closure device. Annals of Plastic Surgery 2012;69(1):79-84. [DOI: 10.1097/ SAP.0b013e318221286c]

\section{Fleischmann 1993 \{published data only\}}

Fleischmann W, Strecker W, Bombelli M, Kinzl L. Vacuum sealing for the treatment of soft tissue damage in open fractures [Vakuumversiegelung zur behandlung des weichteilschadens bei offenen frakturen]. Der Unfallchirurg 1993;96:488-92.

\section{Fleischmann 1995 \{published data only\}}

Fleischmann W, Becker U, Kramer B. Infection prophylaxis by 'vacuum sealing' (VS) of open fractures. Fifth Annual Meeting of the European Tissue Repair Society; 1995, 30 August-2 September; Padova, Italy. 1995:381.

\section{Jeschke 2004 \{published data only\}}

Jeschke MG, Rose C, Angele P, Füchtmeier B, Nerlich MN, Bolder U. Development of new reconstructive techniques: use of Integra in combination with fibrin glue and negative-pressure therapy for reconstruction of acute and chronic wounds. Plastic and Reconstructive Surgery 2004;113(2):525-30. [DOI: 10.1097/01.PRS.0000100813.39746.5A]

Lesiak 2013 \{published data only\}

Lesiak AC, Shafritz AB. Negative-pressure wound therapy. Journal of Hand Surgery 2013;38(9):1828-32. [DOI: 10.1016/ j.jhsa.2013.04.029] 
MAS 2006 \{published data only\}

Medical Advisory Secretariat (MAS). Negative pressure wound therapy: an evidence-based analysis. Ontario Health Technology Assessment Series 2006;6(14):1-38. [ISSN: 19157398]

\section{Moisidis 2004 \{published data only\}}

Moisidis E, Heath T, Boorer C, Ho K, Deva AK. A prospective, blinded, randomized, controlled clinical trial of topical negative pressure use in skin grafting. Plastic and Reconstructive Surgery 2004;114(4):917-22. [DOI: 10.1097/01.PRS.0000133168.57199.E1]

Mouës 2004 \{published data only\}

* Mouës CM, Van Den Bemd GJ, Heule F, Hovius SE. A prospective randomized trial comparing vacuum therapy to conventional moist gauze therapy. Second World Union of Wound Healing Societies Meeting; 2004, 8-13 July; Paris, France. 2004:6. [Abstract A001]

Mouës CM, Van Den Bemd GJ, Meerding WJ, Hovius SE. Cost analysis comparing vacuum-assisted closure wound therapy to conventional moist gauze therapy. Second World Union of Wound Healing Societies Meeting; 2004, 8-13 July; Paris, France. 2004:87. [Abstract A008]

Mouës CM, Vos MC, Van Den Bemd GJ, Stijnen T, Hovius SE. Bacterial load in relation to vacuum-assisted closure wound therapy. 13th Conference of the European Wound Management Association; 2003, 22-24 May; Pisa, Italy. 2003:69.

\section{Mouës 2005 \{published data only\}}

* Mouës CM, Van Den Bemd GC, Meerding WJ, Hovius SE. An economic evaluation of the use of TNP on full-thickness wounds. Journal of Wound Care 2005;14(5):224-7.

Mouës CM, Vos MC, Van Den Bemd GJ, Stijnen T, Hovius SE. Bacterial load in relation to vacuum-assisted closure wound therapy: a prospective randomized trial. Wound Repair and Regeneration 2004;12(1):11-7. [DOI: 10.1111/ j.1067-1927.2004.12105.x]

\section{Mouës 2007 \{published data only\}}

Mouës CM, Van Den Bemd GJ, Heule F, Hovius SE. Comparing conventional gauze therapy to vacuum-assisted closure wound therapy: a prospective randomised trial. Journal of Plastic and Reconstructive Aesthetic Surgery 2007;60(6):672-81. [DOI: 10.1016/j.bjps.2006.01.041]

\section{Mouës 2008 \{published data only\}}

Mouës C, Toornenenbergen AW, Heule F, Hop WC, Hovius SE. The role of topical negative pressure in wound repair: expression of biochemical markers in wound fluid during wound healing. Wound Repair and Regeneration 2008;16(4):488-94. [DOI: 10.1111/j.1524-475X.2008.00395.x]

Rahmanian-Schwarz 2012 \{published data only\} Rahmanian-Schwarz A, Willkomm L-M, Gonser P, Hirt B, Schaller $\mathrm{H}-\mathrm{E}$. A novel option in negative pressure wound therapy (NPWT) for chronic and acute wound care. Burns 2012;38(4):573-7. [DOI: 10.1016/j.burns.2011.10.010]

\section{Rovee 2004 \{published data only\}}

Rovee DT. Editor's message [Proceedings of the 2nd World Union of Wound Healing Societies meeting, Paris, France, July 8-13, 2004]. Wounds 2004;16(12):2-19.

\section{Stannard 2006 \{published data only\}}

Stannard JP, Robinson JT, Anderson ER, McGwin G, Volgas DA, Alonso JE, et al. Negative pressure wound therapy to treat hematomas and surgical incisions following high-energy trauma. Journal of Trauma 2006;60(6):1301-6.

\section{Stannard 2012 \{published data only\}}

Mullins A, Paulos M. Cost effectiveness model: comparison of closed incision management using negative pressure and standard of care over clean closed incisions based on a 2012 randomized controlled trial. Value in Health 2012;15:A68.

* Stannard JP, Volgas DA, McGwin G, Stewart RL, Obremskey W, Moore T, et al. Incisional negative pressure wound therapy after high-risk lower extremity fractures. Journal of Orthopaedic Trauma 2012;26(1):37-42.

Stannard JP, Volgas DA, Robinson J, Anglen JO, De Los Santos A. Topical negative pressure therapy as an adjunct to soft tissue healing following open reduction and internal fixation of high risk fractures: preliminary results. Second World Union of Wound Healing Societies Meeting; 2004, 8-13 July; Paris, France. 2004:19.

\section{Ubbink 2008 \{published data only\}}

Ubbink DT, Westerbos SJ, Nelson EA, Vermeulen H. A systematic review of topical negative pressure therapy for acute and chronic wounds. British Journal of Surgery 2008;95(6):685-92. [DOI: 10.1002/bjs.6238]

\section{Vikatmaa 2008 \{published data only\}}

Vikatmaa P, Juutilainen V, Kuukasjarvi P, Malmivaara A. Negative pressure wound therapy: a systematic review on effectiveness and safety. European Society for Vascular Surgery 2008;36(4):438-48. [DOI: 10.1016/j.ejvs.2008.06.010]

\section{Additional references}

\section{Alexandrescu 2009}

Alexandrescu R, O'Brien SJ, Lecky FE. A review of injury epidemiology in the UK and Europe: some methodological considerations in constructing rates. BMC Health 2009;9:226.

\section{DeBoard 2007}

DeBoard RH, Rondeau DF, Kang CS, Sabbaj A, McManus JG. Principles of basic wound evaluation and management in the emergency department. Emergency Medicine Clinics of North America 2007;25:23-39.

\section{Deeks 2011}

Deeks JJ, Higgins JP, Altman DG, editor(s). Chapter 9: Analysing data and undertaking meta-analyses. In: Higgins JP, Green S, editor(s). Cochrane Handbook for Systematic Reviews of Interventions Version 5.1.0 (updated March 2011). The Cochrane Collaboration, 2011. Available from handbook.cochrane.org. 


\section{Dumville 2015a}

Dumville JC, Land L, Evans D, Peinemann F. Negative pressure wound therapy for treating leg ulcers. Cochrane Database of Systematic Reviews 2015, Issue 7. [DOI: 10.1002/14651858.CD011354.pub2]

\section{Dumville 2015b}

Dumville JC, Owens GL, Crosbie EJ, Peinemann F, Liu Z. Negative pressure wound therapy for treating surgical wounds healing by secondary intention. Cochrane Database of Systematic Reviews 2015, Issue 6. [DOI: 10.1002/14651858.CD011278.pub2]

\section{Edlich 2010}

Edlich RF, Rodeheaver GT, Thacker JG, Lin KY, Drake DB, Mason SS, et al. Revolutionary advances in the management of traumatic wounds in the emergency department during the last 40 years: part 1. Journal of Emergency Medicine 2010;38:40-50.

\section{FDA 2011}

US Food, Drug Administration (FDA). Class II special controls guidance document: non-powered suction apparatus device intended for negative pressure wound therapy (NPWT). www.fda.gov/downloads/MedicalDevices/ DeviceRegulationandGuidance/GuidanceDocuments/ UCM233279.pdf (accessed 8 February 2016).

\section{Glass 2014}

Glass GE, Murphy GF, Esmaeili A, Lai LM, Nachahal J. Systematic review of molecular mechanism of action of negative-pressure wound therapy. British Journal of Surgery 2014;101:1627-36.

\section{Gustilo 1976}

Gustilo RB, Anderson JT. Prevention of infection in the treatment of one thousand and twenty-five open fractures of long bones: retrospective and prospective analyses. Journal of Bone Joint Surgery (American Volume) 1976;58:453-8.

\section{Gustilo 1984}

Gustilo RB, Mendoza RM, Williams DN. Problems in the management of type III (severe) open fractures: a new classification of type III open fractures. Journal of Trauma 1984;24:742-6.

\section{Guy 2012}

Guy H, Grothier I. Using negative pressure therapy in wound healing. Nursing Times 2012;108(18):20.

\section{HHS 2009}

Office of Inspector General, US Department of Health and Human Services (HHS). Comparison of prices for negative pressure wound therapy pumps. oig.hhs.gov/oei/reports/ oei-02-07-00660.pdf. OEI-02-07-00660 (accessed 8 February 2016)

\section{Higgins 2003}

Higgins JP, Thompson SG, Deeks JJ, Altman DG. Measuring inconsistency in meta-analyses. BMJ 2003;327(7414):557-60.

\section{Higgins 2011a}

Higgins JP, Green S, editor(s). Cochrane Handbook for Systematic Reviews of Interventions Version 5.1.0 (updated March 2011). The Cochrane Collaboration, 2011. Available from handbook.cochrane.org.

\section{Higgins 2011b}

Higgins JP, Altman DG, Sterne JA, editor(s). Chapter 8: Assessing risk of bias in included studies. In: Higgins JP, Green S, editor(s). Cochrane Handbook for Systematic Reviews of Interventions Version 5.1.0 (updated March 2011). The Cochrane Collaboration, 2011. Available from handbook.cochrane.org.

\section{Higgins 2011c}

Higgins JP, Deeks JJ, Altman DG, editor(s). Chapter 16: Special topics in statistics. In: Higgins JP, Green S, editor(s). Cochrane Handbook for Systematic Reviews of Interventions Version 5.1.0 (updated March 2011). The Cochrane Collaboration, 2011. Available from handbook.cochrane.org.

\section{Higgins 2011d}

Higgins JP, Deeks JJ. Chapter 7: Selecting studies and collecting data. In: Higgins JP, Green S, editor(s). Cochrane Handbook for Systematic Reviews of Interventions Version 5.1.0 (updated March 2011). The Cochrane Collaboration, 2011. Available from handbook.cochrane.org.

\section{Hollander 1995}

Hollander JE, Singer AJ, Valentine S, Henry MC. Wound registry: development and validation. Annals of Emergency Medicine 1995;5(25):475-85.

\section{KCI Medical 2012}

$\mathrm{KCl}$ Medical. Science behind wound therapy. www.kci1.com/ $\mathrm{KCl} 1$ /sciencebehindwoundtherapy (accessed 8 February 2016).

\section{Lefebvre 2011}

Lefebvre C, Manheimer E, Glanville J. Chapter 6: Searching for studies. In: Higgins JP, Green S, editor(s). Cochrane Handbook for Systematic Reviews of Interventions Version 5.1.0 (updated March 2011). The Cochrane Collaboration, 2011. Available from handbook.cochrane.org.

\section{Liberati 2009}

Liberati A, Altman DG, Tetzlaff J, Mulrow C, Gotzsche PC, Ioannidis JP, et al. The PRISMA statement for reporting systematic reviews and meta-analyses of studies that evaluate health care interventions: explanation and elaboration. PLOS Medicine 2009;6:e1000100.

\section{Mangram 1999}

Mangram AJ, Horan TC, Pearson ML, Silver LC, Jarvis WR. Guideline for prevention of surgical site infection. Infection Control and Hospital Epidemiology 1999;20(4):247-78.

\section{NICE 2017}

National Institute for Health and Care Excellence. Fractures (complex): assessment and management. NICE guideline [NG37]. Last updated November 2017. www.nice.org.uk/ guidance/ng37 (accessed 14 February 2018). 


\section{Parmar 1998}

Parmar MK, Torri V, Stewart L. Extracting summary statistics to perform meta-analyses of the published literature for survival endpoints. Statistics in Medicine 1998;17:2815-34.

\section{Peinemann 2011}

Peinemann F, Sauerland S. Negative-pressure wound therapy: systematic review of randomized controlled trials. Deutsches Arzteblatt International 2011;108:381-9.

\section{RevMan 2014 [Computer program]}

Nordic Cochrane Centre, The Cochrane Collaboration. Review Manager 5 (RevMan 5). Version 5.3. Copenhagen: Nordic Cochrane Centre, The Cochrane Collaboration, 2014.

\section{Saxena 2004}

Saxena V, Hwang CW, Huang S, Eichbaum Q, Ingber D, Orgill DP. Vacuum-assisted closure: microdeformations of wounds and cell proliferation. Plastic and Reconstive Surgery 2004;11(5):1086-96.

\section{Schünemann 2011a}

Schünemann HJ, Oxman AD, Higgins JP, Vist GE, Glasziou P, Guyatt GH. Chapter 11: Presenting results and 'Summary of findings' tables. In: Higgins JP, Green S, editor(s). Cochrane Handbook for Systematic Reviews of Interventions Version 5.1.0 (updated March 2011). The Cochrane Collaboration, 2011. Available from handbook.cochrane.org.

\section{Schünemann 2011b}

Schünemann HJ, Oxman AD, Higgins JP, Deeks JJ, Glasziou P, Guyatt GH. Chapter 12: Interpreting results and drawing conclusions. In: Higgins JP, Green S, editor(s). Cochrane Handbook for Systematic Reviews of Interventions Version 5.1.0 (updated March 2011). The Cochrane Collaboration, 2011. Available from handbook.cochrane.org.

\section{CHARACTERISTICS OF STUDIES}

Characteristics of included studies [ordered by study ID]

\section{SIGN 2017}

Scottish Intercollegiate Guidelines Network (SIGN). Search filters. www.sign.ac.uk/search-filters.html (accessed 12 September 2017).

\section{Sterne 2011}

Sterne JA, Egger M, Moher D. Chapter 10: Addressing reporting biases. In: Higgins JP, Green S, editor(s). Cochrane Handbook for Systematic Reviews of Interventions Version 5.1.0 (updated March 2011). The Cochrane Collaboration, 2011. Available from handbook.cochrane.org.

\section{Thompson 1999}

Thompson SG, Sharp SJ. Explaining heterogeneity in metaanalysis: a comparison of methods. Statistics in Medicine 1999;18:2693-708.

\section{Webster 2014}

Webster J, Scuffham P, Stankiewicz M, Chaboyer WP. Negative pressure wound therapy for skin grafts and surgical wounds healing by primary intention. Cochrane Database of Systematic Reviews 2014, Issue 10. [DOI: 10.1002/14651858.CD009261.pub3]

\section{WHO 2014}

World Health Organization (WHO). Injuries and violence: the facts. 2014. apps.who.int/iris/ bitstream/10665/149798/1/9789241508018_eng.pdf (accessed 31 October 2016).

\section{References to other published versions of this review}

\section{Newton 2017}

Newton K, Wordsworth M, Allan AY, Dumville JC. Negative pressure wound therapy for traumatic wounds. Cochrane Database of Systematic Reviews 2017, Issue 1. [DOI: 10.1002/14651858.CD012522]

* Indicates the major publication for the study

Arti 2016

\begin{tabular}{ll} 
Methods & -arm RCT \\
Conducted in Iran \\
Follow-up: 1 month \\
\hline
\end{tabular}

Participants

90 participants with open fractures

Inclusion criteria: aged 15-55 years; open fracture wound type IIIB based on G/A classification, and accessible clean wound after debridement

Exclusion criteria: type I, II or IIIA and IIIC based on G/A classification; need of vascular repair or reconstruction; presence of multiple fractures in extremities; malnutrition; systemic disease; dermatological 
Arti 2016 (Continued)

disease like psoriasis; taking immunosuppressive drugs; existence of old fracture or implant in the fractured extremity and previous osteomyelitis

Interventions

Group A ( $n=45)$ : conventional wound dressing; changed twice a day. No further details

Group B $(n=45)$ : NPWT VAC. The dressings were changed usually every 48 hand NPWT continued for 10-14 days. Pressure was maintained at $125 \mathrm{~mm} \mathrm{Hg}$ continuously or intermittently 5 min on 2 min off. Therapy was stopped when an adequate granulation base was achieved allowing for change to conventional dressing, split-thickness skin graft, or flap closure.

Co-intervention: open fracture in both wounds underwent debridement before treatment.

\begin{tabular}{ll}
\hline Outcomes & $\begin{array}{l}\text { Primary review outcomes: wound infection (defined as purulent discharge from the wound site or } \\
\text { positive culture of the wound) } \\
\text { Secondary review outcomes: none }\end{array}$ \\
\hline Notes & $\begin{array}{l}\text { Funding source not noted but study authors declare no conflicts of interest, the vice-chancellor for re- } \\
\text { search of Ahwaz } \\
\text { Jundishapur University of Medical Sciences is thanked for support. Research noted as being "derived } \\
\text { from a speciality thesis" of one of the study authors }\end{array}$
\end{tabular}

Risk of bias

\begin{tabular}{lll}
\hline Bias & Authors' judgement & Support for judgement \\
\hline $\begin{array}{l}\text { Random sequence genera- } \\
\text { tion (selection bias) }\end{array}$ & Unclear risk & $\begin{array}{l}\text { Quote: "It is a prospective randomised clinical trial study by simple conve- } \\
\text { nience sampling conducted" } \\
\text { "Then patients were matched for age, sex and type of open fracture and were } \\
\text { assigned to either one of two groups based on random table numbers" } \\
\text { Comment: a random number table used. Possible robust randomisation but } \\
\text { process not clear from paper - classed as unclear }\end{array}$
\end{tabular}

\begin{tabular}{lll}
\hline $\begin{array}{l}\text { Allocation concealment } \\
\text { (selection bias) }\end{array}$ & Unclear risk & $\begin{array}{l}\text { Quote: See above } \\
\text { Comment: methods of allocation concealment unclear }\end{array}$ \\
\hline $\begin{array}{l}\text { Blinding of participants } \\
\text { and personnel (perfor- } \\
\text { mance bias) }\end{array}$ & High risk & Quote: no quote \\
All outcomes & $\begin{array}{l}\text { Comment: no mention of blinding but would not be possible to blind health } \\
\text { professionals to the different treatments so without further detail considered } \\
\text { high risk }\end{array}$
\end{tabular}

Blinding of outcome as-
sessment (detection bias)

Alloutcomes

All outcomes

Quote: no quote

Comment: no mention of blinding in the paper

\begin{tabular}{lll}
\hline $\begin{array}{l}\text { Incomplete outcome data } \\
\text { (attrition bias) } \\
\text { All outcomes }\end{array}$ & Low risk & Quote: no quote \\
\hline $\begin{array}{l}\text { Selective reporting (re- } \\
\text { porting bias) }\end{array}$ & High risk & Quote: "Wound healing duration, presence of infection" \\
& $\begin{array}{l}\text { Comment: wound surface reduction was reported rather than wound healing } \\
\text { duration }\end{array}$ \\
\hline Other bias & Unclear risk & Quote: no quote
\end{tabular}


Chen 2016

Methods 3-arm RCT; conducted in Rabies Prophylaxis and Immunity Clinic of Beijing, China

Follow-up: unclear, however, study duration was 6 months

Participants

586 participants with dog bites to their limbs ( 6 participants receiving standard care were lost to follow-up and excluded from the analysis). Participants had an average of 4.6 wounds.

Inclusion criteria: aged $>18$ years with lacerated limb wounds demanding surgical treatment (lacerations with lengths of $\geq 5 \mathrm{~cm}$, multiple penetrating lacerations of soft tissues, or lacerations accompanied by damage to $\geq 1$ of the following: muscles, tendons, ligaments, nerves, articular capsules, fractures, important blood vessels, acra [sic] amputation)

Exclusion criteria: puncture wounds $(<2 \mathrm{~mm})$; medium or small lacerations $(<5 \mathrm{~cm})$; infected wounds at presentation; having visited a physician's office $>8 \mathrm{~h}$ after the injury; wounds with skin loss requiring plastic surgery; or patients with immune deficiency, using immunosuppressive agents, or with autoimmune disorders or diabetes; refusal to give consent

Interventions Group A ( $n=335$ participants): standard care - sterilised dressings
Group B $(n=123$ participants): polyvinyl alcohol shrink formaldehyde bubble dressing + NPWT set at
$125 \mathrm{~mm} \mathrm{Hg}$

Group C ( $n=128$ participants): polyvinyl alcohol shrink formaldehyde bubble dressing + NPWT set at 75 $\mathrm{mm} \mathrm{Hg}$

Co-intervention: wounds were cleaned and disinfected. This was followed by debridement and important tissue repair after which wounds were covered. All participants were given rabies prophylactic active immunity and/or passive immunity, tetanus antitoxin was also given where necessary. Drainage was also performed, however, removed $24-48 \mathrm{~h}$ before surgery. Antibiotics were administered only after wound infection occurred.

Outcomes

Primary review outcomes: wound infection*; time to clinical healing (defined as the interval from being bitten to the wound achieving clinical healing)

Secondary review outcomes: none reported

*defined as the satisfaction of 1 of the following 3 major criteria: fever (body temperature $\geq 38^{\circ} \mathrm{C}$ ), abscess, and lymphangitis, or 4/5 minor criteria: wound-associated erythema that extended $>3 \mathrm{~cm}$ from the edge of the wound, tenderness at the wound site, swelling at the site, purulent drainage, and a white blood cell count in the peripheral blood of $12,000 / \mathrm{mL}$

Notes

The study authors declare no conflicts of interest. Funding source was not reported

\section{Risk of bias}

Bias Authors' judgement Support for judgement

Random sequence genera- Low risk tion (selection bias)

Quote: "All participants were subjected to block randomisation...using a block random digits table"

Comment: a block random digits table used to ensure the randomisation

\begin{tabular}{ll}
\hline $\begin{array}{l}\text { Allocation concealment } \\
\text { (selection bias) }\end{array}$ & Unclear risk \\
& Quote: see above \\
& Comment: methods of allocation concealment unclear
\end{tabular}




\section{Chen 2016 (Continued)}

Blinding of participants and personnel (performance bias)

All outcomes
High risk Quote: no quote

Comment: no mention of blinding but would not be possible to blind health professionals to the different treatments so without further detail considered high risk
Blinding of outcome as- Unclear risk Quote: no quote sessment (detection bias) All outcomes

Comment: no mention of blinding in the paper

Incomplete outcome data High risk
(attrition bias)

Quote: no quote

All outcomes

Comment: 6 participants in the standard care group without clarifying the reasons vs 0 were lost to follow-up in the NPWT group

Selective reporting (re- Unclear risk

porting bias)

\section{Quote: no quote}

Comment: participants had an average of 4.6 wounds, which would usually result in unit of analysis issues, however, wound infection data suggest the unit of analysis was the participants.

Other bias Low risk

\section{Quote: no quote}

Comment: there was a difference in number of participants with wounds in multiple locations, however, this is unlikely to have introduced bias since the unit of randomisation was the participant; no other areas of potential risk were noted.

Costa 2017

$\begin{array}{ll}\text { Methods } & \begin{array}{l}\text { 2-arm, multi-centre RCT } \\ \text { Conducted in } 24 \text { NHS hospitals in the UK } \\ \text { Follow-up: up to } 12 \text { months }\end{array}\end{array}$

Participants

625 participants ( 460 consenting and 165 not consenting) with open fracture of the lower limb were recruited and randomised from July 2012-December 2015. Data only collected on consenting participants (this process was used due to the patient population often being unable to consent at the point of randomisation).

Inclusion criteria: aged $\geq 16$ years; presented (or transferred) to a trial hospital within $72 \mathrm{~h}$ of injury; had sustained an open fracture of the lower limb graded as G/A 2 or 3 . The treating surgeon determined the $G / A$ grade at the end of surgical debridement as per routine operative practice. Additionally the wound could not be closed primarily after the first surgical debridement.

Exclusion criteria: any contra-indications to anaesthesia such that the participant was unfit for surgery; there was evidence that the participant was unable to adhere to trial procedures or complete questionnaires, such as permanent cognitive impairment. G/A grade 1 injuries were also excluded. In a small proportion of participants, this exclusion criterion would only be determined after randomisation and emergency surgery had taken place. These participants were withdrawn from the study and no participant-identifiable data retained.

Interventions

Group A ( $n=226$ participants) NPWT. The dressing used an 'open-cell' solid foam or gauze and an adherent dressing. Exact details of dressing and pressure were left to the discretion of the treating healthcare team. Most of the participants $(74 \%)$ received pump pressure of $125 \mathrm{mmHg}, 17 \%$ participants did not and in $9.5 \%$ the pressure used is not known. The majority of participants (77\%) received continuous NPWT operation; $6 \%$ received intermittent use and for $17 \%$ the type of use was not known. 
Group B ( $n=234$ participants) Usual care. Standard dressing (without NPWT) comprising a non-adhesive layer applied directly to the wound covered by a sealed dressing or bandage. The exact details of the materials used were left to the discretion of the treating surgeon as per routine care.

All participants received a general or regional anaesthetic, wound debridement and fracture treated with either internal or external fixation. After the initial operation, if the open fracture wound could not be closed, patients were randomised to study groups.

Both groups of participants then followed standard local post-op management of patients with an open fracture of the leg with an open wound. Normally this meant a second operation between 48 and $72 \mathrm{~h}$ after the first, with further debridement performed and the wounds closed or soft tissue reconstruction performed as necessary. Any further dressing to open wounds followed the allocated treatment until definitive closure/cover of the wound.

Outcomes

Primary review outcomes: proportion of wounds healed at 6 weeks; adverse events; wound infection (unblinded assessment of superficial surgical site infection within 30 days and deep surgical site infection at 30 days, also blinded assessment of wound infection using photographs at 6 weeks from recruitment); adverse events

Secondary review outcomes: health-related quality of life (EQ-5D, SF-12); pain; cost-effectiveness.

Notes Funded by the NIHR Health Technology Assessment programme

\section{Risk of bias}

\begin{tabular}{lll}
\hline Bias & Authors' judgement & Support for judgement \\
\hline $\begin{array}{ll}\text { Random sequence genera- } \\
\text { tion (selection bias) }\end{array}$ & Low risk & $\begin{array}{l}\text { Quote: "A computer-generated random allocation sequence was generated } \\
\text { and controlled by York Clinical Trials Unit. The unit of randomisation was the } \\
\text { individual patient on a 1:1 basis, stratified by trial centre and Gustilo and An- } \\
\text { derson score. When a patient entered the trial, non-identifiable details were } \\
\text { logged on the secure, encrypted, web-based, randomisation system and then } \\
\text { the allocation was generated" }\end{array}$ \\
&
\end{tabular}

Allocation concealment Low risk
(selection bias)

Quote: from paper "Trial participants were assigned to their treatment allo(selection bias) cation intraoperatively at the end of initial surgery, but before a wound dressing was applied. All operating theatres included a computer with internet access therefore, a secure, 24 hour, web-based randomisation system was used to generate treatment allocation."

Clarification from study authors that a central randomisation system with independent allocation was used.

Comment: insufficient information

\begin{tabular}{lll}
\hline $\begin{array}{l}\text { Blinding of participants } \\
\text { and personnel (perfor- } \\
\text { mance bias) } \\
\text { All outcomes }\end{array}$ & High risk & $\begin{array}{l}\text { Quote: "As the wound dressings were clearly identifiable, it was not possible to } \\
\text { blind trial participants or clinical teams to treatment allocation" }\end{array}$ \\
\hline $\begin{array}{l}\text { Blinding of outcome as- } \\
\text { sessment (detection bias) }\end{array}$ & Low risk & $\begin{array}{l}\text { Quote: "As the wound dressings were clearly identifiable, it was not possible to } \\
\text { blind trial participants or clinical teams to treatment allocation. However, out- } \\
\text { come assessment was undertaken by trained research associates (nurse or re- } \\
\text { search physiotherapist) independent of the clinical care team. For patient-re- } \\
\text { ported outcomes (disability, pain, quality of life, resource use, other complica- } \\
\text { tions), trial participants completed follow-up questionnaires themselves and } \\
\text { these were returned directly to the central trial office." }\end{array}$
\end{tabular}

Comment: assessment of wound healing was done using photographs by independent assessors unaware of treatment allocation. 
Costa 2017 (Continued)

Incomplete outcome data Unclear risk There was missing data for the healing and infection outcomes (which were (attrition bias) secondary outcomes in the trial). The number of pre- (NPWT $=85$ vs standard

All outcomes care $=80$ ) and post-consent (NPWT $=14$ vs standard care $=15)$ withdrawals as well as deviations from allocated treatment (8 NPWT vs 15 standard care participants crossed over to other intervention group) was balanced between groups.

\begin{tabular}{lll}
$\begin{array}{l}\text { Selective reporting (re- } \\
\text { porting bias) }\end{array}$ & Low risk & Trial registration available (ISRCTN33756652). All outcomes reported. \\
\hline Other bias & Low risk & $\begin{array}{l}\text { Baseline characteristics appeared to be balanced across groups; no other ap- } \\
\text { parent biases }\end{array}$
\end{tabular}

\section{Keskin 2008}

\begin{tabular}{ll}
\hline Methods & -arm RCT \\
Conducted in Turkey \\
Follow-up: 10 days \\
\hline
\end{tabular}

Participants 40 participants with lower extremity, non-diabetic, post-traumatic wounds
Inclusion criteria: age $\geq 18$ years; had given written informed consent to participate; were haemody-
namically stable; well-orientated; and were able to co-operate in answering the questions

Exclusion criteria: none stated, however, none of the participants had any other chronic illnesses; none used mood modifying drugs or anxiolytics at the time of the study

Group A ( $n=20$ participants): standard moist wound care. After debridement wound closure with standard moist gauze dressings that were changed daily

Group B ( $n=20$ participants): VAC. VAC black polyurethane foam was placed over the wound after debridement, a VAC drape was placed over the foam and then pressure was applied at $125 \mathrm{mmHg}$ intermittently. Dressings were changed 3 times/week

\begin{tabular}{|c|c|c|}
\hline Outcomes & \multicolumn{2}{|c|}{$\begin{array}{l}\text { Primary review outcomes: none reported } \\
\text { Secondary review outcomes: none reported }\end{array}$} \\
\hline Notes & \multicolumn{2}{|c|}{ Funding source was not stated } \\
\hline \multicolumn{3}{|l|}{ Risk of bias } \\
\hline Bias & Authors' judgement & Support for judgement \\
\hline \multirow[t]{2}{*}{$\begin{array}{l}\text { Random sequence genera- } \\
\text { tion (selection bias) }\end{array}$} & Unclear risk & $\begin{array}{l}\text { Quote: "They were randomly distributed into two groups according to the way } \\
\text { that their wounds were treated" }\end{array}$ \\
\hline & & Comment: insufficient information \\
\hline \multirow{2}{*}{$\begin{array}{l}\text { Allocation concealment } \\
\text { (selection bias) }\end{array}$} & Unclear risk & Quote: see above \\
\hline & & Comment: methods of allocation concealment unclear \\
\hline $\begin{array}{l}\text { Blinding of participants } \\
\text { and personnel (perfor- } \\
\text { mance bias) }\end{array}$ & High risk & $\begin{array}{l}\text { Quote: "There was no blinding between the two groups since the researcher } \\
\text { could see which dressing material was being used on a particular wound dur- } \\
\text { ing dressing change" }\end{array}$ \\
\hline
\end{tabular}


Keskin 2008 (Continued) All outcomes
Comment: no mention of blinding but would not be possible to blind health professionals to the different treatments so without further detail considered high risk

\begin{tabular}{lll}
\hline Blinding of outcome as- & Unclear risk & Quote: no quote \\
sessment (detection bias) & & Comment: not stated \\
All outcomes & &
\end{tabular}

Incomplete outcome data Low risk
(attrition bias)

All outcomes

Quote: "Patients who had been discharged before the 10th day were excluded from the study and new patients enrolled."

Comment: clarified the procedure of exclusion

\begin{tabular}{ll}
\hline $\begin{array}{l}\text { Selective reporting (re- } \\
\text { porting bias) }\end{array}$ & Quote: no quote \\
& $\begin{array}{l}\text { Comment: study protocol was not available, however, all expected outcomes } \\
\text { appear to have been reported }\end{array}$ \\
\hline
\end{tabular}

Other bias High risk Quote: no quote

Comment: the difference in frequency of change of wound dressings may have resulted in bias. The assignment of additional participants to study groups to replace those lost to follow-up may not have been done at random.

\section{Ondieki 2012}

$\begin{array}{ll}\text { Methods } & \text { 2-arm RCT } \\ \text { Conducted in Kenyatta National Hospital orthopaedic and surgical wards, Kenya } \\ \text { Follow-up: unclear, however, study duration was } 6 \text { months }\end{array}$

Participants 51 participants with 52 class IV wounds ( 1 participant in the gauze group was excluded from analysis for
smoking, however, 1 participant had 2 wounds)

Inclusion criteria: aged $>12$ years with class III or IV acute traumatic wounds and soft tissue loss involving the full thickness of the skin and deeper of the lower limbs, injury occurred $<72 \mathrm{~h}$ prior to recruitment into study, undergone surgical toilet ${ }^{\star}$ to remove all non-viable tissues and foreign bodies.

Exclusion criteria: wounds with exposed major blood vessels or where haemostasis has not been achieved, non-trauma wounds, smokers; diabetes mellitus, psychosis or chronic renal failure; use of corticosteroids, chemotherapy or anticoagulants; refusal to give consent

Interventions

Group A ( $\mathrm{n}=25$ wounds; 25 participants): gauze

Group B ( $n=26$ wounds; 25 participants): NPWT - sterile standard foam manufactured by Bobmil Inc.

NPWT was stopped if there was a contraindication to continue with the treatment, participant opted out or $100 \%$ granulation

Wounds were assessed $12 \mathrm{~h}$ after surgical toilet* ${ }^{\star}$ using normal saline before dressing was applied. Secured suction catheter at $125 \mathrm{mmHg}$ was placed on gauze or foam and dressing was changed every 72 $\mathrm{h}$ until the wound achieved full granulation. Regular dose of analgesics with additional analgesia if required and prophylactic antibiotics

Outcomes

Primary review outcomes: wound infection (defined as purulent discharge from the wound site or positive culture of the wound) 
Secondary review outcomes: pain based on numeric rating scale (combination of VAS and VRS); time to full granulation

$\begin{array}{ll}\text { Notes } & \text { Master degree thesis } \\ & \text { *surgical toilet - involved thorough cleaning of wounds with normal saline under local or general } \\ & \text { anaesthesia }\end{array}$

\section{Risk of bias}

\begin{tabular}{|c|c|c|}
\hline Bias & Authors' judgement & Support for judgement \\
\hline \multirow[t]{2}{*}{$\begin{array}{l}\text { Random sequence genera- } \\
\text { tion (selection bias) }\end{array}$} & Low risk & $\begin{array}{l}\text { Quote: "Randomization and allocation sequence was accomplished by gener- } \\
\text { ating numbers from http://www.randomization.com" }\end{array}$ \\
\hline & & $\begin{array}{l}\text { Comment: block randomisation with computer-generated allocation se- } \\
\text { quence }\end{array}$ \\
\hline \multirow{2}{*}{$\begin{array}{l}\text { Allocation concealment } \\
\text { (selection bias) }\end{array}$} & Unclear risk & Quote: see above \\
\hline & & Comment: methods of allocation concealment unclear \\
\hline \multirow{2}{*}{$\begin{array}{l}\text { Blinding of participants } \\
\text { and personnel (perfor- } \\
\text { mance bias) } \\
\text { All outcomes }\end{array}$} & High risk & $\begin{array}{l}\text { Quote: "There was no blinding between the two groups since the researcher } \\
\text { could see which dressing material was being used on a particular wound dur- } \\
\text { ing dressing change" }\end{array}$ \\
\hline & & $\begin{array}{l}\text { Comment: no mention of performance blinding but would not be possible to } \\
\text { blind health professionals to the different treatments so without further detail } \\
\text { considered high risk }\end{array}$ \\
\hline
\end{tabular}

\begin{tabular}{lll}
\hline $\begin{array}{l}\text { Blinding of outcome as- } \\
\text { sessment (detection bias) }\end{array}$ & High risk & $\begin{array}{l}\text { Quote: "There was no blinding between the two groups since the researcher } \\
\text { could see which dressing material was being used on a particular wound dur- } \\
\text { All outcomes }\end{array}$ \\
$\begin{array}{l}\text { ing dressing change. This may cause bias in some observations like evaluation } \\
\text { of pain" }\end{array}$
\end{tabular}

Comment: this indicates that there was no attempt to blind outcome assessment

\begin{tabular}{|c|c|c|}
\hline $\begin{array}{l}\text { Incomplete outcome data } \\
\text { (attrition bias) } \\
\text { All outcomes }\end{array}$ & Low risk & $\begin{array}{l}\text { Quote: "One patient in the gauze group was dropped from the study because } \\
\text { he was found smoking" } \\
\text { Comment: this is unlikely to cause bias }\end{array}$ \\
\hline $\begin{array}{l}\text { Selective reporting (re- } \\
\text { porting bias) }\end{array}$ & Low risk & $\begin{array}{l}\text { Quote: no quote } \\
\text { Comment: all expected outcomes were reported }\end{array}$ \\
\hline Other bias & Low risk & $\begin{array}{l}\text { Quote: no quote } \\
\text { Comment: no other apparent biases and reporting was sufficient to be rea- } \\
\text { sonably confident that these were unlikely to be present. }\end{array}$ \\
\hline
\end{tabular}

\section{Stannard 2009}

\begin{tabular}{ll}
\hline Methods & -arm RCT \\
Conducted in USA (Division of Orthopaedic surgery, University of Alabama*) \\
Follow-up: mean $28(14-67)$ months
\end{tabular}



low-knee amputation at initial surgical procedure). 54 participants (92\%) had Type III open fractures. Most participants had tibia, pilon or femur fractures.

Inclusion criteria: severe open fracture that required serial surgical debridements; age $>18$ years and willingness to complete the treatment protocol and follow-up. Eligible fractures included heavily contaminated type II fractures, type IIIA fractures that were either heavily contaminated or had a remarkably severe soft tissue injury and all type IIB or IIIC fractures according to G/A classification.

Exclusion criteria: open fractures that could be closed after the initial surgery and did not require serial debridements, an infected open fracture, a surgical incision that could not be treated with NPWT, prisoners, pregnant women, patients or family members who were unable or unwilling to sign study consent and anyone unable to complete the treatment protocol including NPWT

Interventions

Group A ( $n=23$ participants; 25 fractures): standard care - saline wet to moist dressings

Group B ( $n=35$ participants; 37 fractures): NPWT VAC dressing. Review authors suggest likely use of GranuFOAM dressing, not confirmed with study authors.

Co-interventions: all fractures had an irrigation, debridement and skeletal stabilisation of the injury. This was followed by a second surgery that included irrigation and debridement of the open fracture wound within 36-72 hours of the initial procedure. This procedure was repeated as needed until all wounds achieved grade A status (abundant granulation tissue and ready for closure or coverage). All participants received prophylactic IV antibiotics (the type depended on the level of contamination) until $24 \mathrm{~h}$ after closure or coverage.

\section{Outcomes Primary review outcomes: wound infection}

Secondary review outcomes: health status: SF-36 (3, 6, 9 and 12 months); time to readiness ${ }^{\star}$ for wound closure

*Wounds were considered ready for closure when they had abundant granulation tissue

\section{Risk of bias}

\begin{tabular}{lll}
\hline Bias & Authors' judgement & Support for judgement \\
\hline $\begin{array}{l}\text { Random sequence genera- } \\
\text { tion (selection bias) }\end{array}$ & Unclear risk & $\begin{array}{l}\text { Quote: "A random sampling algorithm was used to assign patients to receive } \\
\text { either NPWT or control in a 1:1 ratio }\end{array}$ \\
& $\begin{array}{l}\text { Comment: a random component was used but there are insufficient details as } \\
\text { to how the sequence was derived }\end{array}$ \\
\hline $\begin{array}{l}\text { Allocation concealment } \\
\text { (selection bias) }\end{array}$ & Unclear risk & Quote: see above \\
& Comment: methods of allocation concealment unclear
\end{tabular}

$\begin{array}{ll}\begin{array}{l}\text { Blinding of participants } \\ \text { and personnel (perfor- } \\ \text { mance bias) }\end{array} & \text { High risk }\end{array} \begin{aligned} & \begin{array}{l}\text { Quote: "All patients underwent identical treatment protocols with the excep- } \\ \text { tion of the dressing over the open fracture" }\end{array} \\ & \text { All outcomes }\end{aligned} \begin{aligned} & \begin{array}{l}\text { Comment: no mention of blinding but would not be possible to blind health } \\ \text { professionals to the different treatments so without further detail considered } \\ \text { high risk }\end{array}\end{aligned}$

Blinding of outcome as-
sessment (detection bias)


Stannard 2009 (Continued)

Incomplete outcome data Low risk Quote: no quote
(attrition bias)

Comment: data for one participant were omitted, however, this was not considered sufficient to bias results

Selective reporting (re- High risk
porting bias)

Quote: "Short Form 36 data were obtained on our patients at the following time intervals: injury, 3 months, 6 months, 9 months, 12 months, and final follow-up."

Comment: only data recorded at 3, 6 and 9 months were reported

Other bias Unclear risk Quote: “...a disproportionate number of patients who are smokers randomising to the study group" (Discussion section)

Comment: unclear what impact smoking ( 7 vs 18 ) would have had on the outcomes of interest

Virani 2016

$\begin{array}{ll}\text { Methods } & \text { 2-arm RCT } \\ & \text { Conducted in India } \\ & \text { Follow-up: } 23 \text { weeks } \pm 6 \text { weeks }\end{array}$

Participants

95 participants with open tibial fractures (2 participants excluded due to the need for amputation). Most participants had Grade IIIA or IIIB fractures.

Inclusion criteria: age $\geq 18$ years suffering from an open tibial fracture who were willing to be part of the trial; consent.

Exclusion criteria: age $<18$; wounds that could be closed at the index surgery; those not needing repeated debridements and dressings; reluctance to give consent; having periarticular tibial fractures; needing amputations; wounds on which it would not be possible to use NPWT. All Grade I and most of Grade II fractures had to be excluded from the study as the wounds could be closed after debridement.

Group A ( $n=50$ participants): standard care. Daily cleaning, dressing and debridement
Group B ( $n=43$ participants): VAC dressing and negative pressure of about $125 \mathrm{mmHg}$ applied intermit-
tently. The wound was opened every fourth day for reapplication of dressing.
All participants underwent debridement and received perioperative antibiotic coverage. These antibi-
otics were continued post-operatively. Serial irrigation and debridement was continued till the wounds
were ready for closure or coverage.

Outcomes Primary review outcomes: wound infection*

Secondary review outcomes: time to closure or coverage surgery

*Signs of acute wound infection like pyrexia, raised total leucocyte count and local signs like pus discharge from the wound with erythema of skin edges within 1 week of primary debridement was considered to have an acute infection. Deep infections included cases developing features of chronic osteomyelitis like a discharging sinus, fixed puckered overlying soft tissue and radiological changes consistent with chronic osteomyelitis.

\section{Risk of bias}


Virani 2016 (Continued)

Bias Authors' judgement Support for judgement

Random sequence genera- Low risk tion (selection bias)
Quote: "Using a random number generator, 50 patients were allotted to the control group and 43 to the group receiving negative pressure therapy"

Comment: a random component used

\begin{tabular}{lll}
\hline $\begin{array}{l}\text { Allocation concealment } \\
\text { (selection bias) }\end{array}$ & Unclear risk & $\begin{array}{l}\text { Quote: see above } \\
\text { Comment: } \text { methods of allocation concealment unclear }\end{array}$ \\
\hline $\begin{array}{l}\text { Blinding of participants } \\
\text { and personnel (perfor- } \\
\text { mance bias) }\end{array}$ & High risk & $\begin{array}{l}\text { Quote: "There was no blinding between the two groups since the researcher } \\
\text { could see which dressing material was being used on a particular wound dur- } \\
\text { ing dressing change" }\end{array}$ \\
$\begin{array}{l}\text { Comment: } \text { no mention of blinding but would not be possible to blind health } \\
\text { professionals to the different treatments so without further detail considered } \\
\text { high risk }\end{array}$
\end{tabular}

Blinding of outcome as- Unclear risk sessment (detection bias)

All outcomes

\section{Quote: no quote}

Comment: not stated

$\begin{array}{ll}\begin{array}{l}\text { Incomplete outcome data } \\ \text { (attrition bias) }\end{array} & \text { Quote: no quote } \\ \text { All outcomes } & \text { Comment: of the } 95 \text { recruited participants there were two participants that } \\ & \begin{array}{l}\text { were excluded for needing amputations. It is not clear which group these par- } \\ \text { ticipants belonged to, however, this was not considered a source of bias. }\end{array}\end{array}$

Selective reporting (re- Unclear risk
porting bias)

Quote: no quote

Comment: study protocol not available, however, all expected outcomes appear to have been reported

Other bias Low risk

\section{Quote: no quote}

Comment: no other apparent biases, and reporting was sufficient to be reasonably confident that these were unlikely to be present.

G/A: Gustilo and Anderson; IV: intravenous; NHS: National Health Service; NPWT: negative pressure wound therapy; RCT: randomised controlled trial; VAC: Vacuum-Assisted Closure Device; VAS: visual analogue scale; VRS: visual rating scale

\section{Characteristics of excluded studies [ordered by study ID]}

\begin{tabular}{ll}
\hline Study & Reason for exclusion \\
\hline Braakenburg 2006 & Ineligible patient population \\
\hline Brown 2012 & Ineligible study design \\
\hline Colom 2006 & Ineligible intervention \\
\hline Dorafshar 2012 & Ineligible patient population \\
\hline Fleischmann 1993 & Ineligible study design \\
\hline Fleischmann 1995 & Ineligible study design \\
\hline P
\end{tabular}




\begin{tabular}{|c|c|}
\hline Study & Reason for exclusion \\
\hline Jeschke 2004 & Ineligible intervention \\
\hline Lesiak 2013 & Ineligible study design \\
\hline MAS 2006 & Ineligible study design \\
\hline Moisidis 2004 & Ineligible patient population \\
\hline Mouës 2004 & Ineligible patient population \\
\hline Mouës 2005 & Ineligible patient population \\
\hline Mouës 2008 & Ineligible patient population \\
\hline Mouës 2007 & Ineligible patient population \\
\hline Rahmanian-Schwarz 2012 & Ineligible patient population \\
\hline Rovee 2004 & Ineligible study design \\
\hline Stannard 2006 & Ineligible wound type \\
\hline Stannard 2012 & Ineligible wound type \\
\hline Ubbink 2008 & Ineligible study design \\
\hline Vikatmaa 2008 & Ineligible study design \\
\hline
\end{tabular}

\section{DATA AND ANALYSES}

\section{Comparison 1. NPWT $125 \mathrm{mmHg}$ versus standard care in open fracture wounds}

\begin{tabular}{lllll}
\hline Outcome or subgroup title & No. of studies & $\begin{array}{l}\text { No. of partici- } \\
\text { pants }\end{array}$ & Statistical method & Effect size \\
\hline $\begin{array}{l}1 \text { Wounds healed (short-term fol- } \\
\text { low-up) }\end{array}$ & 1 & & Risk Ratio (M-H, Fixed, 95\% Cl) & Subtotals only \\
\hline $\begin{array}{l}2 \text { Wound infection (short- to medi- } \\
\text { um-term follow-up) }\end{array}$ & 4 & 596 & $\begin{array}{l}\text { Risk Ratio (M-H, Random, 95\% } \\
\text { Cl) }\end{array}$ & $0.48[0.20,1.13]$ \\
\hline $\begin{array}{l}3 \text { Wound infection: sensitivity analy- } \\
\text { sis }\end{array}$ & 4 & 701 & $\begin{array}{l}\text { Risk Ratio (M-H, Random, 95\% } \\
\text { Cl) }\end{array}$ & 0.49 [0.19, 1.27] \\
\hline $\begin{array}{l}4 \text { Health-related quality of life at 12 } \\
\text { months }\end{array}$ & 1 & & $\begin{array}{l}\text { Mean Difference (IV, Random, } \\
95 \% \text { Cl) }\end{array}$ & Subtotals only \\
\hline $\begin{array}{l}4.1 \text { SF-12 (Physical Component } \\
\begin{array}{l}\text { Score) } \\
\hline\end{array}\end{array}$ & 1 & 329 & $\begin{array}{l}\text { Mean Difference (IV, Random, } \\
95 \% \text { Cl) }\end{array}$ & $-0.5[-4.08,3.08]$ \\
\hline
\end{tabular}




\begin{tabular}{lllll}
\hline Outcome or subgroup title & No. of studies & $\begin{array}{l}\text { No. of partici- } \\
\text { pants }\end{array}$ & Statistical method & Effect size \\
\hline 4.2 EQ-5D Utility & 1 & 364 & $\begin{array}{l}\text { Mean Difference (IV, Random, } \\
95 \% \mathrm{Cl})\end{array}$ & $-0.01[-0.08,0.06]$ \\
\hline
\end{tabular}

Analysis 1.1. Comparison 1 NPWT $125 \mathrm{mmHg}$ versus standard care in open fracture wounds, Outcome 1 Wounds healed (short-term follow-up).

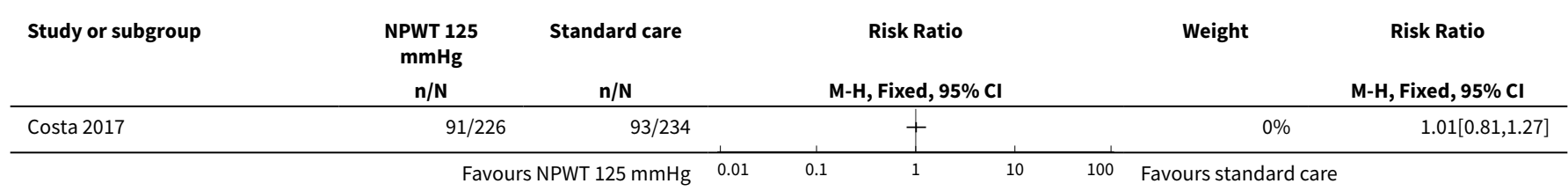

Analysis 1.2. Comparison 1 NPWT $125 \mathrm{mmHg}$ versus standard care in open fracture wounds, Outcome 2 Wound infection (short- to medium-term follow-up).

\begin{tabular}{|c|c|c|c|c|c|}
\hline Study or subgroup & $\begin{array}{l}\text { NPWT } 125 \\
\mathrm{mmHg} \\
\mathrm{n} / \mathrm{N}\end{array}$ & $\begin{array}{c}\text { Standard care } \\
n / N\end{array}$ & $\begin{array}{c}\text { Risk Ratio } \\
\text { M-H, Random, } 95 \% \mathrm{CI}\end{array}$ & Weight & $\begin{array}{c}\text { Risk Ratio } \\
\text { M-H, Random, } 95 \% \mathrm{Cl}\end{array}$ \\
\hline Arti 2016 & $3 / 45$ & $4 / 45$ & $\longrightarrow+$ & $20.17 \%$ & $0.75[0.18,3.16]$ \\
\hline Costa 2017 & $27 / 175$ & $31 / 180$ & $\vdash$ & $40.33 \%$ & $0.9[0.56,1.44]$ \\
\hline Stannard 2009 & $2 / 35$ & $7 / 23$ & & $19.52 \%$ & $0.19[0.04,0.83]$ \\
\hline Virani 2016 & $2 / 43$ & $11 / 50$ & $\longrightarrow$ & $19.99 \%$ & $0.21[0.05,0.9]$ \\
\hline Total $(95 \% \mathrm{Cl})$ & 298 & 298 & & $100 \%$ & $0.48[0.2,1.13]$ \\
\hline \multicolumn{6}{|c|}{ Total events: 34 (NPWT 125 mmHg), 53 (Standard care) } \\
\hline \multicolumn{6}{|c|}{ Heterogeneity: $\mathrm{Tau}^{2}=0.42 ; \mathrm{Chi}^{2}=6.86, \mathrm{df}=3(\mathrm{P}=0.08) ; \mathrm{I}^{2}=56.28 \%$} \\
\hline \multicolumn{6}{|c|}{ Test for overall effect: $Z=1.68(P=0.09)$} \\
\hline
\end{tabular}

Analysis 1.3. Comparison 1 NPWT $125 \mathrm{mmHg}$ versus standard care in open fracture wounds, Outcome 3 Wound infection: sensitivity analysis.

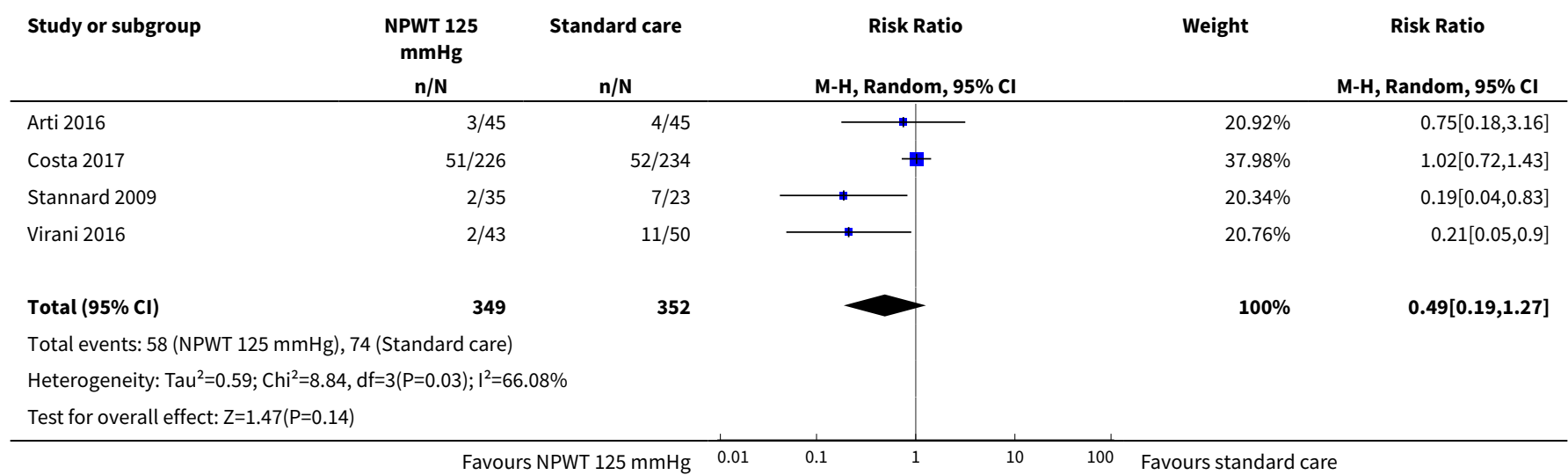


Analysis 1.4. Comparison 1 NPWT 125 mmHg versus standard care in open fracture wounds, Outcome 4 Health-related quality of life at 12 months.

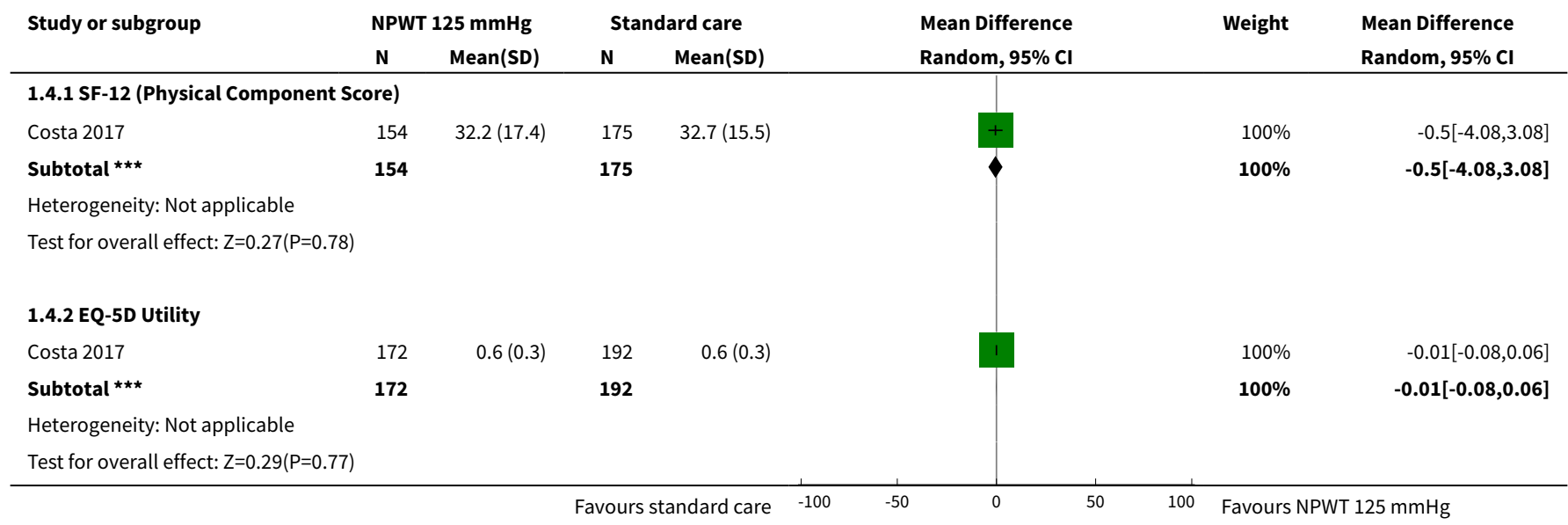

Comparison 2. NPWT 125 mmHg versus standard care in other open traumatic wounds

\begin{tabular}{lllll}
\hline Outcome or subgroup title & No. of studies & $\begin{array}{l}\text { No. of partici- } \\
\text { pants }\end{array}$ & Statistical method & Effect size \\
\hline $\begin{array}{l}1 \text { Wound infection (follow-up un- } \\
\text { clear) }\end{array}$ & 2 & 509 & $\begin{array}{l}\text { Risk Ratio (M-H, Random, 95\% } \\
\text { Cl) }\end{array}$ & $0.61[0.31,1.18]$ \\
\hline 2 Pain (short-term follow-up) & 1 & $\begin{array}{l}\text { Mean Difference (IV, Fixed, 95\% } \\
\text { Cl) }\end{array}$ & Subtotals only \\
\hline
\end{tabular}

Analysis 2.1. Comparison 2 NPWT $125 \mathrm{mmHg}$ versus standard care in other open traumatic wounds, Outcome 1 Wound infection (follow-up unclear).

\begin{tabular}{|c|c|c|c|c|c|}
\hline Study or subgroup & $\begin{array}{c}\text { NPWT } \\
\mathbf{n} / \mathbf{N}\end{array}$ & $\begin{array}{c}\text { Standard care } \\
n / N\end{array}$ & $\begin{array}{c}\text { Risk Ratio } \\
\text { M-H, Random, 95\% Cl }\end{array}$ & Weight & $\begin{array}{c}\text { Risk Ratio } \\
\text { M-H, Random, } 95 \% \mathrm{Cl}\end{array}$ \\
\hline Chen 2016 & $5 / 123$ & $30 / 335$ & $\longrightarrow$ & $50.98 \%$ & $0.45[0.18,1.14]$ \\
\hline Ondieki 2012 & $6 / 26$ & $7 / 25$ & & $49.02 \%$ & $0.82[0.32,2.11]$ \\
\hline Total $(95 \% \mathrm{Cl})$ & 149 & 360 & & $100 \%$ & $0.61[0.31,1.18]$ \\
\hline \multicolumn{6}{|c|}{ Total events: 11 (NPWT), 37 (Standard care) } \\
\hline Test for overall effect & & & & & \\
\hline
\end{tabular}


Analysis 2.2. Comparison 2 NPWT $125 \mathrm{mmHg}$ versus standard care in other open traumatic wounds, Outcome 2 Pain (short-term follow-up).

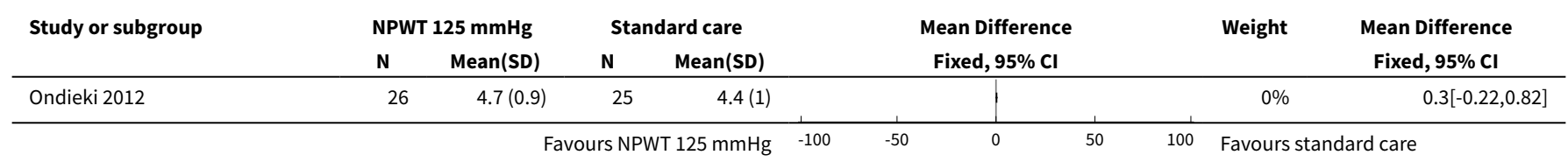

Comparison 3. NPWT $75 \mathrm{mmHg}$ versus standard care in other open traumatic wounds

\begin{tabular}{lllll}
\hline Outcome or subgroup title & No. of studies & $\begin{array}{l}\text { No. of partici- } \\
\text { pants }\end{array}$ & Statistical method & Effect size \\
\hline 1 Wound infection (follow-up unclear) & 1 & 463 & $\begin{array}{l}\text { Risk Ratio (M-H, Random, } \\
95 \% \mathrm{Cl})\end{array}$ & $0.44[0.17,1.10]$ \\
\hline
\end{tabular}

Analysis 3.1. Comparison 3 NPWT $75 \mathrm{mmHg}$ versus standard care in other open traumatic wounds, Outcome 1 Wound infection (follow-up unclear).

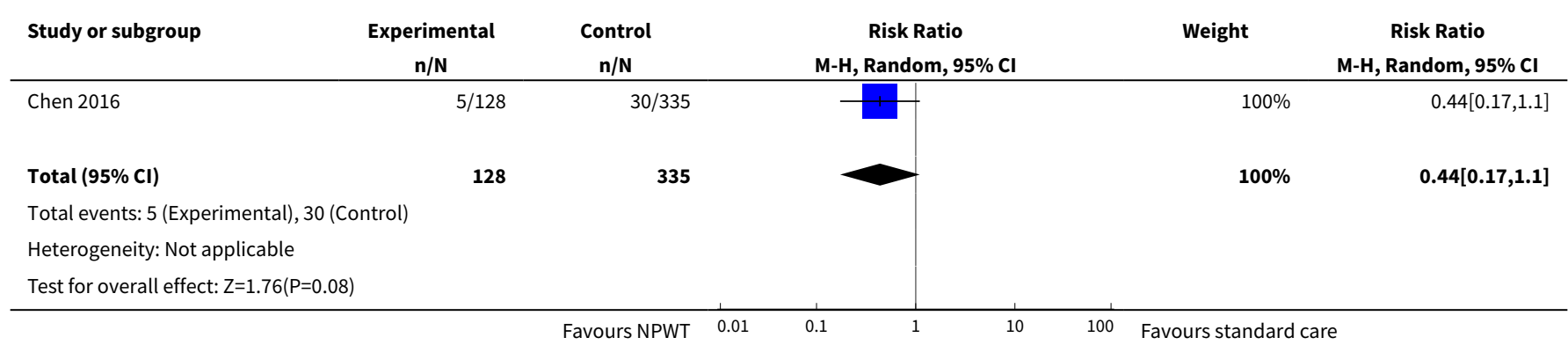

Comparison 4. Different pressures of NPWT in other open traumatic wounds

\begin{tabular}{lllll}
\hline Outcome or subgroup title & No. of studies & $\begin{array}{l}\text { No. of partici- } \\
\text { pants }\end{array}$ & Statistical method & Effect size \\
\hline $\begin{array}{l}1 \text { Wound infection (follow-up un- } \\
\text { clear) }\end{array}$ & 1 & & Risk Ratio (M-H, Fixed, 95\% Cl) & Subtotals only \\
\hline $1.1125 \mathrm{mmHg}$ versus $75 \mathrm{mmHg}$ & 1 & 251 & Risk Ratio (M-H, Fixed, 95\% Cl) & $1.04[0.31,3.51]$ \\
\hline
\end{tabular}


Analysis 4.1. Comparison 4 Different pressures of NPWT in other open traumatic wounds, Outcome 1 Wound infection (follow-up unclear).

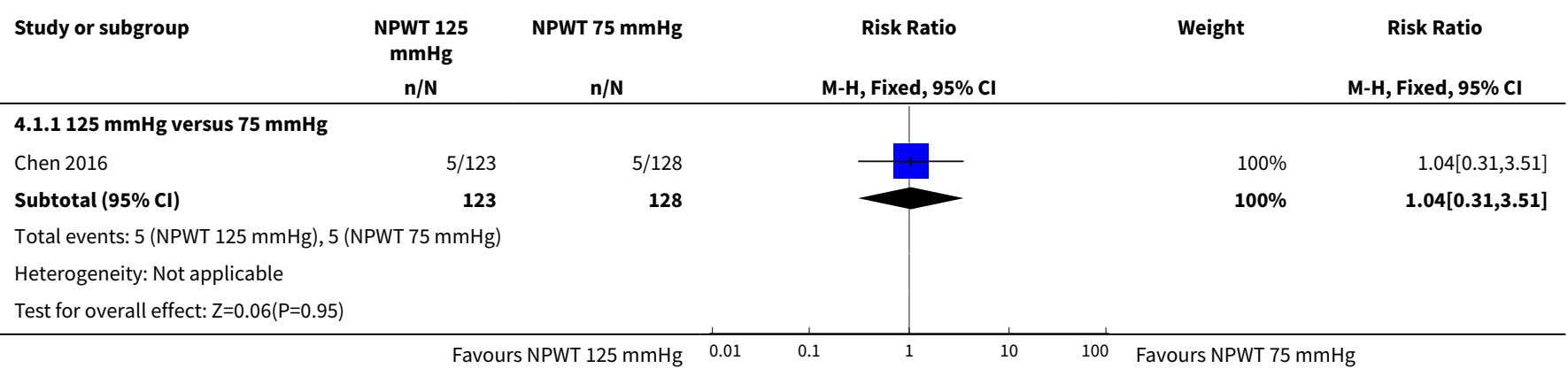




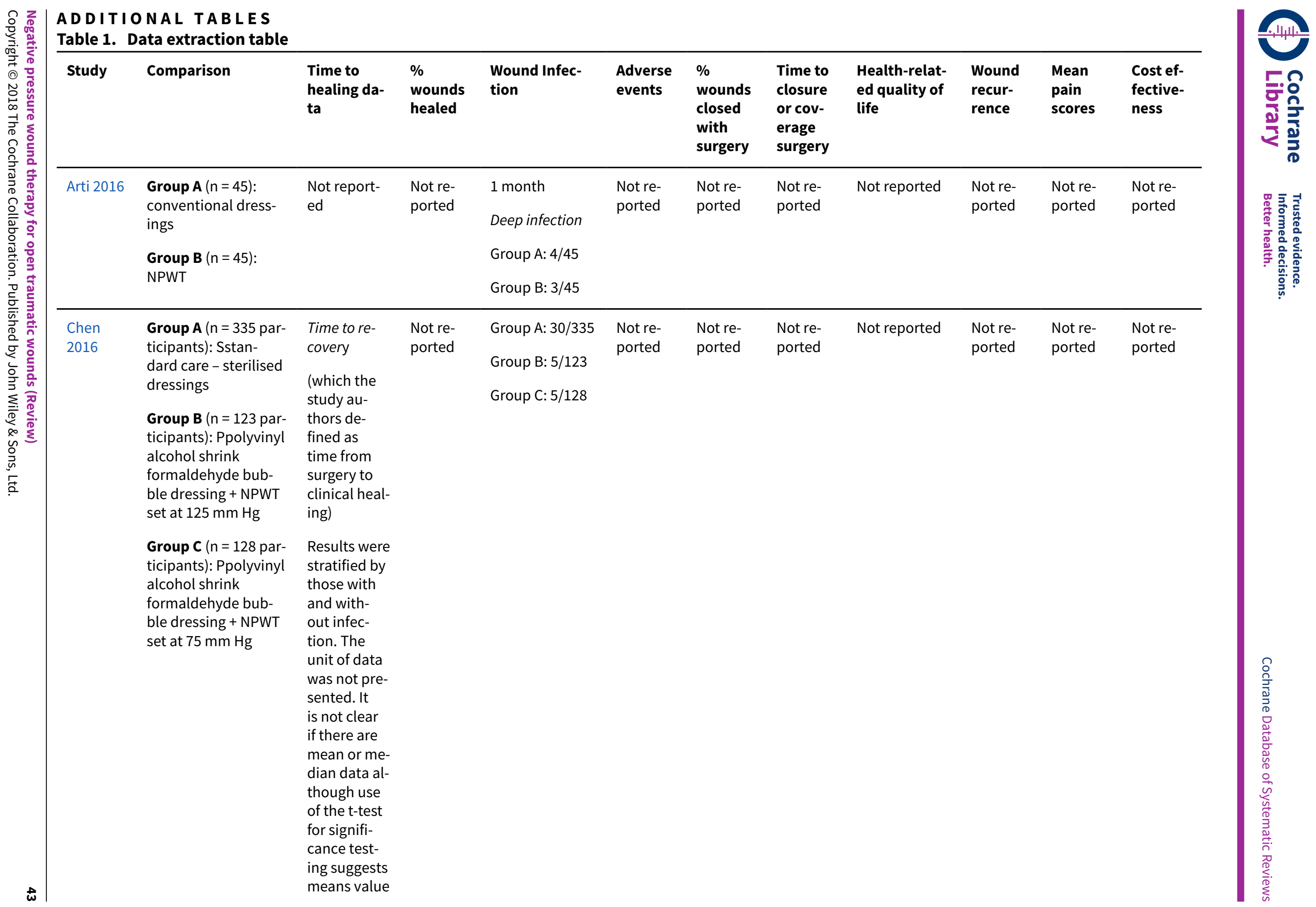




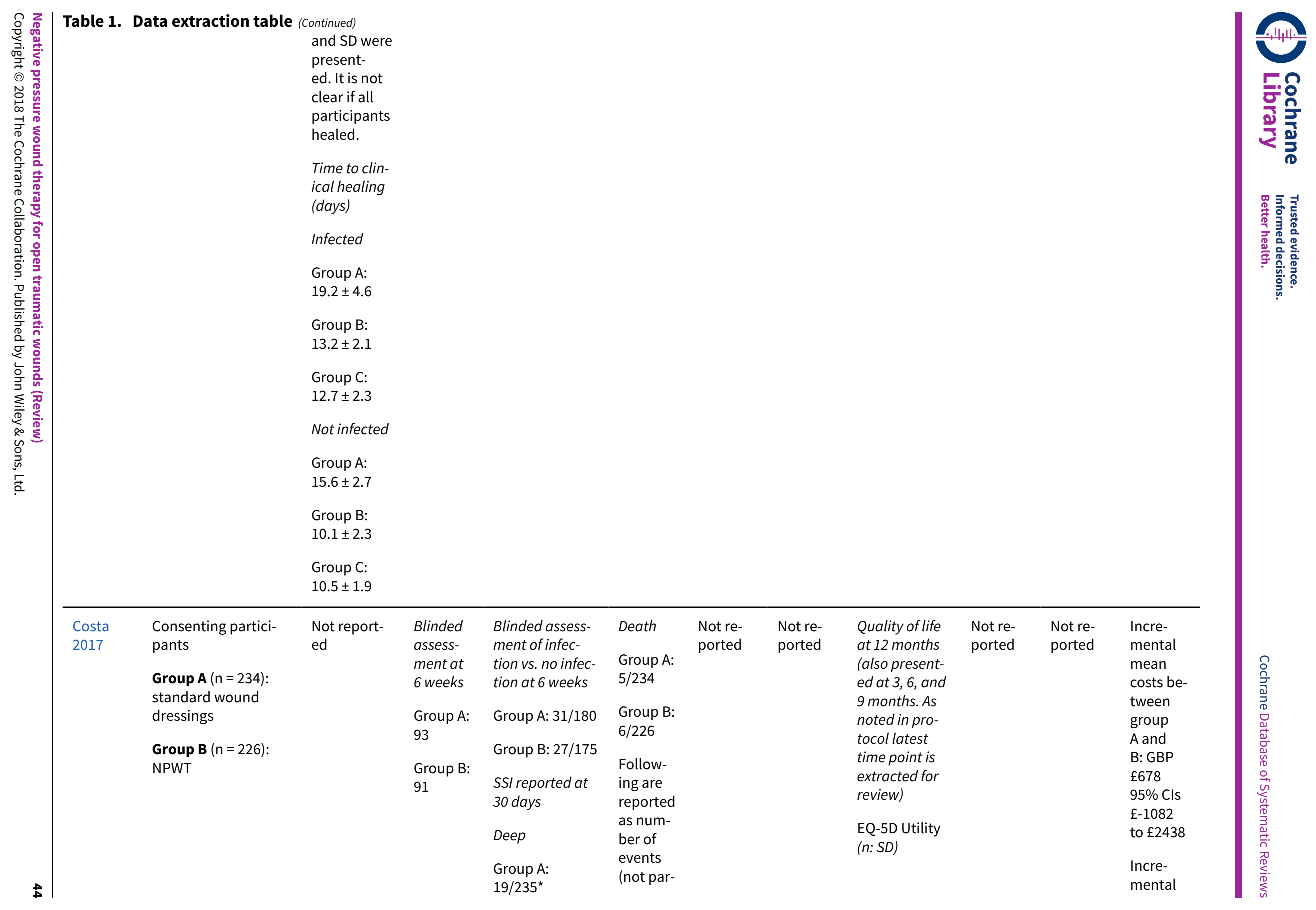




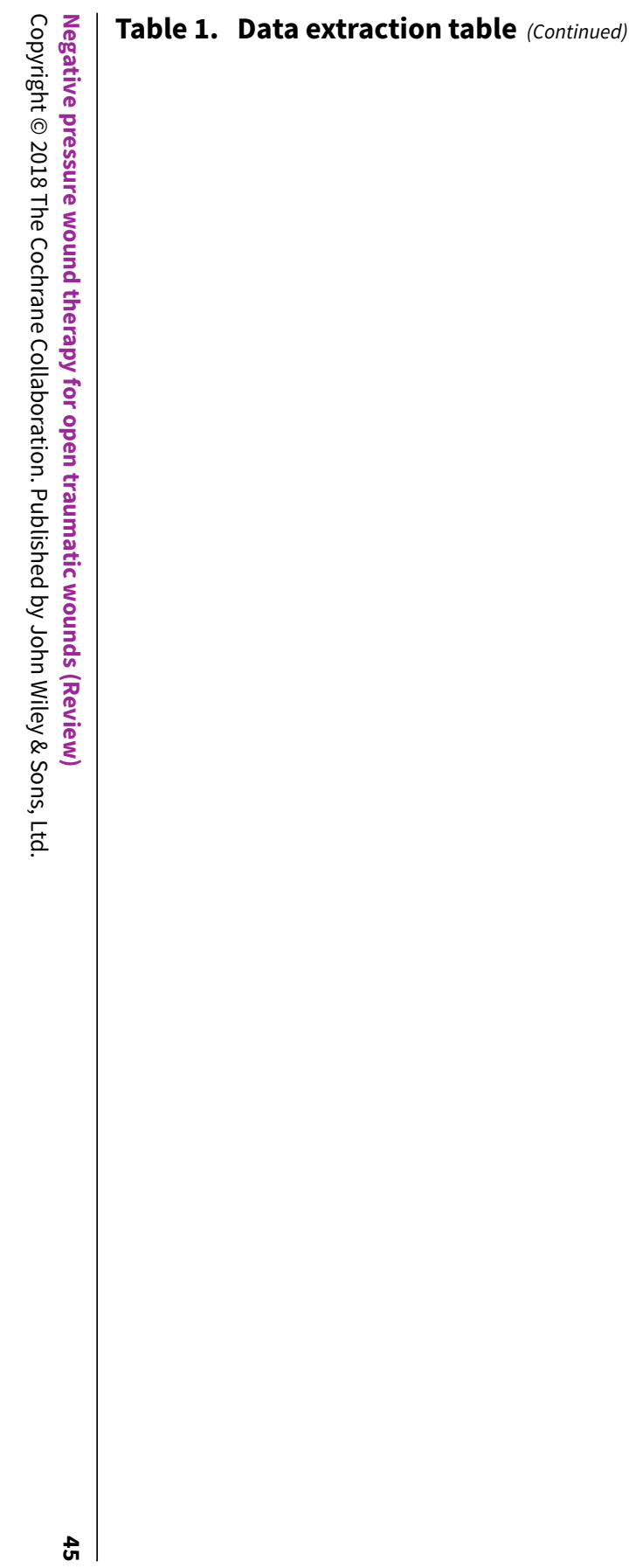

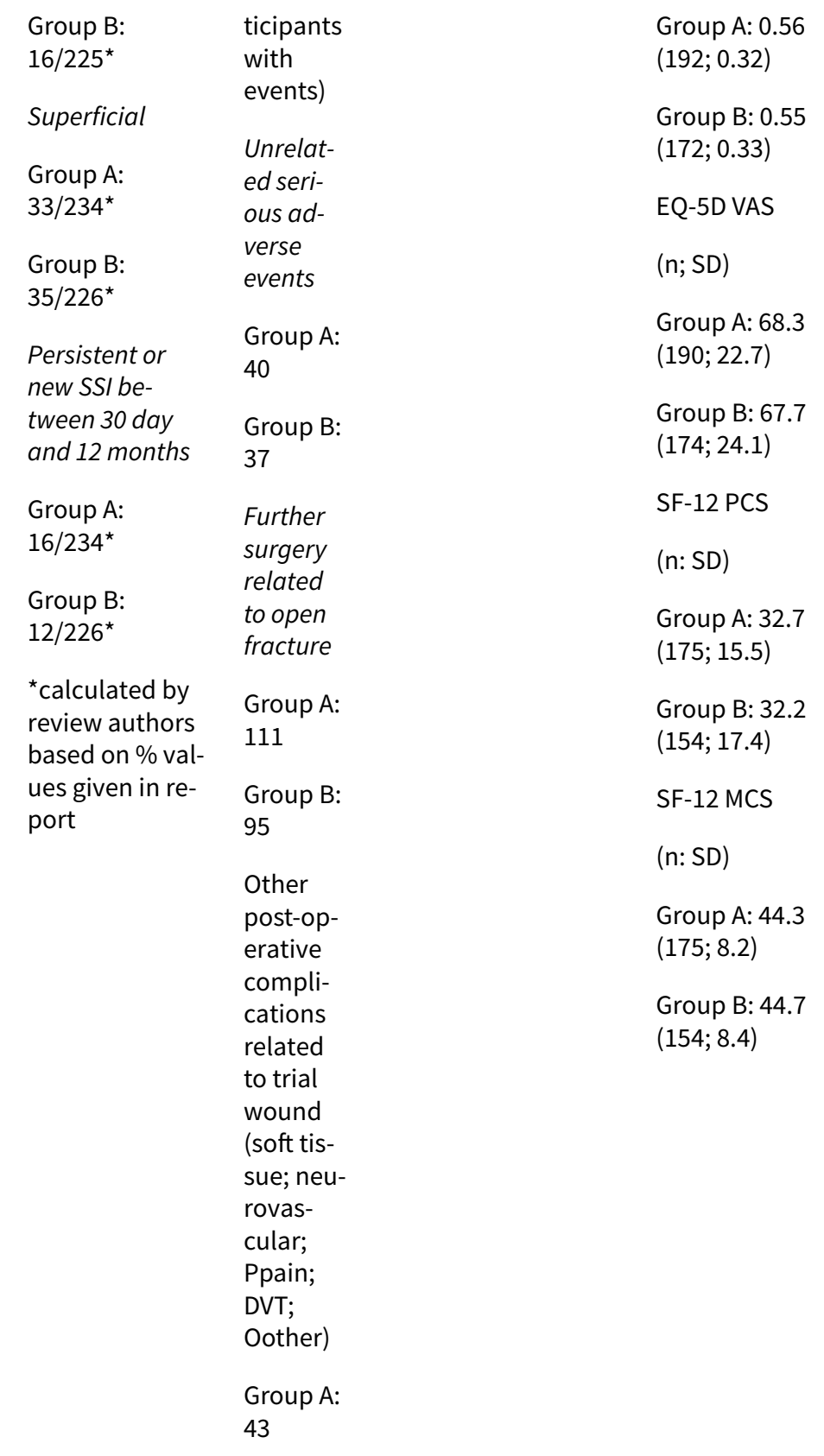

QALYS

between

Group

$A$ and

B: 0.002

95\% Cls

-0.054 to

0.059

ICER:

GBPE

267,910

Proba-

blity of

NPWT

being

cost ef-

fective

at fol-

lowing

thresh-

olds of

cost per

QALY:

$£ G B P$

15,000:

$25 \%$

$£ G B P$

20,000:

$24 \%$

£GBP

30,000 :

$27 \%$ 


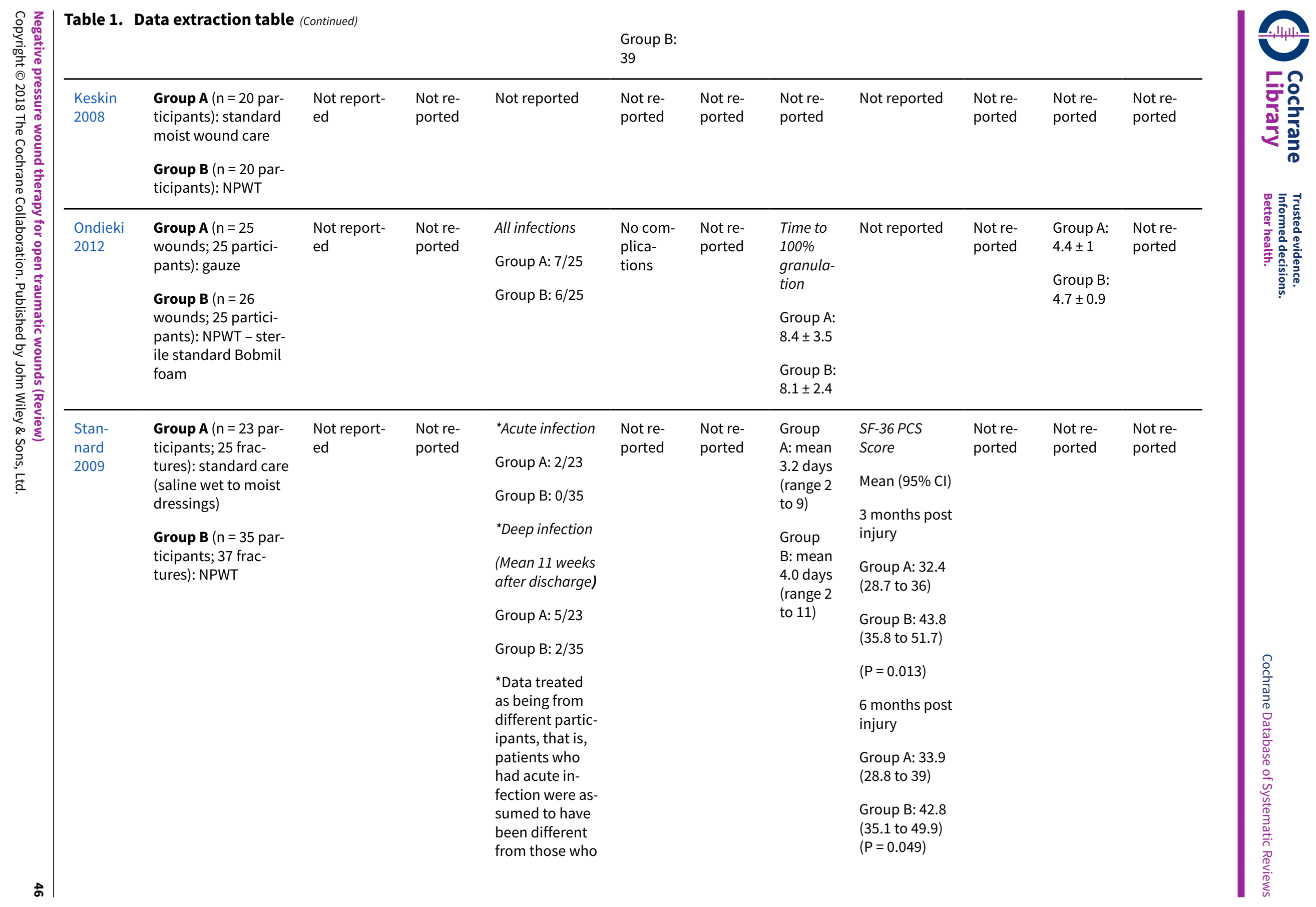




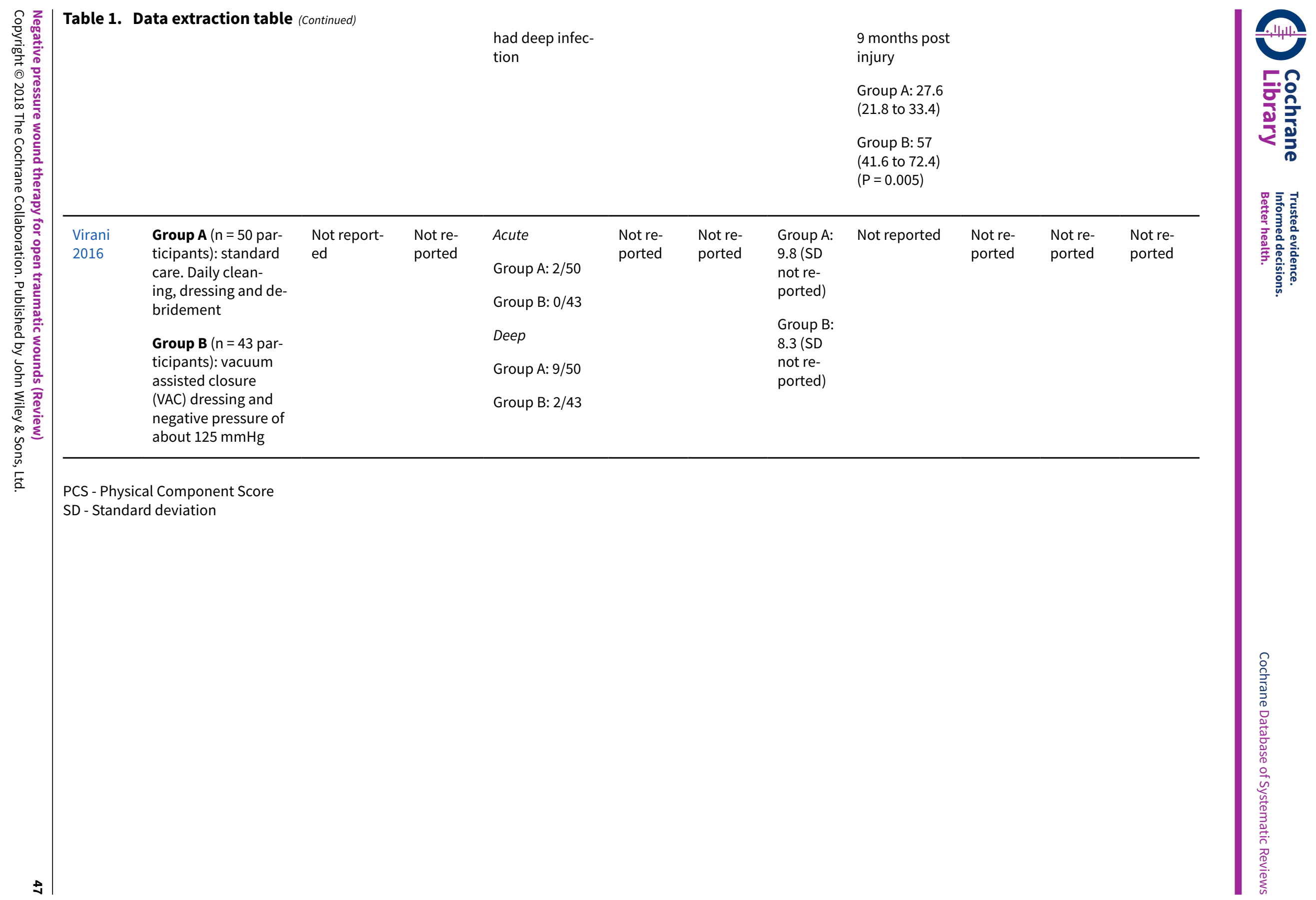




\section{AP PEN DICES}

\section{Appendix 1. Search strategies}

\section{Cochrane Wounds Specialised Register}

1 MESH DESCRIPTOR Wounds, Penetrating EXPLODE ALL AND INREGISTER

2 MESH DESCRIPTOR Lacerations EXPLODE ALL AND INREGISTER

3 MESH DESCRIPTOR Fractures, Open EXPLODE ALL AND INREGISTER

4 (laceration* or gunshot or gun shot or stab or stabbing or stabbed or (open near3 fracture*)) AND INREGISTER

5 (traumatic wound ${ }^{\star}$ or acute wound ${ }^{\star}$ ) AND INREGISTER

6 (mechanical trauma or polytrauma) AND INREGISTER

7 ((blast or crush or avulsion) near2 injur $\left.{ }^{\star}\right)$ AND INREGISTER

8 \#1 OR \#2 OR \#3 OR \#4 OR \#5 OR \#6 OR \#7

9 MESH DESCRIPTOR Negative-Pressure Wound Therapy EXPLODE ALL AND INREGISTER

10 MESH DESCRIPTOR Suction EXPLODE ALL AND INREGISTER

11 MESH DESCRIPTOR Vacuum EXPLODE ALL AND INREGISTER

12 (negative pressure or negative-pressure or TNP or NPWT) AND INREGISTER

13 (sub-atmospheric or subatmospheric) AND INREGISTER

14 ((seal* ${ }^{\star}$ ear2 surface $\left.^{\star}\right)$ or $\left(\right.$ seal $^{\star}$ near2 $\left.\left.^{\text {aspirat }}{ }^{\star}\right)\right)$ AND INREGISTER

15 (wound near2 suction ${ }^{\star}$ ) AND INREGISTER

16 (wound near5 drainage) AND INREGISTER

17 ((foam near2 suction) or (suction near2 dressing $\left.{ }^{\star}\right)$ ) AND INREGISTER

18 (vacuum assisted closure or VAC) AND INREGISTER

19 ((vacuum near2 therapy) or (vacuum near2 dressing ${ }^{\star}$ ) or (vacuum near2 seal ${ }^{\star}$ ) or (vacuum near2 closure) or (vacuum near2 compression) or (vacuum near2 pack $^{*}$ ) or (vacuum near2 drainage) or (suction* near2 drainage)) AND INREGISTER

20 \#9 OR \#10 OR \#11 OR \#12 OR \#13 OR \#14 OR \#15 OR \#16 OR \#17 OR\#18 OR \#19

21 \#20 AND \#8

\section{The Cochrane Central Register of Controlled Clinical Trials (CENTRAL)}

\#1 MeSH descriptor: [Wounds, Penetrating] explode all trees

\#2 MeSH descriptor: [Lacerations] explode all trees

\#3 MeSH descriptor: [Fractures, Open] explode all trees

\#4 (laceration* or gunshot or "gun shot" or "stab" or stabbing or stabbed or (open near/3 fracture*)):ti,ab,kw

\#5 (traumatic next wound ${ }^{\star}$ ) or (acute next wound $\left.{ }^{\star}\right):$ ti,ab,kw

\#6 ("mechanical trauma" or polytrauma):ti,ab,kw

\#7 ((blast or crush or avulsion) next injur $\left.{ }^{\star}\right): \mathrm{ti}, \mathrm{ab}, \mathrm{kw}$

$\# 8$ \{or \#1-\#7\}

\#9 MeSH descriptor: [Negative-Pressure Wound Therapy] explode all trees

$\# 10 \mathrm{MeSH}$ descriptor: [Suction] explode all trees

$\# 11$ MeSH descriptor: [Vacuum] explode all trees

\#12 ("negative pressure" or negative-pressure or TNP or NPWT):ti,ab,kw

\#13 (sub-atmospheric or subatmospheric):ti,ab,kw

\#14 ((seal ${ }^{\star}$ next surface $\left.{ }^{\star}\right)$ or (seal ${ }^{\star}$ next aspirat $\left.\left.{ }^{\star}\right)\right):$ ti,ab,kw

\#15 (wound near/3 suction*):ti,ab,kw

\#16 (wound near/3 drainage):ti,ab,kw

\#17 ((foam near suction) or (suction near dressing*)):ti,ab,kw

\#18 ("vacuum assisted closure" or VAC):ti,ab,kw

\#19 ((vacuum near therap*) or (vacuum near dressing*) or (vacuum near seal ${ }^{\star}$ ) or (vacuum near closure) or (vacuum near compression) or (vacuum near pack*) or (vacuum near drainage) or (suction ${ }^{\star}$ near drainage)):ti,ab,kw

$\# 20$ \{or \#9-\#19\}

$\# 21$ and \#8, \#20\} in Trials

\section{Ovid MEDLINE}

1 exp Wounds, Penetrating/

2 exp Lacerations/

3 exp Fractures, Open/

4 (laceration* or gunshot or gun shot or stab or stabbing or stabbed or (open adj3 fracture*)).tw.

5 (traumatic wound ${ }^{\star}$ or acute wound ${ }^{\star}$ ).tw.

6 (mechanical trauma or polytrauma).tw. 
7 ((blast or crush or avulsion) adj injur $\left.{ }^{\star}\right)$. tw.

8 or/1-7

$9 \exp$ Negative-Pressure Wound Therapy/

10 exp Suction/

11 exp Vacuum/

12 (negative pressure or negative-pressure or TNP or NPWT).tw.

13 (sub-atmospheric or subatmospheric).tw.

$14\left(\left(\right.\right.$ seal $^{\star}$ adj surface $\left.{ }^{\star}\right)$ or $\left(\right.$ seal $^{\star}$ adj aspirat $\left.\left.{ }^{\star}\right)\right) . t w$.

15 (wound adj2 suction*).tw.

16 (wound adj5 drainage).tw.

17 ((foam adj suction) or (suction adj dressing $\left.\left.{ }^{\star}\right)\right)$.tw.

18 (vacuum assisted closure or VAC).tw.

19 ((vacuum adj therapy) or (vacuum adj dressing*) or (vacuum adj seal ${ }^{\star}$ ) or (vacuum adj closure) or (vacuum adj compression) or (vacuum adj pack ${ }^{\star}$ ) or (vacuum adj drainage) or (suction* adj drainage)).tw.

20 or/9-19

21 and $/ 8,20$

22 randomized controlled trial.pt.

23 controlled clinical trial.pt.

24 randomi?ed.ab.

25 placebo.ab.

26 clinical trials as topic.sh.

27 randomly.ab.

28 trial.ti.

29 or $/ 22-28$

30 exp animals/ not humans.sh.

3129 not 30

3221 and 31

\section{Ovid Embase}

1 exp penetrating trauma/

2 exp laceration/

3 exp open fracture/

4 (laceration* or gunshot or gun shot or stab or stabbing or stabbed or (open adj3 fracture*)).tw.

5 (traumatic wound ${ }^{\star}$ or acute wound $\left.{ }^{\star}\right)$.tw.

6 (mechanical trauma or polytrauma).tw.

7 ((blast or crush or avulsion) adj injur $\left.{ }^{\star}\right)$.tw.

8 or/1-7

9 exp vacuum assisted closure/

10 exp suction/

11 exp vacuum/

12 (negative pressure or negative-pressure or TNP or NPWT).tw.

13 (sub-atmospheric or subatmospheric).tw.

$14\left(\left(\right.\right.$ seal $^{\star}$ adj surface $\left.^{\star}\right)$ or (seal ${ }^{\star}$ adj aspirat $\left.\left.{ }^{\star}\right)\right)$. tw.

15 (wound adj2 suction*).tw.

16 (wound adj5 drainage).tw.

17 ((foam adj suction) or (suction adj dressing $\left.{ }^{\star}\right)$ ).tw.

18 (vacuum assisted closure or VAC).tw.

19 ((vacuum adj therapy) or (vacuum adj dressing ${ }^{\star}$ ) or (vacuum adj seal ${ }^{\star}$ ) or (vacuum adj closure) or (vacuum adj compression) or (vacuum adj pack ${ }^{\star}$ ) or (vacuum adj drainage) or (suction* adj drainage)).tw.

20 or/9-19

21 and $/ 8,20$

22 Randomized controlled trials/

23 Single-Blind Method/

24 Double-Blind Method/

25 Crossover Procedure/

26 (random ${ }^{\star}$ or factorial ${ }^{\star}$ or crossover ${ }^{\star}$ or cross over $^{\star}$ or cross-over $^{\star}$ or placebo or assign $^{\star}$ or allocat ${ }^{\star}$ or volunteer $^{\star}$ ).ti,ab.

27 (doubl* adj blind $\left.^{\star}\right)$.ti,ab.

28 (singl $^{*}$ adj blind $\left.{ }^{\star}\right)$.ti,ab.

29 or $/ 22-28$

30 exp animals/ or exp invertebrate/ or animal experiment/ or animal model/ or animal tissue/ or animal cell/ or nonhuman/ 31 human/ or human cell/ 
32 and $/ 30-31$

3330 not 32

3429 not 33

3521 and 34

\section{EBSCO CINAHL Plus}

\section{S35 S21 AND S34}

S34 S22 OR S23 OR S24 OR S25 OR S26 OR S27 OR S28 OR S29 OR S30 OR S 31 OR S 32 OR S 33

S33 TI allocat* random* or AB allocat* random*

S32 MH "Quantitative Studies"

S31 TI placebo* or AB placebo*

S30 MH "Placebos"

S29 TI random* allocat* or AB random* allocat*

S28 MH "Random Assignment"

$\mathrm{S} 27 \mathrm{TI}$ randomi?ed control ${ }^{\star}$ trial $^{\star}$ or $\mathrm{AB}$ randomi?ed control ${ }^{\star}$ trial ${ }^{\star}$

S26 AB ( singl* or doubl* or trebl* or tripl* ) and AB ( blind* or mask ${ }^{\star}$ )

S25 TI ( singl* or doubl* or trebl* or tripl ${ }^{\star}$ ) and $\mathrm{TI}$ ( blind $^{\star}$ or mask ${ }^{\star}$ )

S24 TI clinic* N1 trial* or AB clinic* N1 trial*

S23 PT Clinical trial

S22 MH "Clinical Trials+"

S21 S9 AND S20

S20 S10 OR S11 OR S12 OR S13 OR S14 OR S15 OR S16 OR S17 OR S18 OR S19

S19 (MH "Negative Pressure Wound Therapy")

S18 (MH "Suction+")

S17 (MH "Vacuum")

S16 TI ( (negative pressure or negative-pressure or TNP) ) OR AB ( (negative pressure or negative- pressure or TNP) )

S15 TI ( (sub-atmospheric or subatmospheric) ) OR AB ( (sub-atmospheric or subatmospheric))

S14 TI ( (seal* N1 surface* or seal ${ }^{\star}$ N1 aspirat $\left.{ }^{\star}\right)$ ) OR AB ( (seal* N1 surface* or seal* N1 aspirat $\left.{ }^{\star}\right)$ )

S13 TI (wound N2 suction*) OR AB (wound N2 suction*)

S12 TI ( (foam suction or suction dressing*) ) OR AB ( (foam suction or suction dressing*) )

S11 TI ( (vacuum assisted closure or VAC) ) OR AB ( (vacuum assisted closure or VAC) )

S10 TI ( vacuum therapy or vacuum dressing* or vacuum seal* or vacuum closure or vacuum compression or vacuum pack or vacuum drainage ) OR AB ( vacuum therapy or vacuum dressing ${ }^{\star}$ or vacuum seal ${ }^{\star}$ or vacuum closure or vacuum compression or vacuum pack or vacuum drainage )

S9 S1 OR S2 OR S3 OR S4 OR S5 OR S6 OR S7 OR S8

S8 TX ((blast or crush or avulsion) N1 injur ${ }^{\star}$ )

S7 TX (mechanical trauma or polytrauma)

S6 TX (traumatic wound* or acute wound ${ }^{\star}$ )

S5 TX (laceration* or gunshot or gun shot or stab or stabbing or stabbed or (open N3 fracture $\left.{ }^{\star}\right)$ )

S4 (MH "Trauma+") AND ( (MH "Wounds and Injuries+"))

S3 (MH "Fractures, Open")

S2 (MH "Tears and Lacerations+")

S1 (MH "Wounds, Penetrating+")

\section{US National Institutes of Health Ongoing Trials Register (ClinicalTrials.gov)}

Negative pressure wound therapy

Topical pressure therapy

Vacuum therapy

World Health Organization International Clinical Trials Registry Platform

Negative pressure wound therapy

Topical pressure therapy

Vacuum therapy 


\section{Appendix 2. Risk of bias assessment (individually randomised controlled trials)}

\section{Assessment of risk of bias (individually randomised controlled trials)}

\section{Was the allocation sequence randomly generated?}

\section{Low risk of bias}

The investigators describe a random component in the sequence generation process such as: referring to a random number table; using a computer random number generator; coin tossing; shuffling cards or envelopes; throwing dice; drawing of lots.

\section{High risk of bias}

The investigators describe a non-random component in the sequence generation process. Usually, the description would involve some systematic, non-random approach, for example: sequence generated by odd or even date of birth; sequence generated by some rule based on date (or day) of admission; sequence generated by some rule based on hospital or clinic record number.

\section{Unclear}

Insufficient information about the sequence generation process to permit judgement of low or high risk of bias.

\section{Was the treatment allocation adequately concealed?}

\section{Low risk of bias}

Participants and investigators enrolling participants could not foresee assignment because one of the following, or an equivalent method, was used to conceal allocation: central allocation (including telephone, web-based and pharmacy-controlled randomisation); sequentially numbered drug containers of identical appearance; sequentially numbered, opaque, sealed envelopes.

\section{High risk of bias}

Participants or investigators enrolling participants could possibly foresee assignments and thus introduce selection bias, such as allocation based on: use of an open random allocation schedule (e.g. a list of random numbers); assignment envelopes without appropriate safeguards (e.g. envelopes were unsealed, non-opaque or not sequentially numbered); alternation or rotation; date of birth; case record number; any other explicitly unconcealed procedure.

\section{Unclear}

Insufficient information to permit judgement of low or high risk of bias. This is usually the case if the method of concealment is not described or not described in sufficient detail to allow a definite judgement, for example if the use of assignment envelopes is described, but it remains unclear whether envelopes were sequentially numbered, opaque and sealed.

\section{Blinding - was knowledge of the allocated interventions adequately prevented during the study?}

\section{Low risk of bias}

Any one of the following.

- No blinding, but the review authors judge that the outcome and the outcome measurement were not likely to be influenced by lack of blinding.

- Blinding of participants and key study personnel ensured, and unlikely that the blinding could have been broken.

- Either participants or some key study personnel were not blinded, but outcome assessment was blinded and the non-blinding of others unlikely to introduce bias.

\section{High risk of bias}

Any one of the following.

- No blinding or incomplete blinding, and the outcome or outcome measurement was likely to be influenced by lack of blinding.

- Blinding of key study participants and personnel attempted, but likely that the blinding could have been broken.

- Either participants or some key study personnel were not blinded, and the non-blinding of others likely to introduce bias.

\section{Unclear}

Either of the following.

- Insufficient information to permit judgement of low or high risk of bias.

- The study did not address this outcome. 


\section{Were incomplete outcome data adequately addressed?}

\section{Low risk of bias}

Any one of the following.

- No missing outcome data.

- Reasons for missing outcome data unlikely to be related to true outcome (for survival data, censoring unlikely to be introducing bias).

- Missing outcome data balanced in numbers across intervention groups, with similar reasons for missing data across groups.

- For dichotomous outcome data, the proportion of missing outcomes compared with observed event risk not enough to have a clinically relevant impact on the intervention effect estimate.

- For continuous outcome data, plausible effect size (difference in means or standardised difference in means) among missing outcomes not enough to have a clinically relevant impact on observed effect size.

- Missing data have been imputed using appropriate methods.

\section{High risk of bias}

Any one of the following.

- Reason for missing outcome data likely to be related to true outcome, with either imbalance in numbers or reasons for missing data across intervention groups.

- For dichotomous outcome data, the proportion of missing outcomes compared with observed event risk enough to induce clinically relevant bias in intervention effect estimate.

- For continuous outcome data, plausible effect size (difference in means or standardised difference in means) among missing outcomes enough to induce clinically relevant bias in observed effect size.

- 'As-treated' analysis done with substantial departure of the intervention received from that assigned at randomisation.

- Potentially inappropriate application of simple imputation.

\section{Unclear}

Either of the following:

- Insufficient reporting of attrition/exclusions to permit judgement of low or high risk of bias (e.g. number randomised not stated, no reasons for missing data provided).

- The study did not address this outcome.

\section{Are reports of the study free of suggestion of selective outcome reporting?}

\section{Low risk of bias}

Either of the following.

- The study protocol is available and all of the study's pre-specified (primary and secondary) outcomes that are of interest in the review have been reported in the pre-specified way.

- The study protocol is not available but it is clear that the published reports include all expected outcomes, including those that were pre-specified (convincing text of this nature may be uncommon).

\section{High risk of bias}

Any one of the following.

- Not all of the study's pre-specified primary outcomes have been reported.

- One or more primary outcomes are reported using measurements, analysis methods or subsets of the data (e.g. subscales) that were not pre-specified.

- One or more reported primary outcomes were not pre-specified (unless clear justification for their reporting is provided, such as an unexpected adverse effect).

- One or more outcomes of interest in the review are reported incompletely so that they cannot be entered in a meta-analysis.

- The study report fails to include results for a key outcome that would be expected to have been reported for such a study.

\section{Unclear}

Insufficient information to permit judgement of low or high risk of bias. It is likely that the majority of studies will fall into this category. 


\section{Other sources of potential bias}

\section{Low risk of bias}

The study appears to be free of other sources of bias.

\section{High risk of bias}

There is at least one important risk of bias. For example, the study:

- had a potential source of bias related to the specific study design used; or

- has been claimed to have been fraudulent; or

- had some other problem.

Unclear

There may be a risk of bias, but there is either:

- insufficient information to assess whether an important risk of bias exists; or

- insufficient rationale or evidence that an identified problem will introduce bias.

\section{Appendix 3. Risk of bias (cluster-randomised controlled trials)}

In cluster-randomised trials, particular biases to consider include: recruitment bias; baseline imbalance; loss of clusters; incorrect analysis; and comparability with individually randomised trials.

- Recruitment bias can occur when individuals are recruited to the trial after the clusters have been randomised, as the knowledge of whether each cluster is an 'intervention' or 'control' cluster could affect the types of participants recruited.

- Cluster-randomised trials often randomise all clusters at once, so lack of concealment of an allocation sequence should not usually be an issue. However, because small numbers of clusters are randomised, there is a possibility of chance baseline imbalance between the randomised groups, in terms of either the clusters or the individuals. Although not a form of bias as such, the risk of baseline differences can be reduced by using stratified or pair-matched randomisation of clusters. Reporting of the baseline comparability of clusters, or statistical adjustment for baseline characteristics, can help reduce concern about the effects of baseline imbalance.

- Occasionally complete clusters are lost from a trial, and have to be omitted from the analysis. Just as for missing outcome data in individually randomised trials, this may lead to bias. In addition, missing outcomes for individuals within clusters may also lead to a risk of bias in cluster-randomised trials.

- Many cluster-randomised trials are analysed by incorrect statistical methods, not taking the clustering into account. Such analyses create a 'unit of analysis error' and produce over-precise results (the standard error of the estimated intervention effect is too small) and $P$ values that are too small. They do not lead to biased estimates of effect. However, if they remain uncorrected, they will receive too much weight in a meta-analysis.

- In a meta-analysis including both cluster- and individually randomised trials, or including cluster-randomised trials with different types of clusters, possible differences between the intervention effects being estimated need to be considered. For example, in a vaccine trial of infectious diseases, a vaccine applied to all individuals in a community would be expected to be more effective than if the vaccine was applied to only half of the people. Another example is provided by a Cochrane Review of hip protectors. The cluster trials showed large positive effect whereas individually randomised trials did not show any clear benefit. One possibility is that there was a 'herd effect' in the cluster-randomised trials (which were often performed in nursing homes, where compliance with using the protectors may have been enhanced). In general, such 'contamination' would lead to underestimates of effect. Thus, if an intervention effect is still demonstrated despite contamination in those trials that were not cluster-randomised, a confident conclusion about the presence of an effect can be drawn. However, the size of the effect is likely to be underestimated. Contamination and 'herd effects' may be different for different types of cluster.

\section{WHAT'S NEW}

\begin{tabular}{lll}
\hline Date & Event & Description \\
\hline 8 September 2017 & Amended & $\begin{array}{l}\text { We have changed the title by adding the word 'open' to make } \\
\text { clear the type of traumatic wounds that are of interest in this re- } \\
\text { view. }\end{array}$ \\
\hline
\end{tabular}




\section{CONTRIBUTIONS OF AUTHORS}

Zipporah Iheozor-Ejiofor: extracted data; analysed or interpreted data; undertook quality assessment; performed statistical analysis; produced the first draft of the review; contributed to writing or editing the review; wrote to study authors/experts/companies; approved the final review prior to submission; and is a guarantor of the review.

Katy Newton: advised on the review; performed previous work that was the foundation of the current review; and approved the final review prior to submission.

Jo Dumville: conceived, designed and co-ordinated the review; extracted data; checked the quality of data extraction; checked the quality of the statistical analysis; contributed to writing and editing the review; secured funding; performed previous work that was the foundation of the current review; wrote to study authors/experts/companies; approved the final review prior to submission; and is a guarantor of the review.

Matthew Costa: checked the quality of the statistical analysis; advised on the review; provided data; and approved the final review prior to submission.

Gill Norman: extracted data; contributed to writing or editing the review; and approved the final review prior to submission.

Julie Bruce: checked the quality of the statistical analysis; advised on the review and approved the final review prior to submission.

\section{Contributions of the editorial base}

Kurinchi Gurusamy (Editor): edited the protocol and the review; advised on methodology, interpretation and content; approved the final review prior to publication.

Gill Rizzello (Managing Editor): co-ordinated the editorial process; advised on content; edited the protocol and the review.

Reetu Child and Naomi Shaw (Information Specialists): designed the search strategy, ran the search and edited the search methods sections.

Ursula Gonthier (Editorial Assistant): edited the Plain Language Summary and reference sections of the review.

\section{DECLARATIONSOF INTEREST}

Zipporah Iheozor-Ejiofor: none known.

Katy Newton: none known.

Jo Dumville: received research funding from the National Institute for Health Research (NIHR) UK for the production of systematic reviews focusing on high priority Cochrane Reviews in the prevention and treatment of wounds.

Matthew Costa: was the Chief Investigator of an included study but did not undertake any data extraction or assessment for this study. $\mathrm{KCl}$ and Smith \& Nephew supplied the hospitals involved in the trial with NWPT dressings at cost for the purposes of the trial. The University of Oxford is paid consultancy fees from UCB and Pluristem for work not related to this review. He receives a small honorarium as an Editor of the Bone and Joint Journal, and as a Course Director for the AO foundation.

Gill Norman: my employment at the University of Manchester was funded through an NIHR (UK National Institute for Health Research) grant focusing on high priority Cochrane reviews in the prevention and treatment of wounds.

Julie Bruce: is a co-author on a clinical trial included within the review but did not undertake any data extraction or assessment for this study.

\section{SOURCES OF SUPPORT}

\section{Internal sources}

- Division of Nursing Midwifery and Social Work, School of Health Sciences, Faculty of Biology, Medicine and Health, University of Manchester, UK.

\section{External sources}

- National Institute for Health Research (NIHR), UK.

This project was supported by the NIHR, via Cochrane Infrastructure and Cochrane Programme Grant funding (NIHR Cochrane Programme Grant 13/89/08- High Priority Cochrane Reviews in Wound Prevention and Treatment) to Cochrane Wounds. The views and 
opinions expressed therein are those of the authors and do not necessarily reflect those of the Systematic Reviews Programme, NIHR, NHS or the Department of Health, UK.

- National Institute for Health Research Collaboration for Leadership in Applied Research and Care (NIHR CLAHRC), Greater Manchester, UK.

Jo Dumville was partly funded by the NIHR CLAHRC Greater Manchester. The funder had no role in the design of the studies, data collection and analysis, decision to publish, or preparation of the manuscript. However, the review may be considered to be affiliated to the work of the NIHR CLAHRC Greater Manchester. The views expressed herein are those of the authors and not necessarily those of the NHS, NIHR or the Department of Health.

- NIHR Manchester Biomedical Research Centre, UK.

Jo Dumville and Gill Norman's work on this review was co-funded by the NIHR Manchester Biomedical Research Centre. The views expressed in this publication are those of the authors and not necessarily those of the NHS, the National Institute for Health Research or the Department of Health.

- NIHR Oxford Biomedical Research Centre, UK.

Matthew Costa's work on this review was funded by the NIHR Oxford Biomedical Research Centre. The views expressed in this publication are those of the authors and not necessarily those of the NHS, the National Institute for Health Research or the Department of Health.

\section{DIFFERENCES BETWEEN PROTOCOLANDREVIEW}

Description of the condition: we added additional information to the Background section to highlight key wound types and provide some more information on these.

Types of participants: we clarified that the focus of this review was traumatic wounds that were treated as open wounds prior to closure.

Types of outcome measures: we made a post hoc decision to assess wound infection as a primary outcome. This should have been included in the protocol but was omitted in error. This is an important outcome from a clinical perspective and NPWT is used widely with the aim of preventing wound infection. We also presented cost data; although it was not planned at protocol stage, exclusion of this important outcome was an oversight. We removed incidence of compartment syndrome based on peer review comments.

Unit of analysis issues: there was one study where the unit of analysis ( 25 versus 26 wounds) was different from the unit of randomisation ( 25 versus 25 participants). As we were unable to quantify the difference this would have made to the study findings we decided to use the participants as the unit of analysis.

Data synthesis: we made the decision to treat trials that enrolled participants with open fracture wounds separately from trials enrolling participants with other types of traumatic wounds. This decision was made on clinical advice following the publication of the protocol. We analysed data for NPWT $125 \mathrm{mmHg}$ and NPWT $75 \mathrm{mmHg}$ separately, as they were considered different doses of the treatment.

\section{INDEX TERMS}

\section{Medical Subject Headings (MeSH)}

Fractures, Open [*therapy]; Negative-Pressure Wound Therapy [*methods]; Quality of Life; Quality-Adjusted Life Years; Randomized Controlled Trials as Topic; Soft Tissue Injuries [*therapy]; Wound Healing; Wound Infection [prevention \& control]

\section{MeSH check words}

Humans 